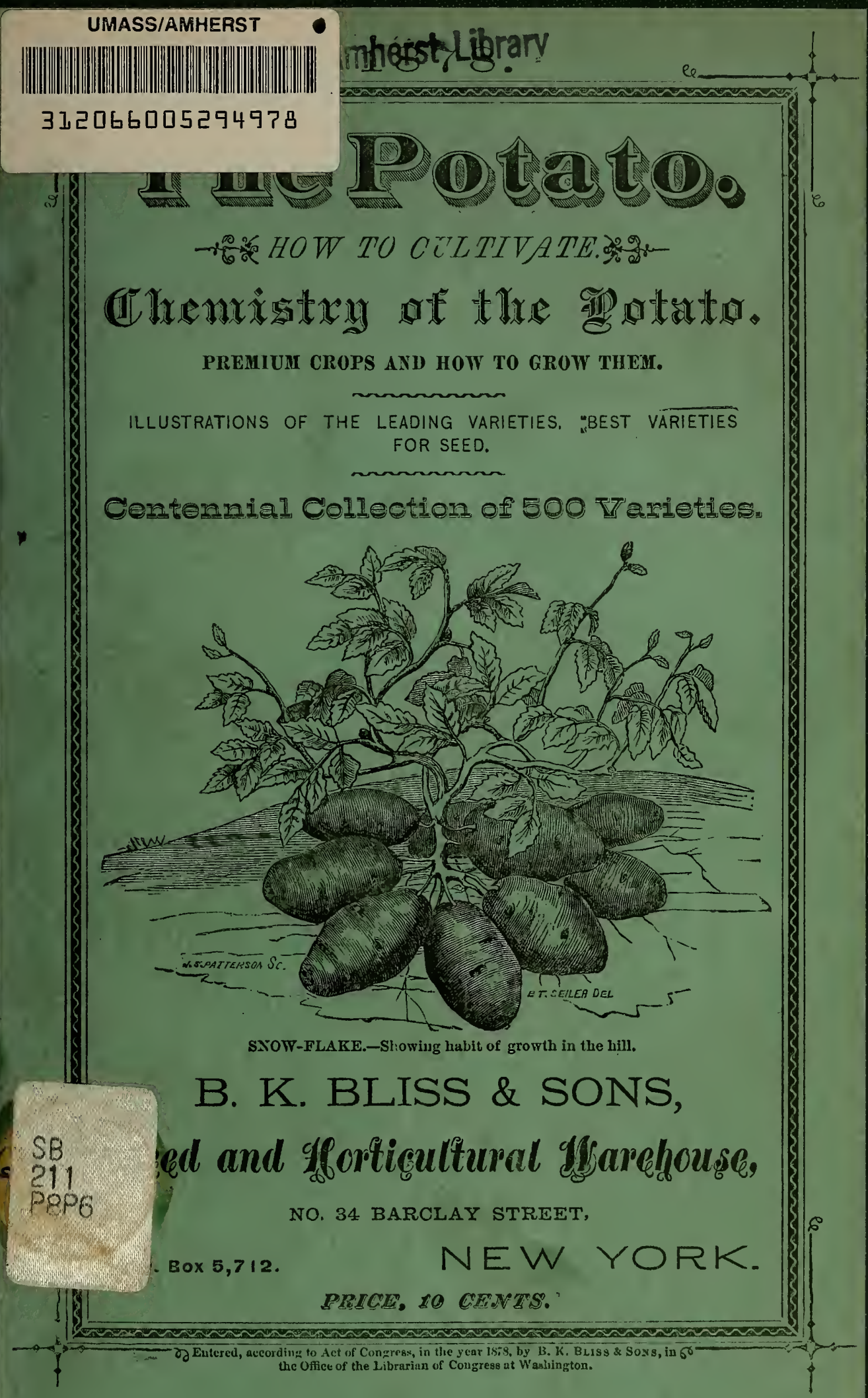




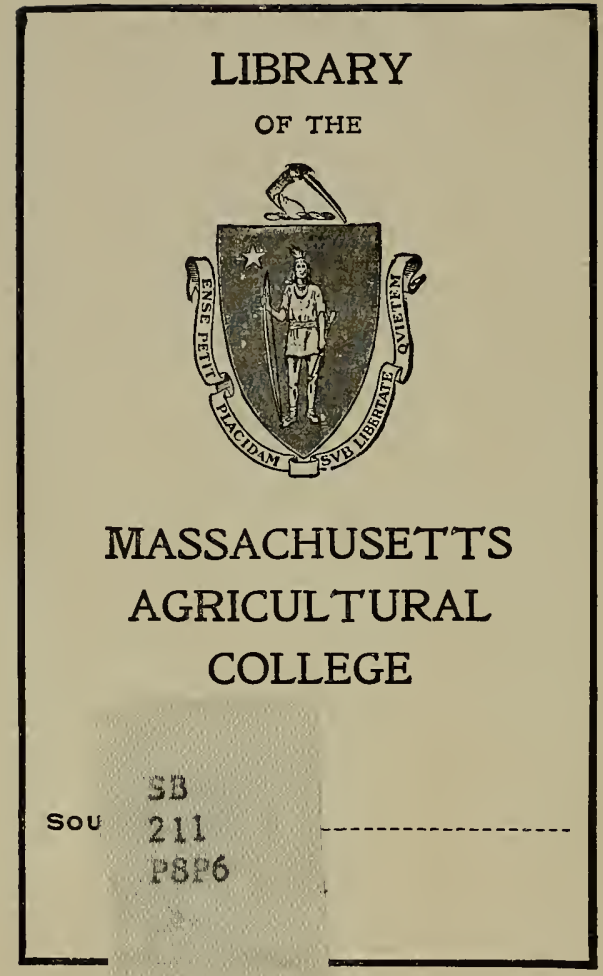


This book may be kept out

\section{T W O WE EKS}

only, and is subject to a fine of TWO CENTS a day thereafter. It will be due on the day indicated below. 


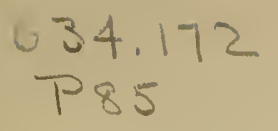

\section{ILLTSTRATED AND DESCRIPTIVE OATAIOGUE $\longrightarrow \mathrm{OF} \longrightarrow$

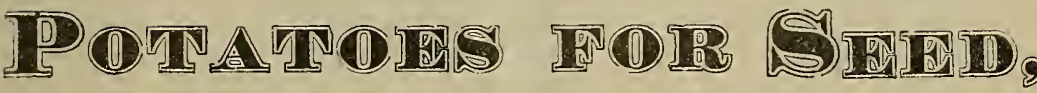 \\ FOR SALE BY

\author{
B. K. BLISS \& SONS, \\ At their Seed and Horticultural Warehouse, \\ No, 34 BARCLAY STREET, \\ NeW rorlz. \\ THE POTATO.
} \\ P. O. BOX 5,712.}

THIs valuable and well-known esculent, now so widely cultivated, is a native of the mountainous parts of tropical America, and was taken to Spain and Italy by early adventurers in the sixteenth century, for we read of its cultivation in those countries in the year 1550 . The usual size of the potato in its wild state is rarely more than an inch in diameter, and the flavor very insipid and almost unpalatable.

When first introduced into Europe it created great excitement, of a similar nature to that caused by the introduction of tobacco and coffee; for many years it was only to be found on the tables of the opulent, where it was used as a dessert either in the form of a sweetmeat or as a fruit. The first varieties grown in the United States were brought from Europe. The quality was very poor, and not a variety then in use would at the present time be deemed fit for the table. It is only within a comparatively recent period that it has found its way into both continents as a general article of food for man and beast, or has received attention from agriculturists. Many of our most practical and foremost gardeners are now directing their attention and energies to its improvement and propagation.

In the year 1S 4 , the disease known as the rot appeared and nearly destroyed the whole crop. About this time a few persons, among others the late C. E. Gondrich, of Utica, importecl a lot of the wild varieties directly from South America, and procegded to raise seedlings by crossing with the various kinds then in use. Many thousand seedlings were then produced, but few of them were ever bronght to any state of perfection.

One of the principal sorts saved was the Garnet Chili, which had a great reputation, and is the parent of many of our new sorts which are now attracting so much attention. Twenty-five years ago, a farmer who raised one hundred bushels of potatoes was looked upon as having an enormous stock; while to-day, many growers in the vicinity of our large cities raise from ten to twenty thousand bushels, without exciting any unusual attention. Within this period nearly all the numerous varieties with which we are now acquainted have been brought to notice, and every year adds its score of new seedlings to the already overgrown lists. Hundreds of millions of bushels are now raised annually in this country, and the demand is always gieater than the supply-the crop of this State alone being twenty-five million bushels, raised on a little over two luundred and fifty thousand acres of land.

The uses of this tuber are numerous, aside from their principal use as an article of food. Thousands of bushels are annually manufactnred into starch, and alcohol is distilled from its juices. Even sugar has been made; but with so nuch competition in this liue, it has never proved a great success. Too much cannot be said in favor of this valuable staple, and we shall endeavor to instruct our readers in these few pages as to the methods used to increase the supply, without increasing the expense of its cultivation. 


\section{CULTIT ATION.}

The soil acknowledged to be the best for the potato is a rich loam, sandy, and neither too wet or too dry. A cool, moist soil will produce larger potatoes, but the danger of too much wet is so great that a warmer soil is preferable in this climate. Early potatoes reach their maturity sooner in a quick, light soil, and present a brighter and cleaner appearance, than when dug from that which is heavier. A calcareous formation gencrally jields a sure crop.

Old sod land, well turned under in the fall, and lightly plowed and harrowed in the Spring, will produce a sound crop, and often an astonishingly large one. Clover sod for this purpose is excellent, and furnishes a large amount of vegetable substance to the ground. When turned under in August or September it will rot by the following Spring, and only a top-dressing of some well-established fertilizer will be required to carry through the crop. Wetland produces a coarse, unpalatable article, and one of little value even as food for cattle. Barnyard manures are of little benefit to such land. Lands should never be plowed while wet and heavy; it injures the soil and does more harm than the manure can offset. Prepare the ground as carefully and thoroughly for potatoes as for any other crop. Attention in this particular well repays the farmer.

Land intended for potatoes requires but little manure, and that should be old and well rotted. By many, spreading the manure before plowing in the Spring is thought to be the best mode. At the time of planting, bone-dust, ashes, plaster, marl and like fertilizers can be used to great advantage with this crop, as they are of a dry or absorbent nature. On wet soils they are very beneticial, as they prevent disease as well as promote the growth of the tubers. On warm, dry, light land, muck compost may advantageously be used; decayed leaves are excellent. In seasons of disease among potatoes, fields where ashes have been used have suffered but little from the rot.

Potatoes are usually planted in drills or hills, the latter being the more common method in this country. Some varieties require more space than others. For drills, two and a half feet by three is ample; while, when planted in hills, three to three and a half feet is the usual distance. The latter method has some advantages, as the cultivator or horse-hoe can be used both ways of the field. Some of the earlier varieties may be planted closer without loss to the crop. Cover about four inches in light soil, and not so deep in the heavier. Cultivation should be commenced soon after the shoots appear above the ground, and weeds should be kept down with as much care as in a carrot-bed. The earth should be drawn a little towards the hill at each hoeing, that the rootlets may gain strength and nutriment from the surrounding earth. When the blossoms appear, hoeing should be discontinued, and in fact is rarely necessary, as the vines then cover the ground and discourage the growth of weeds. An excellent plan is to go over the field occasionally and remove carefully any weeds that appear in the hill, for they draw largely from the susteuance required for the developing tubers.

Many farmers still continue to plant three to five eyes to the hill. In our opinion this is a mistake, and the last few years' experience confirms our views. Potatoes cut carefully to a single eye, the hills, perhaps, a trifle closer, will yield a larger crop than the careless way of throwing in seed by wholesale. We all know the effects of too close a growth of carrots, turnips and such roots on the crop, and we think the same rule applies equally to potatoes. Two good eyes to the hill, with a proper proportion of the flesh to each eye, will produce a far larger crop of merchantable tubers than two whole ones; will yield from one-third to one-half more in weight-an item of no small consequence--to say nothing of the saving of nearly one-half the seed. Any intelligent farmer who is up with the times and reads the leading agricultural papers will corroborate this statement.

In order to secure an early crop, the seed must be planted as soon as the ground is in proper working order. This time differs in the various parts of our extended country, so that no set time can well be given. The earliest varieties can be marketed in sixty-five to seventy days from planting, tlius competing successfully with Southern crops of the more common kinds. A second crop can thus be planted, as described elsewhere, allowed to thoroughly mature, and thus have good seed tor another year and a sound article of food for Winter use. The yield of the tirst planting will give a handsume profit, for early potatoes always command a higl price when near a city or town. Thic later varieties do better when planted some weeks after the early kinds; and the farmer lias this advantage, he can get the former well started and cultivated before he turns his labor and attention to the latter.

A common method of forcing potatoes is to select whole, sound tubers of some early variety of medium size, placing them close tngether in a moderately heated bed, composed of either light loam or partially decayeil leaves. This should be done several weeks-say three or four-before the time of planiting. By that time the tubers will have started sufficiently to be set out. Cut the potatoes into pieces as has been directed, and use care not to fujure the young slooots. Plant three inclies deep, apply a little liorse manure to the bottom of each hill, to afford warmth and to urge forward and nourish the young starting tubers.

The decay of the tops indicate the maturity of the roots. The later kinds often continue to grow till checked by autuma frosts. They should, however, be duy before the ground is touched by frost at night. 


\section{HOW TO CUT TO A SINGLE EYE.}

Take any potato and hold before you, with the stem end (the place where it was joined to the vine) down. It will then be noticed that the eyes are arranged around the tuber in regular ascending rotation from the bottom to the top, similar to the thread of a corkscrew, each eye being a little above and further around the side than the one next below it. Now take the potato in the left hand, with the stem end down, keeping it in a perpendicular position throughout the entire cutting. Take a sharp, thin-bladed knife and remove the first eye, by placing the knife about equally

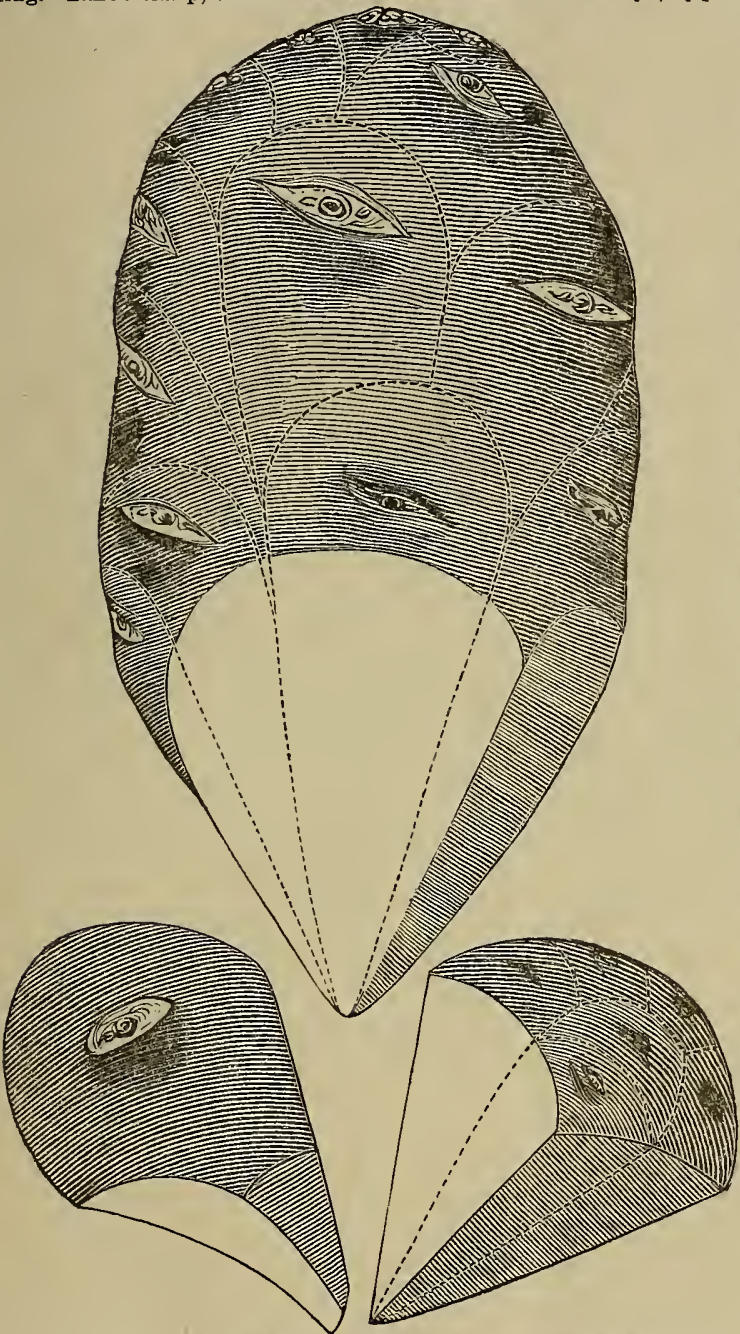

distant between it and the eye next in rotation above it, sloping it to the indenture left by the stem (see dotted lines in center cut), removing the flesh with it. When the firsteye is removed, turn the potato around in the hand until the next eye above appears. Remove this one in the same manner, and keep on turning the potato, removing each eye as it appears in exact rotation, always sloping the knife to the stem. After three or four eyes are thus removed, the bottom part of the tuber will have a somewhat pyramidal form (see center cut). It will be noticed that each eye removed has a similar form to that represented by the cuton the left, and has its proportionate share of the flesh attached.

After the first two eyes are removed no further trouble will be found until the seed end is reached, and only a little extra care will he required to remove these closeily clustered eyes. The cut on the right represents what remains of the potato after all but the small eyes are removed, while the dotted lines show how to separate each of these. It will be noticed that the base retains the same form throughout, and by sloping the kuife each time, and cutting down to the apex of this inverted pyramid (which is the center of the tuber), each eye will be supported by an equal amount of the flesh which is to start it into a strong, healthy growth. With common varieties, where seed is cheap, many will think this manner of cutting too troublesome. But if every farmer should save one-half his seed, as he easily could do (for it will only require two barrels of sets for an acre, instead of four, as is usually planted, the increase being equal), thousands of bushels would annually be saved, worth many thousands of dollars. But to those who wish to obtain a large increase from a small quantity of seed, as is necessary to those who buy the new and valuable varieties, this manner of cutting so that every eye is saved will prove invaluable. 


\section{CUTTING.}

This is one of the most important subjects to be considered in the propagation of potatoes, and there is such a dirersity of opinion regarding the manner and method of cutting, that many pages could be filled in giving the different experiences of the professors in this art. While we do not attempt to decide this question to the satisfaction of every one, we shall give our own riews, and claim that in our method an enormous quantity of the tubers now annually planted may be thrown into the narket. causing a reduction in the prices charged for this common and necessary crop. Without discussing the respective merits of planting whole potatoes, or half a dozen pieces, each piece containing three and four eyes, in a hill, we shall state, what has been proven by so many cultivators, that two good eyes are ample for one hill, and the yield of large, marketable potatoes is larger than when more are planted. With the aid of the cut and remarks on page 3 , we trust our readers may be enabled to understand our method.

\section{HON TO RAISE FROM CUTTINGS.}

For this purpose any ordinary hot-bed may be used. About the 1st of March take the potatoes to be propagated, dividing them lengthwise, and laying these pieces with the cut side down upon the soil of the hot-bed. Keep them perfectly dry until the cut part has healed over and the sprouts bave commenced to start. When the sprouts reach the height of three or four inches, cut them off about half an inch above the eye, and insert the end of the cuttings thus obtained into the soil of the hot-bed. Shade them from the sun, and water carefully until they are well rooted and the leaves begin to develop. The old pieces of the potato will continue to throw $\mathrm{np}$ shoots to an almost incredible number. and these are all to be removed as soon as strong enough in the same manner as the first ones. In order to increase the crop still more, as soon as these cuttings have reached the height of eight inches, their tops may also be removed and planted in the same manner as the slips from the potato. As soon as the ground becomes warm and can be worked, prepare it as is nsual in planting the tubers, and set out these young plants. It is best to transplant them on some cloudy day or towards evening, as the hot sun withers them and destroys many if planted in the hot part of the day. These plants will be found to grow very rapidly, and can be propagated indefinitely from cuttings of the older plants. No cuttings should be taken after the 1st of August, as they will likely be destrojed by the cold weather before the crop is matured. The immense increase of stock by the use of this method may be illustrated as follows: A pound usually contains four medium-sized potatoes, and there are from twelve to twenty eyes on each tuber. When cut and sprouted they will give, at least, five hundred plants. From each of these plants three cuttings may be taken, which gives a total of two thousand plants to be set in the ground. With the ordinary yield, each hill, at the lowest estimate, would give one and one-half pounds, or three thousand pounds; in all making about eighteen barrels of good, sound potatoes, or a year's supply for a large family. We do not claim that this is either profitable or advisable with the common sorts of potatoes; but with the many new and high-priced varieties which are now being disseminated at the prices of one, two, or three dollars a pound, it is alnost invaluable, as for a slight expenditure a large stock may be obtained, paying to the propagator a thousand-fold. This is no new experiment, but has been practiced by the initiated for the last few years, and has ever proved a success. It is not confined to hot-beds, but many of our most prominent nurserymen have devoted whole greenhouses to this use, and we would confidently recommend it to onr readers.

\section{TWO CROPS A YEAR.}

Take good, sound, early potatoes, and cut them into single eyes, as is shown in the article on cutting. Allow these pieces to dry for a day or two, and then plant as early as the ground can be worked (a slight frost will not injure the potato after being well planted). With ordinarily favorable weather the new crop of tubers will mature in from eight to ten weeks. As soon as they are ripe, dig them, and after remaining a day or two in some dry and warm place, proceed to cut them into single eyes as before. Place the pieces thus obtained into pans or boxes containing dry plaster or gypsum. This absorbs the abundant moisture, which would otherwise greatly check the growth if it did not destroy the sets entirely. Allow them to remain in the plaster for ten or twelve days, or until the eyes commence to start, when they are to be taken out and planted as before. In the latitude of New York this is only applicable to early varieties, like the famous Early Rose, or Extra Early Vermont, which are of quick growth, and early maturity; but in many. parts of the South, where the growing season is long, it may be practiced indiscriminately upon all varieties. A gentleman has raised troo crops of Early Rose, a short time since, in this vicinity, 
the two crops yielding an aggregate weight of twenty-five hundred pounds. He planted his pound, cut into single eyes, early in March, and dug his first crop about the middle of May. These were then treated as above described and planted the 10th of June, and the second crop dug the 1st of September. The yield from the one pound at the first digging. was fifty pounds. and the second crop of this increase was twenty-five hundred pounds, or orer forty bushels. This method is within the reach of all, and there is no extra expense incurred for hot-bed sashes or any other forciug requisites.

\section{HOW TO RAISE SEEDLINGS.}

Sare any well-ripened seed-balls from a good variety, and plant in early Spring, in welldrained boxes of sandy loam. Sow the seed on the surface, and sift fine soil over them to the depth of one-quarter to one-half an inch; water sparingly, and when the seedlings are three inches high, remove them from the seed box withont disturbing the earth around them more than is necessary, and plant in more roomy quarters. Many successful growers, however, prefer sowing the seed in operi ground, when a partially shaded spot may be selected, and the seeds may be sown in drills about ten inches apart; cover with half an inch of soil. When the plants are strong enough, transplant in rows three feet apart, two feet in the rows, and keep rown the weeris until the tubers ripen. Some few strong growing varieties, will form tubers weighing from six to eight ounces the first year. As a general rule they will be about the size of a walnut. The seed we offer this season, "Pringle's hybrid," is far in advance of any hitherto offered, as will be seeu by referring to the description on page 21 . Store the tubers carefully until the next season, keeping them as cool as may be without freezing, when they may be planted in the same manner as any mature potato.

It usually takes three years to ascertain the true value of a seedling, and if a person is favored by fincling one really good variety among the many seedlings, he may feel well repaid for his time and trouble. Many new varieties are raised by hybridization. which is a more difficult method, although it generally secures a greater number of good varieties. The manner of procedure is as follows: Remove all flowers excepting those you wish to hybridize, then with a pair of sharp seissors remove all the anthers from the stamens in the flowers to be impregnated, just before they conmence to discharge their pollen. When the flowers are dry, shake the flower containing the stamens of the variety which you wish to cross with it, being careful to do it when they are ready to discharge their pollen. Fit a piece of fine netting over the impregnated flower, to prevent the bee and other insects from leaving the pollen of other varieties npon the exposed pistil. The covering may be removed after two or three clays. Do not disturb them again until the seed-ball has ripened, when the treatment as given in the first part of this article may be applied.

Instances have been known, though rare, where one potato would produce two distinct sorts from its different buds or eyes. The White Peachblow, for example, has been found growing on the same stalk with the Jersey Peachblow. As so much interest is now excited in the growth and propagation of new seedlings, and many of the new varieties command such bigh pricesit behooves our farmers and amateur gardeners to avail themselves of the latest and, by actual tests, the best method of producing new varieties.

\section{HOW TO STORE AND KEEP.}

It is a matter of no small importance to the farmer to be able to keep his crop of potatoes in good condition through our long Winters, and to present them for sale, free from blemish or mildew, in the Spring. A well-kept potato brings three or four times its value in market in early Spring than the same stock will if sold in the Fall, paying an extra profit over and above the cost of storing, handling and care required.

Of the three methods of storing in general use, each has its champions. They are: storing in barrels, bins, or heaps or pits. The advantage of placing in barrels is, they can be easily handled, do not suffer from abrasion, can be readily looked over, and if disease presents itself it can be checked or removed.

When thousands of bushels are raised on one farm, this method cannot be followed on account of the time and expense involved. Bins are largely used by our fore-handed farmers, especially those near large cities, as the roots can at any time be reached and got reacly for market. A dry, cool, well-ventilated cellar, with the light excluded, is the best place to store potatoes. It has been found very alvantageous in preventing decay to sprinkle lime in the barrels or bin at the rate, say, of one pound to each barrel. It acts as an absorbent and neutralizes the earthy odors, thus directly acting as a preventive of decay to the roots.

The importance of excluding light from potatoes and keeping them as cool as possible, cannot be over-estimatel as means of preserving the crop. 
become in an abnormal condition, and prove a prey to attacks of fungus, resulting in disease or "rot." The attempt, on the other hand, to improve the quality of the potato as food, so far as depends upon the presence of starch in the tuber, will be found to be more encouraging when the action of potash in potato manure is considered. As will be seen further on, potash invariably increases the starch formation, and without its presence no stareli can be found. When grown upon newly recovered forest land, or upon any land of suitable mechanical texture, containing available potash, or supplied with the same in the form of unleached wood ashes or potash salts (of proper kinds) potatoes are iuvariably of superior quality.

The variation: in the ash or mineral constituents of the potato are remarkable, and probably exceed those of any other crop. With the exception of phosphoric acid and potash in the tubers, and lime, magnesia and sulphuric acid in the vines, the mineral ingredients, soda, iron, pure silica, chlorine, etc., vary to such an extent that they almost seem to be taken up by the roots for convenience rather than for any actual needs of the plants. Soda is found to exist in the ash of the tubers in quantity quite or next to nothing, up to twelve per cent. Oxile of iron from nothing to six per cent. Silica from nothing to over six per cent. Chlorine from nothing to nearly nine per cent.

In all these ash analyses, however, the proportions of potash and phosphoric acid are uniformly large; in the case of potash, from forty-two to seventy-three per cent., while the phosphoric acid is found to rarely fall below twelve per cent., and often rises to over twenty-seven per cent. (average say twenty per cent).

We are thus enabled to see, so far as the development of the tuber of the potato is concerned, that notwithstanding the large rariations in the proportions of its ash constituents, the presence of potash and phosphoric acid, but particularly the former is essential. Practice fully corrohorates this view, for the good effects resulting from the use of wood ashes and bone, (well known sonrces for these ingredients, ) have caused their almost universal adoption as special manures for potato culture.

The increased yield per acre from the addition of potasli alone has been, in several cases, from 150 to 200 bushels in excess of the quantity produced on another portion of the same land to which the potash was not supplied, but otherwise well manured.

The potato vines, as indicated by their analyses, seem to require full supplies of lime and magnesia as well as of sulphuric acid, and as these ingredients are generally found to exist in the vines in increased proportion as the season advances towards October, it would indicate that they are required more particularly for use by the vines themselves. The remaining ingredients found in the vines at the end of their growing season, show, on the contrary, a decreased percentage. This is particularly the case with the potash and phosphoric acid, showing that these ingredients, so important in the growth of the potato, have been transmitted from the vines for use by the tubers.

\section{ANALYSTS OF POTATO VINES (WOLFF).}

\begin{tabular}{|c|c|c|c|c|c|c|c|c|c|c|c|c|c|c|c|c|}
\hline & & , & & & & & & & & & & & & \multicolumn{3}{|c|}{ Per $100 \mathrm{lbs}$, of as } \\
\hline Potash, - & - & - & - & - & - & - & - & - & - & - & - & - & - & - & 14.50 & 6.30 \\
\hline Soda, - & - & - & - & - & - & - & - & - & - & - & - & - & - & - & 2.70 & 0.80 \\
\hline Magnesia, & - & - & - & - & - & - & - & - & - & - & - & - & - & - & 16.80 & 22.60 \\
\hline Lime, - & - & - & - & - & - & - & - & - & - & - & - & - & - & - & 39.00 & 46.20 \\
\hline Phospliori & acid, & - & - & - & - & - & - & - & - & - & - & - & - & - & 6.10 & 5.50 \\
\hline Sulphuric & acid, & - & - & - & - & - & - & - & - & - & - & - & - & - & 5.60 & 5.50 \\
\hline Silica, - & - & - & - & $=$ & - & - & - & - & - & - & - & - & - & - & 8.10 & 4.20 \\
\hline Chlorine, & - & - & - & - & - & - & - & - & - & - & - & - & - & - & 4.60 & 3.00 \\
\hline Percentag & of as & & - & - & - & - & - & - & - & - & - & - & - & - & 8.90 & 5.12 \\
\hline
\end{tabular}

The benefit arising from the use of plaster (sulphuric acid and lime) so successfully practiced by potato growers, as well as from magnesia salts, is probably due to their effects upon the vines, in increasing their power to sustain the entire plant in sufficient strength and vigor to enable it to withstand, especially during seasons of sudden and extreme changes of tcmperature and moisture, all parasitical attacks or fungus growth. It has been stated that a strong healthy vine is not liable to become affected even when brought into actual contact or rubbed with a diseased plant. The predisposition towards disease, through impaired vitality, must exist before there is danger of "rot."

The success claimed for the good action of common salt (chlorine and soda) on potatoes can hardly be due to any direct manurial action on the plant, but rather to its indirect action in aiding in rendering soluble and available the other ingredients on the soil. As Professor S. W. Johnson states: "Soda is an extremely variable ingredient of the ash of plants, and though gen- 
erally present in some proportion, has been observed to be absent in weighable quantities in the seeds of grain and in the tubers of potatoes."

The evidence of the importance of the presence of potash in the soil for potato culture, as given by the fact of its uniform presence in large quantities in the tubers, as well as by the good effects that always attend its use in a fertilizer for potatoes, is made even much stronger when it is remembered that without the presence of potash in the leaves of a plant no starch can be formed. Starch, as we hare stated, forms from nearly one-half to over two-thirds the entire weight of air-dry tubers.

The following interesting summary of the experiments, made by Dr. Nobbe and others in Germany, is taken from a lecture recently delivered by Professor W. O. Atwater, before the Connecticut State Agricultural Society, and will be found to fully cover the importance of the presence of potash for starch formation.

"If we examine a green leaf with a microscope, we may find in it thousands of minute sacs or cells as they are called. Some of these contain the green substance called chlorophyll. Inside these grains of chlorophyll appear still smaller grains of starch. Starch is composed of the elements carbon, oxygen, and hydrogen. It is produced inside the leaves. The carbon is taken from the carbonic acid of the air by the agency of the chlorophyll, is united with hydrogen and oxygen, the elements of water, and thus starch is produced. After the starch is so formed, it is conveyed to the other parts of the plant, and either stored away, as in potatoes or grain, which consist largely of starch, or transformed into the other materials of which the plant is made up. And this formation of starch in the chlorophyll grains, and transportation, transformation and storage to build up the plant is going on continually as the plant grows. If then, no starch is formed by the chlorophyll in the leaves, normal growth is impossible."

Now, in every one of Dr. Nobbe's plants grown in artificial soil without potash, after the starch of the seeds was used up, no more appeared in the leaves. As Dr. Nobbe says at the conclusion of over a hundred pages of description of his experiments, "without potasl the plant cannot assimilate (the materials needful for its growth) and shows no increase in weight, because, without the co-operation of potash in the chlorophyll grains, no starch is formed."

The extent of the variations of the leading organic ingredients in potatoes, and some of the reasons for the same as given by Dr. Voelcker of England, are here given as comprising some of the most reliable data offered at the present time.

"The variation in proportion of starch in different samples of potatoes are chiefly caused by the variety cultivated, by the soil upon which and the locality where the plants were grown, and by the time during which the tubers have been kept. Thus the following varieties grown in Scotland yielded respectively of starch:"

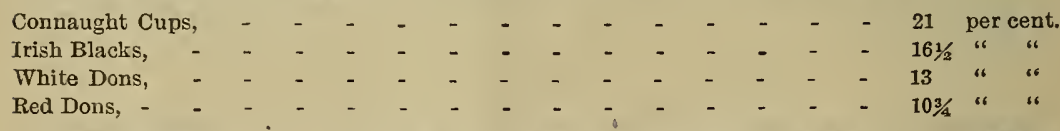

"The influence of soil and locality in affecting proportion of starch in the same variety of potato is seen from the following determinations, according to which

Buffs gave in Mid Lothian, - _ _ _ _ _ _ _ _ $\quad$ - $\quad$ - $\quad$ - 14.89 per cent. Buffs gave in Forfarshire, Cups gave in Argyleshire, Cups gave in Mid Lothian,

On lreeping, the proportion of starch diminishes in potatoes. Thus Payen found the same variety of potato to yield in

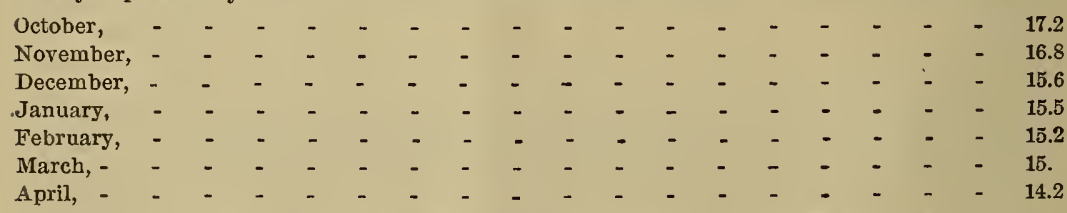

"The amount of the albuminous or flesh forming constituents of potatoes, according to Boussingault, is greater in newly dug potatoes than in others which have been kept some time. Thus.in newly dug potatoes he found them to amount to $2 \frac{1}{4}$ per cent., and in long kept potatoes to only $11 / 2$ per cent. of their weight. The first, according to this determination, when dried, contained 9 and the latter only 6 per cent. of albuminous substances."

"In diseased potatoes the proportion of albuminous matters is smaller than in healthy, as the disease primarily attacks the albuminous matters, which, when once attacked are readily decomposed, and changed into ammonia and other compounds." 
Dr. Voelcker also states that the analysis of the ash of a diseased potato failed to show any material difference from that of a healthy one. A small increase in the amount of silica in the diseased potato was the only noticeable difference.

PROXIMATE ANALYSIS OF THE POTATO.

Potato Tuber (air dry).

Average Composition (100 lbs.), as given by

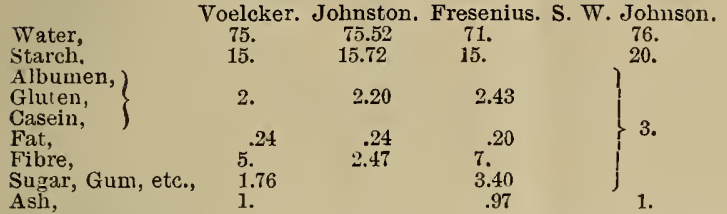

1 Maximum percentage of water in 27 varieties Young Potatoes was 82 per cent. (Voelcker.)

2 Caluulated on basis 75 per cent. water in air dry potatoes; from 2.60 to 8 per cent given as ash in potatoes (dried).-(How Crops Grow.)

The Variations ix tul Ash Ingredients of different varieties of Potatoes grown upon the same soil and precisely similar circumstances are shown in the following analyses by Herapath.

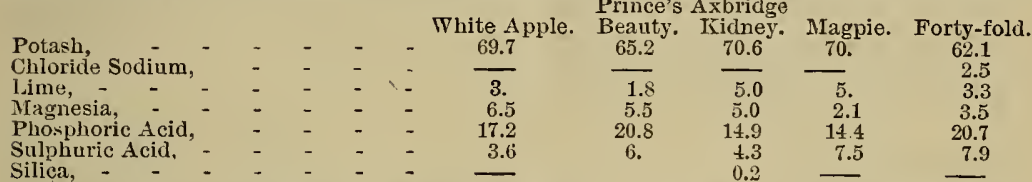

The extreme variations in the ash ingredients of Potatoes of different varieties and grown upon various soils may be seen in the annexed table, taken from Prof. Johnson's standard work, "How Crops Grow." (page 156).

Per cent. of ash,

Potash

Soda,

Magnesia,

Lime,

Oxide Irou

Plosphoric Acid.

Sulphuric Acid,

Silica,

Chlorine,

Average composition of 1000 Ibs. of Potato Tubers, natural condition (air dry); also of 100 bushels and one bushel.

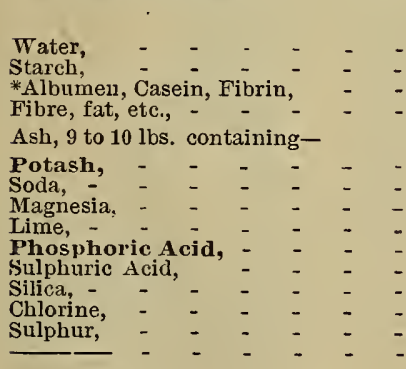

Lowest Percentages. Highest Percentages. 38 Analyses. 39 Analyses.

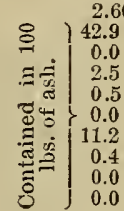

8.05
73.60
12.80
6.60
6.20
6.
27.10
18.00
6.50
8.70

$\begin{array}{cc}\text { Extreme percentages. } \\ \text { (Various authorities.) } \\ \text { Lowest. } & \text { Highest. } \\ 68.94 & 77 . \\ 10.75 & 21 . \\ 1.50 & 2.85 \\ .10 & .42 \\ 3 . & 7 .\end{array}$

Extreme percentages.

)

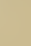


in weather, liability to rot, etc. Soda and chlorine, if found to act well, will cost but little in the form of refuse salt or brine. The main fertilizing ingredients, however, with which the potato-grower, need concern himself are the following : Nitrogen, Phosphoric Acid and Potash. The following gives the quantity of each contained in 1,000 pounds, as well as in 100 bushels, and a single bushel of tubers:

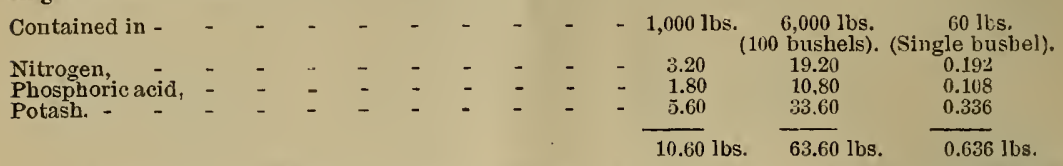

To supply all the phosphoric acid and potash required for the growth of each 100 bushels of potato tubers (the vines supposed to remain on the land) without exhausting the soil of any of its resources in these ingredients, would therefore require say 11 pounds of phosphoric acid, and say 34 pounds of potash, and for continued potato culture an application of an equal quantity for each crop. In the case of nitrogen, however, the quantity may safely be reduced to 10 pounds, instead of using nearly 20 pounds, as called for by the composition of 100 bushels of tubers. The reasons for this reduction in the quantity of nitrogen in the manure are as before explained, viz.: The natural power of the potato plant to derive nitrogen from the air, (at cheap source,) the tendency as shown in practice, of nitrogen to induce, except when used in very limited quantity, an over-rank vine-growth and a poor quality and a limited quantity of tubers, besides an almost certain tendency on the part of the potato crop towards "disease."

Taking the quantities of nitrogen, phosphoric acid and potash, as above advised, we lave the cost of the same at the current rates, furnished in the best known forms, (Peruvian Guano, blood or flesh, dissolved-bone and potash salts), as follows:

For 100 bushels of potatoes:

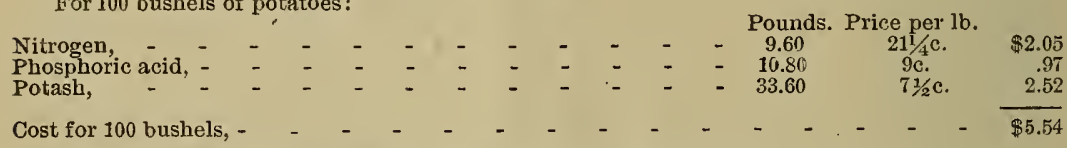

Equal to a cost for single bushel. $5 \frac{1}{2}$ cents.

To grow 300 bushels of potatoes, irrespective of resources of the soil, would require of:

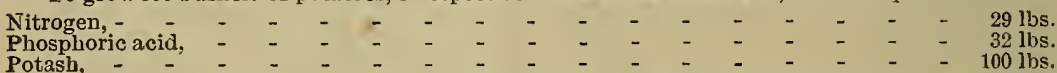

The following table gives the leading commercial sources for the above named ingredients, and also the quantities of each required to supply the necessary quantity of potash, phosphoric acid and nitrogen required for 300 bushels of potatoes.

\section{COMHERCIAL SOURCES OF POTASH.}

Quantity of Each Required to Yield 100 1bs. of Potash.

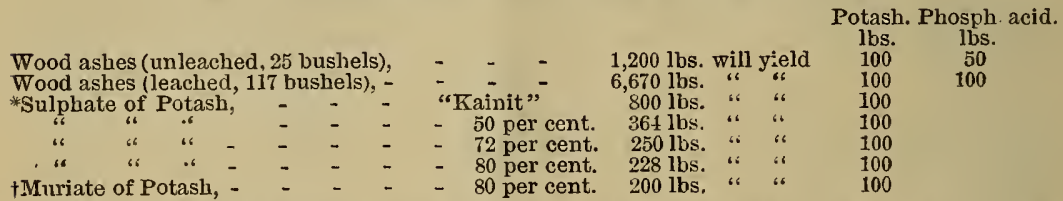

*In the use of the low grade potash salts known as "Kainit," as a source of potash for pota. toes, it is necessary to take precautions against damage arising from the presence of chloride of magnesium which this grade of potash salt contains to the extent of some ten per cent. (200 lbs. to the ton). These "Kainit" salts average only some 13 per cent. of actual potash, it therefore requires some $700 \mathrm{lbs}$. per acre, provided this salt is used alone, to give $100 \mathrm{lbs}$. of actual potash, (the quantity required for 300 bushels of potatoes). The use of this quantity per acre would be attended with serious danger to the crop owing to the presence of some $70 \mathrm{lbs}$. (10 per cent.) of chloride magnesium. The only safe method of application is to sow broadcast and harrow in several weeks before planting.

Professor S. W. Jolnnson advises the mixing of fifteen pounds of air-slacked lime_with each one hundred pounds of "Kainit" before use. This is said to counteract any injurious effects that might otherwise arise from the presence of the chloride of magnesium. In Germany they seldom use this grade in quantities exceeding 500 to $600 \mathrm{lbs}$. per acre.

†The muriate of potash is open to the objection for use on potatoes, that it has a tendency to produce tubers of an inferior quality - watery and waxy. It is recommended to use as a source 
of potash, when the formation of starch or sngar is desired, either wool asbes or some grade of sulphate of potash (as fiee as possible from any chloride salt.)

\section{COMMERCIAL SOURCES OF PHOSPHORIC ACID.}

Quantity of Eacli Required to Yield 32 1bs. of Phosphoric Acid.

Pure Fine Bone, (dissolved in sulphuric acid), Pure Bone Meal,

Dissoived Bome BIack -

Rectified Peruvian Guano,

\begin{tabular}{lccc}
\multicolumn{5}{c}{$\begin{array}{c}\text { Nitrogen. Phos. acid. Potash. } \\
\text { lbs. }\end{array}$} & $\begin{array}{c}\text { lbs. } \\
\text { lbs. }\end{array}$ \\
267 lbs. will yield & 6 & 32 & \\
160 lbs. "“ "6 & 6 & 32 & \\
230 lbs. " ". & & 32 & \\
228 lbs. " " & 16. & 32 & 4132
\end{tabular}

COMMERCIAL SOURCES OF NITROGEN.

Quantity Required of Each to Yield 30 1bs. of Nitrogen.

Dried Flesh or Blood,

Rectified Peruvian, -

+ Nitrate of Soda,

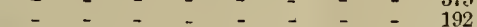

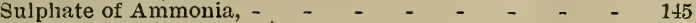

Pure Bone Meal, - - - - $\quad$ - $\quad-\quad-\quad-\quad-\quad-\quad 800$

Nitrogen. Phos. acid. Potash.

$\begin{array}{lll}30 & & \\ 30 & 521 / 2 & 61 / 2 \\ 30 & & \end{array}$

30

30

160

¥These articles, nitrate of soda and sulphate of ammonia, as they furnish nothing of value but nitrogen, should be used in potato culture with caution, and in small quantities. Their effect upon potatoes, except when nsed on soil abounding in the mineral ingredients (particularly phosphoric acid and potash), will be to produce an excessive vine-growth and a yield of tubers small in quantity and inferior in quality.

\section{*A COMPLETE MANUIE FOR POTATOES.}

The composition of a good potato manure for average soils, and suitable for continued culture of this crop, would be:

Nitrogen,

Phosphoric acid (from dissolved bone ö Péruvian Giano-

Per $100 \mathrm{lbs}$.

cid (from dissolved bone or Peruvian Guano), -

Potash (in the form of a Sulphate of Potash), - - - - - - 13 to 14 " "

*This formula will be found to correspond in composition with the potato manure offered for sale by us. Price per ton, $\$ 52.00$; per bag $(200 \mathrm{lbs}$.$) , \$ 5.40$; eartage (50c) chargerl only on less than half toll. One to three bags sufficient per acre. Directions for use accompany each bag. See our Price List of Fertilizers.

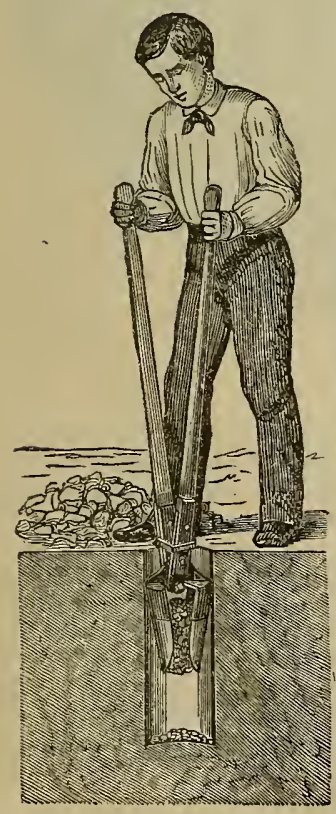

\section{Eureka Tree and Post-Hole Digger.}

Indispensable to Every Farmer, Nurseryman, and Railroad and Telegraph $\mathrm{Co}$.

The Grand Medal of the Centennial Exhibition has been awarded to us for our Digger for "distinguished merit" and great " excellence." We have also received the prize at six State, and twenty County fairs, and have always received the premiums wherever we have exhibited.

This tool has been thoronghly tested during the past three years, and as yet no place has been found where it has failed to do its work satisfactorily. The principle on which it works prevents adhesion in. sticky soils, hence it always works free and easy; no clogging,'no knee work, no backache. It is far superior to all Plungers, Augers and Boring Machines, as it works equally well in stony, sandy and clay soils. Quicksand under water is as certainly haniled ancl removed as though no water existed. Hundreds have used then for setting curbs in wells, where there was quicksand. For setting out trees and transplanting it is unequaled; also for cleansing out wells and for tiling.

One man with this Digger can do five times as much work in the same time, as can be done in any other way. One great advantage in using the Eureka Digger is, that you need make the posthole only a little larger than the post, thus causing it to set firmer than where a larger hole is dug. The size of the hole dug is bounded only by the requirements of its purpose, and can be made of any inclination or shape, and anything that can be reduced or loosened to five inches or less in diameter, can be easily removed. As constructed for ordinary use, it will dig readily four feet deep. Its durability will equal any tool made for any purpose, the material being cast steel. But should any part fail from use or accident, duplicate parts can be furnished; in this way it can be kept good for a generation. Price, $\$ 5.00$. Send for Circular. 
OF

\section{POTATOES FOR 1878.}

WE take much pleasure in offering two new Potatoes, which we are confident are destined to occupy a prominent position in the list of varieties heretofore introduced by us.

We refer with pleasure to the'great popularity of most of the varieties sent out by us within the past ten years, among which are the Early Rose, King of the Earlies, Bresee's Prolific, Peerless, Climax, Late Rose, Extra Early Vermont, Compton's Sulprise, Brownell's Beaity, Eureka, Snowflake, Alpha, Ruby, Centennial, Superior and Bliss's Improved Peach Blow. There is no section of the country in which these varieties have been tested, where they have have not proved superior to the older varieties in cultivation, so much so, that in our leading markets, by far the greater portion of those now offered for sale were tirst introduced by us. Many of our varieties are also exceedingly popular in foreign markets, where they have been successfully hybridized with their finest sorts, producing varieties far superior to those formerly in cultivation.

Notwithstanding the many fine sorts now in cultivation, we believe the Potato to be susceptible of still greater improvement, and our numerons growers in various parts of the country, are constantly exerting themselves, by careful bybridization, to introduce some new variety which shall exceed, in some important respect, those already in cultivation. We have many very promising varieties on trial, and shall continue to add to our list, from time to time, such as we think worthy of dissemination.

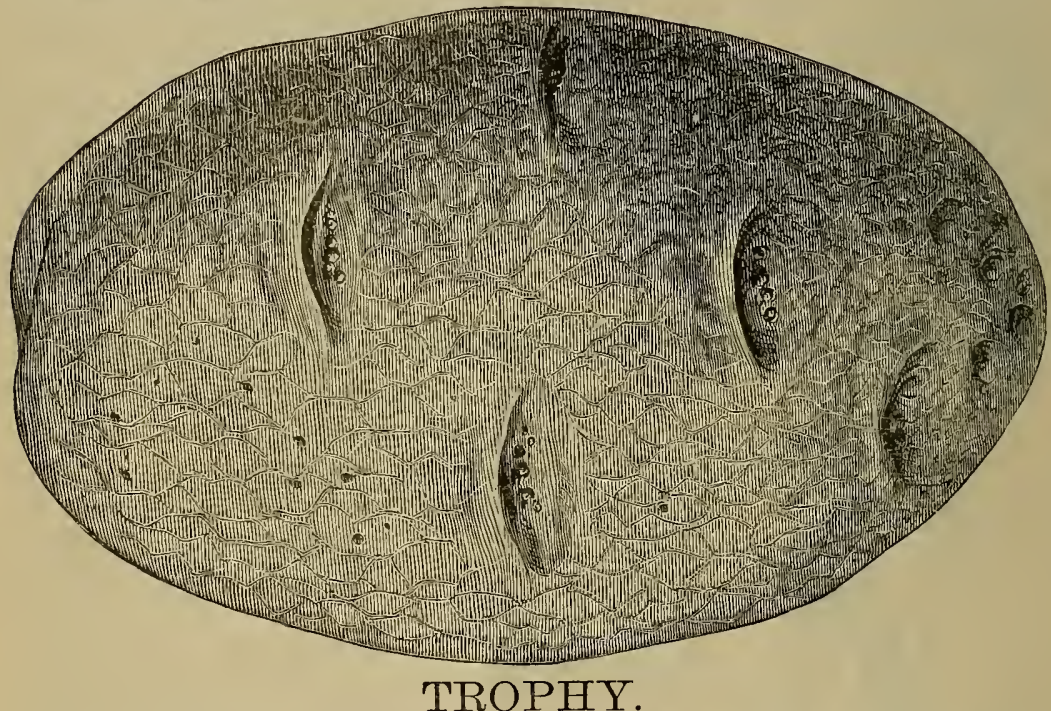

This new and exceedingly fine variety is, like most of those heretofore sent out by us, a native of northern Vermont, and is one of several very promising varieties raised from a packet of Pringle's Hybridized Potato seed, by a most successful cultivator, and is sure to become a general fa-. vorite. It is a seedling of the Ruby impregnated with the Excelsior, and is a decided improvoment upon both of these varieties.

Tubers of medium size, very regular in form, elongated oval, somewhat flattened, eyes very few, almost flat ppon the surface, resembling, in many respects, the well-known Snowflake, skin reddish, slightly russeted, flesh fine grain, white, and of excellent quality, either baked or boiled. Vines are stout and vigorous, foliage dark green. It matures its crop about two weeks later than the Early Rose. The tubers are compactly clustered around the base of the stalk, and easily dug. It is a good keeper, very productive, and we are confident will become a general favorite.

This variety was exhibited in London at the great International Potato Show, in October last, and received a first-class certificate.

Price, $\$ 1.00$ per pound; three pounds to one address, $\$ 2.50$; by mail, post-paid. 


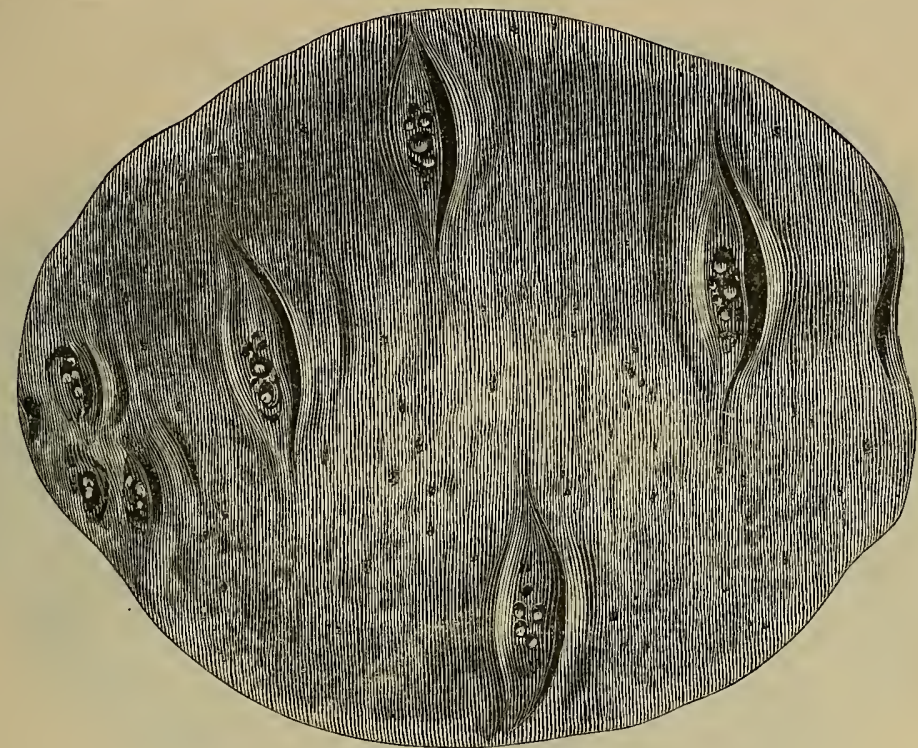

BLISS'S TRIUMPH.

This new and beautiful variety is, without exception, the most attractive in appearance of any that we have yet offered, and will also compare favorably with the best of them in qualicy. It originated in the State of Connecticut, several years since, and has been faithfully tested. by the originator, and found to maintain its good qualities from year to year. It was raised from a seed ball of the well-known Peerless crossed with a seedling of the Early Rose. It combines the wonderful productiveness of the Peerless, with all the good qualities of the Early Rose, is much more productive, and matures its crop at least ten days in advance of that favorite sort, before the second crop of beetles appear. In color and form it resembles the Garnet Chili, though greatly improved in form and quality. Tubers of medium size, round and uniform in shape, with but a very few small ones, eyes slightly depressed, color a beautiful light red, strongly resembling the early varieties from Bermuda; flesh fine grain and of excellent flavor. Vines about two feet in hight, erect, with but a few lateral branches, covered with long, dark-green foliage.

The tubers grow compactly in the hill, are easily harvested. It is an excellent keeper; not inclined to sprout early. Its great beanty, productiveness, and fine quality, will make it one of the best market varieties in cultivation.

Price, $\$ 1.00$ per pound; three pounds to one-address, $\$ 2.50$ by mail, post-paid. By express or freight, charges to be paid by the purchaser, one-half peck, $\$ 3.00 ;$ one peck, $\$ 5.00$.

\section{$\longrightarrow$ \\ HARLEQUIN, \\ OR VARIEGATED-LEAVED EARLY ROSE.}

This singular variety was discovered, several years since, in a field of Early Rose, and only differs from that variety in the foliage, which is beantifully variegated with different shades of white and yellow, resembling many of the ornamental varieties of the Coleus now so extensively grown in the flower garden. It has been cultivated for several years, and the variegations are quite constant. In some soils it is almost entirely white or straw color, witl an occasional green leaf, and in others the green predominates. The variegation is much more marked in light soil but little manured. By planting this variety, you not only have a desirable crop for domestic use, but a decorative plant worthy of a place in every tlower garden.

Price per pound, $\$ 1.00$; single tubers, 25 cents each. 


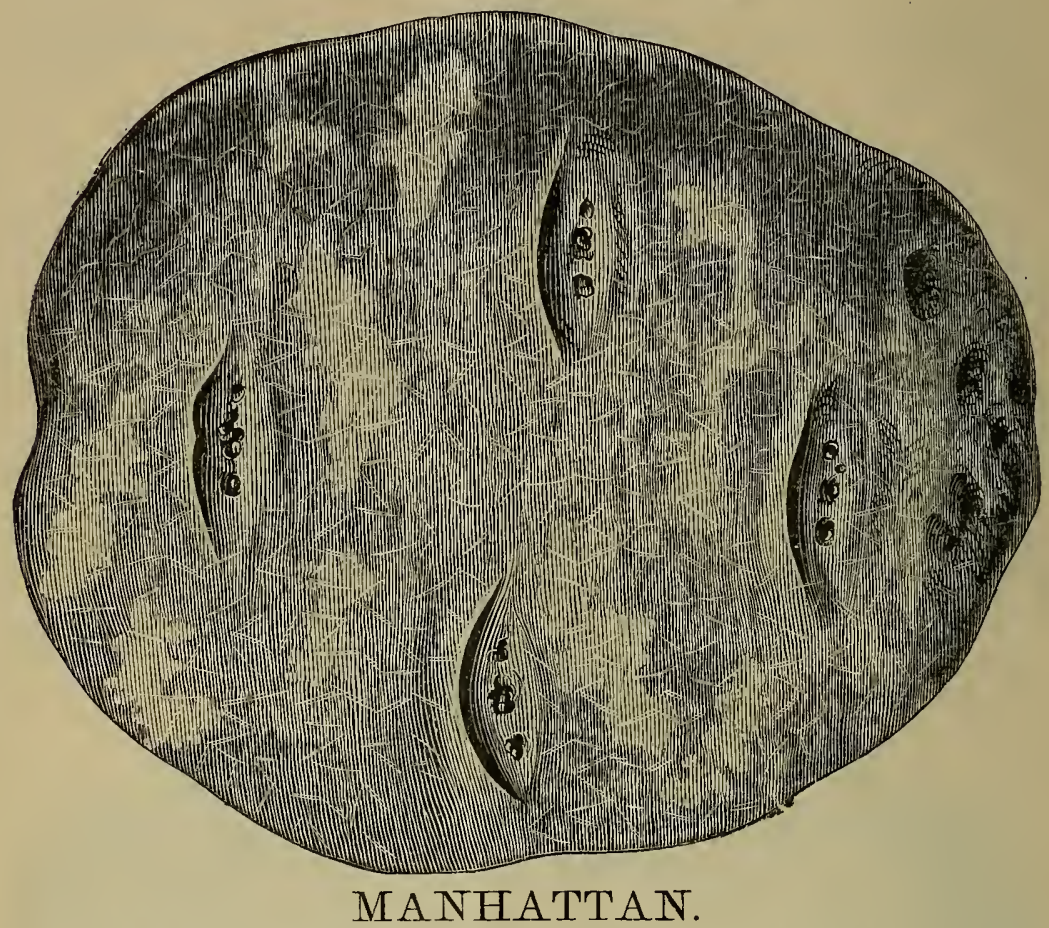

In this variety we have what may be called an "Improved Compton's Surprise." It combines atl the good qualities of that favorite variety, but is much more regular in form, and consequently more desirable as a market variety. In shape it is nearly round, sometimes a little oblong, skin dark purple, occasionally blotched with white; origin unknown; flesh white, very solid, tine grain, cooks through evenly, either in baking or boiling; dry and mealy, ard of excellent quality. Size, medium to large, eyes slightly depressed, vines vigorous, a little spreading, of a dark green color; one of the most productive in cultivation. It is an excellent keeper, and can be strongly recommended as a main crop variety.

Price, 75 cents per $l b . ; 3 l b s . \$ 2.00$, by mail post-paid; by express, freight paid by the purchaser, $\$ 3.00$ per peck, $\$ 10.00$ per bushel.

\section{EARLY OHIO.}

A seedling of the Early Rose, and similar in color, habit of growth, and appearance, with the exception of being a round oblong, while the former is more of an oval oblong, so that side by side it is readily distinguishable. It is several days earlier and more productive, and of very fine quality. It has given general satisfaction wherever it has been tested.

By mail, 60 cents per pound; 2 pounds $\$ 1.00$.

By express or freight at expense of purchaser, 1 peck $\$ 1.00 ; 1$ bushel $\$ 2.25 ; 1$ bbl. $\$ 5.00$.

\section{BURBANK'S SEEDLING.}

A seedling of the Early Rose, tubers large, long and slim, eyes few and but littie depressed; flesh white, fine grain, dry and floury; cooks through readily. It is a second early variety, very productive, and superior for the market, as its size and general appearance are very much in its favor.

By mail, 60 cents per pound ; 2 pounds $\$ 1.00$.

By express or freight at purchaser's expense, 1 peck $\$ 1,00 ; 1$ bushel $\$ 2.25 ; 1$ bbl. $\$ 5.00$. 


\section{Varieties for 1877.}

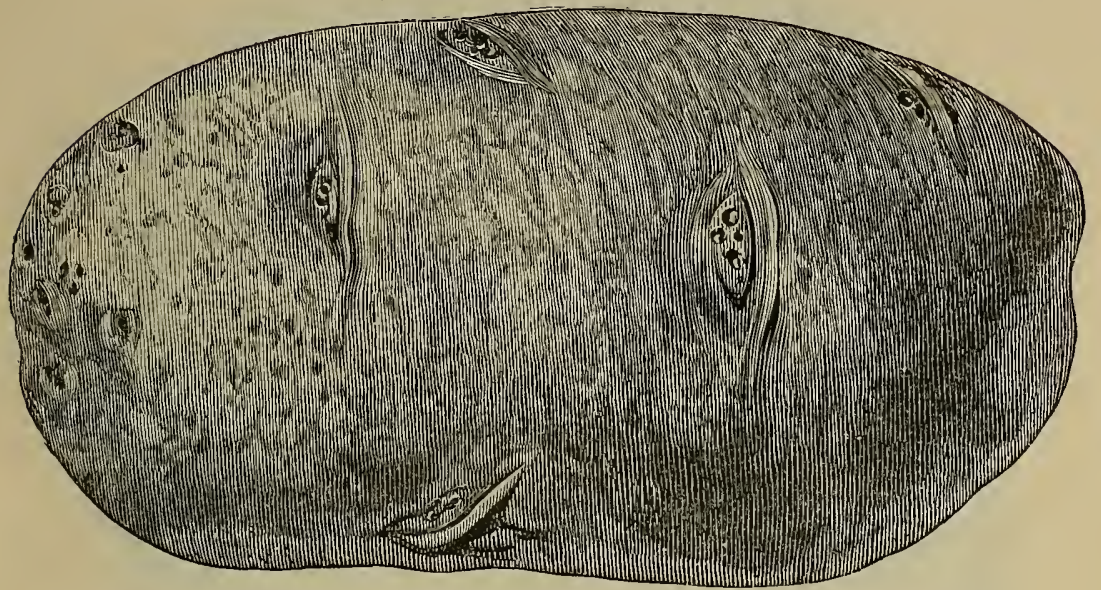

SUPERIOR. (Brownell.)

The parentage of this variety is the same as that of tbe "Centennial." It was produced in 1873 , from a seed ball of Brownell's Beauty, fertilized with Peachblow. The yield of this new seedling potato is enormous; six bundred and seventy-three pounds were grown from one pound of seed, during a season of unprecedented drouth, when many older varieties did not yield enough to pay for the digging. Its tubers are medium to large, elongated oval or cylindrical, of a peculiar dark copper color, and very uniform and handsome in appearance. Skin very fine and smooth, eyes few and small. The vines are strong and healthy, and the growth of the roots and tubers, close around the stalks. It ripens second early or medium late ; keeps well during Winter, and retains its mealiness and excellent table qualities throngh the entire season. A certificate of merit was awarded to this variety at the great International Potato Exhibition at London, last September.

Price, 60 cts. per pound; 2 lbs., $\$ 1.00$, by mail to one address, post-paid. By express or freight, charges to be paid by purchaser; 1 peck $\$ 1.00$, bush., $\$ 3.00$, bbl. $\$ 7.00$.

\section{DUNMORE.}

This new seedling-a white skinned and white fleshed variety, which originated in Vermont, tested side by side with over forty varieties, in every requisite of a first-class potato, ranks but second to the Burbank. It is superior in its yield, size of the tubers, handsome appearance and fine floury quality either boiled or baked, of the varieties that have recently become famous. As the same potato varies on different soils, possibly on some soils the Dunmore may give greater satisfaction than the Burbank Seedling.

The past season the crop has been remarkably large. Some of the potatoes weighing two pounds each, and were perfect in sbape. Its general appearance somewhat resembles the Peerless, but it surpasses that well known variety in both yield and quality.

By mail 60 cts. per lb., 2 lbs. \$1.00. By express or freight, at purchaser's expense; 1 peck, $\$ 1.00,1$ bush. $\$ 2.25,1$ bbl. $\$ 5.00$.

\section{WHITE ROSE.}

Similar in many respects to the Late Rose, said by the raiser to be of very superior quality. $\$ 5.00$.

By mail, 60 cts. per lb., 2 lbs. $\$ 1.00$. By express or freight, 1 peck $\$ 1.00,1$ bush. $\$ 2.25,1$ bbl. 


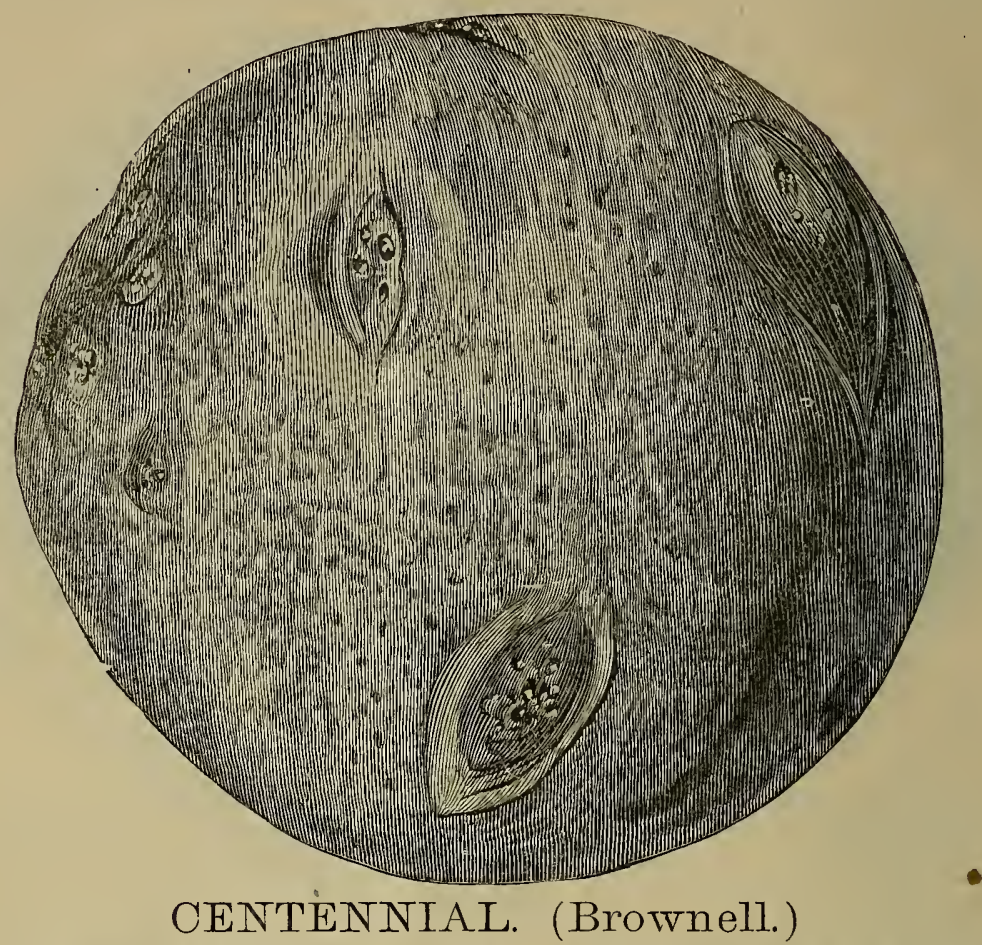

This new seedling was raised by E. S. Brownell, the originator of that well-known and favorste rariety, "Brownell's Beauty." It was produced in 1874, by fertilizing the blossoms of the Brownell's Beauty with pollen from the White Peachblow. The vines are upright, stout, vigorous and of medium hight; foliage dark green, strongly resembling the leaves of a Raspberry: very healthy. 'The tubers are compactly clustered around the base of the stalks, consequently. easy to dig; are of a good medium and uniform size; shape nearly round, somewhat flattened, very symmetrical, remarkably uniform and handsome, never rough or prongy, eyes few and quite small, and but slightly depressed near the seed end; stem set in a shallow, round hasin; skin of a deep red color, smooth and uniform in coloring; season second early or medium. Its flesh is of exceedingly fine grain, white, and when boiled or baked of a lightness and porosity seldom equaled; cook through evenly without any hard or watery core.

During the past two seasons it has proved to be one of the most productive varieties; its tuhers were perfectin every respect, never hollow or false-hearted; and their excellent and delicate flavor places them in the first ranks of our best table potatoes.

Per lb., $60 \mathrm{cts}, ; 2$ lbs. to one address, $\$ 1.00$ by mail, prepaid. By express or fieight, charges paid by the purchaser, 1 peck, $\$ 1.00 ;$ bnsh., $\$ 3.00 ;$ bbl., $\$ 7.00$.

\section{TWO NEW VARIETIES OF SWEET CORN.}

Dolly Dutton.-The earliest sweet corn ever introduced. A very dwarf-growing sort, stalks from three to four feet high. Ear's small, averaging from four to five inches in length, kernels of good size; tender, very sweet and delicious. It ripens from seven to ten days earlier than the Early Minnesota, and is of much better quality.

Package containing sufficient for fifly hills, 25 cents; five packages for $\$ 1.00$; selected ears, 15 cents each; two for 25 cents: $\$ 1.25$ per dozen.

Washington Market.-This is, without exception, the best of the large varieties of sweet corn, and when better known, will, we are confident, become a standard variety for general cultivation. See description, page 120, in our Guide to the Flower and Kitchen Garden.

Select ears, 30 cents each. Packets containing sufficient seed for one hundred hills, 25 cents; 50 cents per pint; 75 cents per quart. By express, freight paid by the purchaser. or when delivered at our counter, 50 cents per quart ; $\$ 3.00$ per peck.

\section{EARLY LIMA BEAN.}

This variety has been in cultivation for several years by a skillful horticulturist, but is now offered for the first time. A careful trial the past season proved it to be ten days earlier than the ordinary variety, besides'being very productive and of extra fine quality.

Packets, 25 cents each; per pint, $\$ 1.00$. 


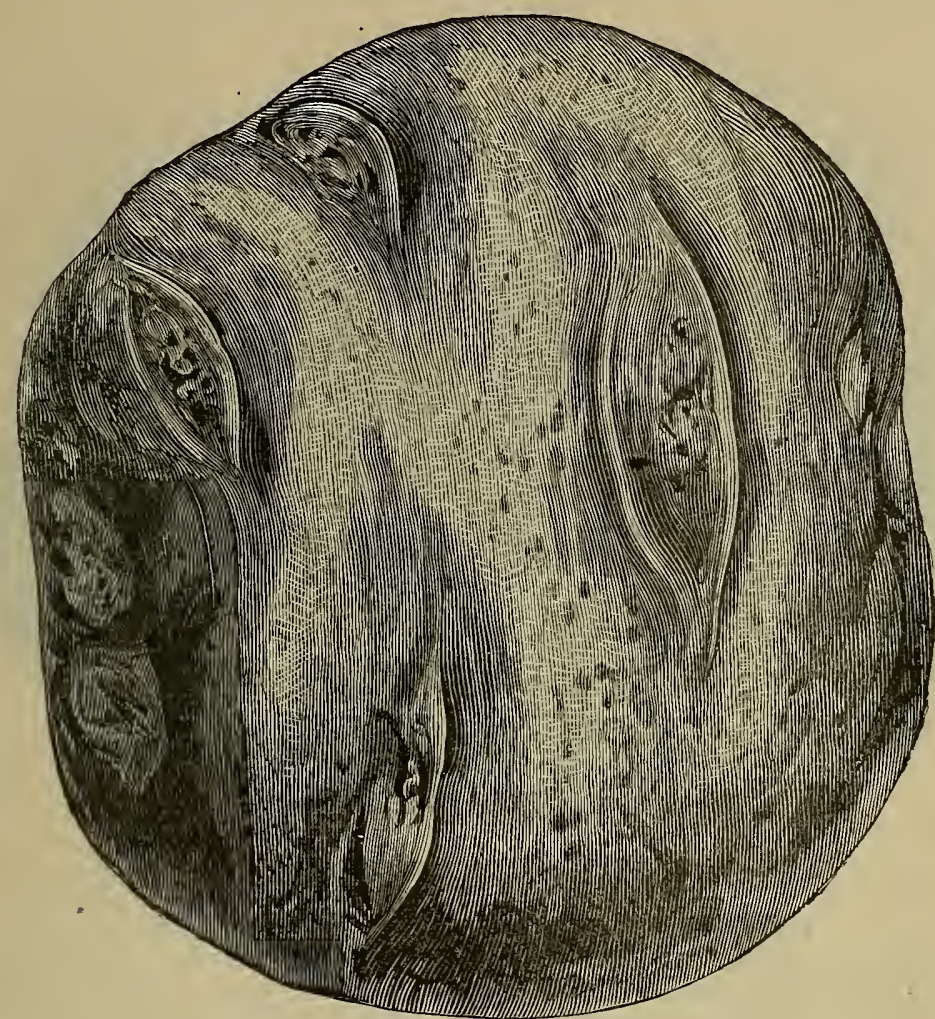

IMPROVED PEACHBLOW.

A cross between the "Jersey Peachblow" and "Excelsior," grown in 1873 by an experienced hybridizer of Vermont, who has devoted many years in experimenting with the Potato. It partakes some characteristics of each of its parents, the vines and leaves having the appearance of the "Excelsior," while its tubers resemble the "Peachblow." The form of the tubers, however, is more round and regular than that of the "Peachblow." While in quality it fully equals that old standard market sort, in productiveness it far excels the same, yielding nearly double as much per acre. Its season of ripening is somewhat earlier than that of the "Peachblow," and the growth of its tubers is more compact and closer in the hills. Taking all its points together, it may be considered a rejurenated and reinvigorated "Peachblow," combining all the best qualities of that general favorite, in its best days, with the additional advantages of earlier ripening and compacter growth.

Price, $\$ 0.60$ per lb.; 2 lbs. for $\$ 1.00$, by mail, to one address, postpaid. By express or freight, charges to be paid by the purchaser, 1 peck, $\$ 1.00 ;$ bush., $\$ 3.00 ; b b l ., \$ 7.00$.

\section{Bliss's Improved Long Orange Carrot.}

This superior variety is the result of a careful selection, for successive years, of the best formed, largest and deepest colored roots of the Improved Long Orange Carrot, by which it has attained a perfection hitherto unknown in this useful vegetable, being larger, better flavored, and of a deeper orange color, and more sure to produce a crop. Butter makers will find this variety very useful in giving to their butter a rich, deep yellow color. We unhesitatingly pronounce it the best variety in the market, and one which will not fail to give satisfaction to the purchaser One ounce, 15 cents; four ounces, 40 cents; one lb., $\$ 1.25$; by mail, postpaid. 


\section{Varieties of 1875 and 1876.}

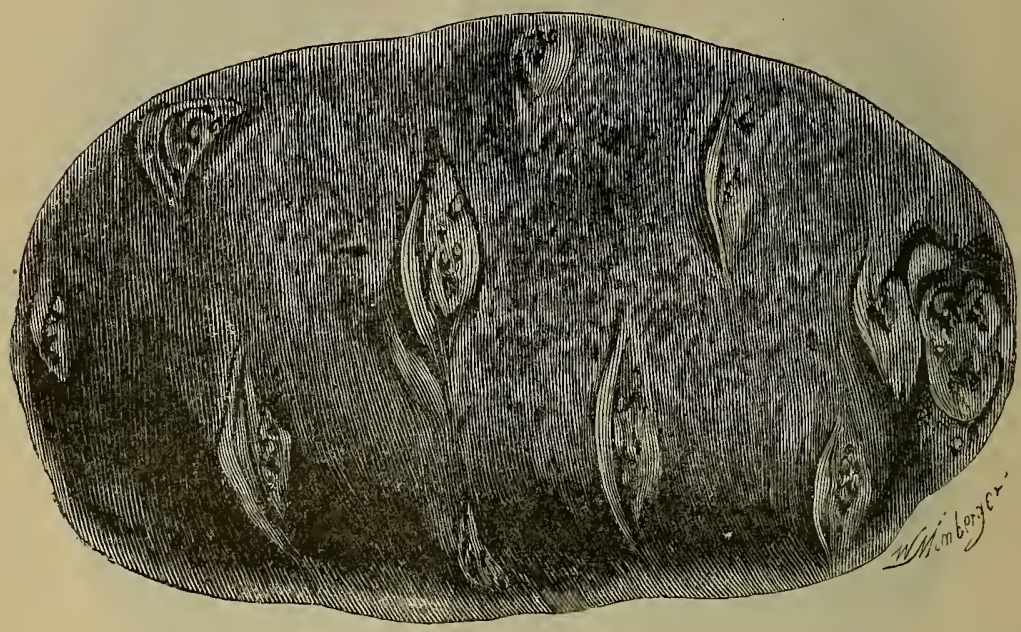

RUBY. (Pringle.)

1,982 lbs. (33 bushels) grown from one pound of Seed.

A new red kidney-shaped Potato of superior quality, raised in 1871 from the Early Rose hybridized with the White Peachblow. Its hybrid origin is quite apparent. The shape is oblong, slightly flattened, resembling that of the Early Rose. In its coloring the red of the latter variety is deepened by the carmine which shows in the blotches of the White Peachblow. The eyes, which are but slightly sunken, are carmine like those of this variety. The flesh possesses much the character of the Peachblows, being white, fine-grained, firm, and of excellent flavor. The tubers are of approved medium size; and are clustered close about the foot of the stalks. These are short and stout, with foliage broad, thick, and of a very dark green color. The time of maturity is the same as that of the Early Rose, and it is equally productive.

In short, we believe this variety combines in a rare manner the good points of its parents; and to those with whom the Peachblows are favorites we can recommend it with confidence as an early variety of the Peachblows without any of their faults. At the recent International Potato Exhibition held in the Alexandra Palace, London, in September, this seedling, in common with a few others sent by us, received a certificate of merit. To those whe prefer a red-skin Potato, we can contidently recommend this excellent variety.

The following extract from the report of the committee who selected the premiums offered by us for this variety, gives their opinion of its merits:

"The Ruby, although not presenting as striking characteristics as the Alpha, has proved to be a valuable introduction. It is declared to be a 'No. 1 Potato in every particular,' and seems to be especially valued for its remarkable exemption from rot. Although there was so much rain in some of the Western States, that Potatoes generally failed to grow, and those that grew generally rotted, yet no rotten ones were found among these, and their quality was excellent. Its large yield and very handsome appearance, combined with excellent quality, make it a valuable market variety, where red-skinned Potatoes are in demand." In Europe it has likewise succeeded exceedlngly well. Mr. P. Robertson of Scotland, says: "they were pronounced of excellent quality by every person who has tried them."

For further information see the reports of the successful growers in the following pages:

Per ib., 60 cts.; 2 lbs. to one address, $\$ 1.00$; by mail, prepaid. By express or freight, charges paid by the purchaser, 1 peck, $\$ 1.00,1 / 2$ bush., $\$ 1.50$, bush., $\$ 2.25, b b l ., \$ 5.00$. 


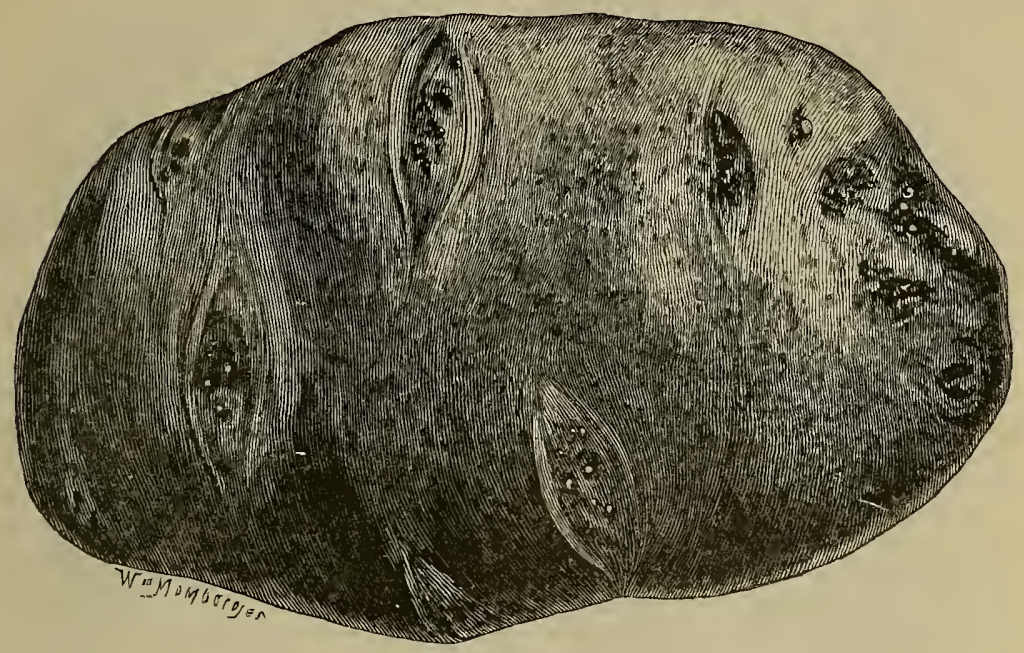

\section{ALPHA. (Pringle.)}

The Earliest Variety in Cultivation. 1,70y 1bs. (28 1-4 bush.) grown from one pound of Seed.

Raised in 1870, from seed borne on Early Rose and impregnated by pollen of Sebec. A very early variety for farm and garden culture, also for forcing under glass; fit for the table ten or fifteen days before the Early Rose. Tubers of medium size, oblong, somewhat flattened, with eyes but slightly depressed; color a clear white, with the slightest tinge of red about the eyes; flesh very white, fine grained, dry and firm, and possessed of a decided and excellent flavor; stalks short and close jointed, seldom exceeding a foot in hight; leaf broad, light green and shining above; tubers clustiered about the base of the stalk; quality of the lighest excellence. A firstclass certificate was awarded by the Royal Horticultural Society, of London, in 1874. A silver medal was also awarded by the Massachusetts Horticultural Society. It has been thoroughly tested the past season in various sections of this country, and has given perfect satisfaction. We can recommend this with the greatest confidence as the very best early variety in cultivation.

\section{(From the Report of the Royal Horticultural Society of London.)}

ALPHA-(B. K. BLISS \& Soxs.)-Haulm compact, about 12 inches long; ripening off very early, stem pale green, leaflets broad, flat, very pale green; tuber medium size, half round, flat; eyes large, skin smooth, very clear, pale straw-colored; flesh firm, white, of excellent quality for early use. Moderate cropper; one of the very earliest of potatoes. First-class certificate.

The committee who awarded the premiums offered by us last Spring, after examining the various communications received from competitors for premiums, report as follows:

"The AI pha has by many growers been declared " much the earliest of any seedlings." It was found to be "fit for use, in sixty days from the day of planting," " of excellent quality when cooked in any way, and gaining steadily in quality and yield." In this latter respect the Alpha differs from most new seedlings. But few improve after the third year, while many deteriorate rapidly. The Alpha, when first lorought to notice, was below medium size, and so delicate that it was thought only suitable for garden culture. But gradually we found it increasing in size and productiveness, while it retains its earliness and excellent quality. That it will henceforth rank as the earliest Potato for the field as well as the garden, and that it yields enormous crops, even under ordinary culture, has been sufficiently proved by Mr. Clute's 1,535 pounds, grown without manture whatever." For further information respecting this variety, see the reports of the successful competitors in the following pages.

Per $l b ., 60$ cents; 2 lbs. to one address, $\$ 1.00$, by mail, prepaid. By express or freight, charges paid by the purchaser, 1 peck, $\$ 1.25 ; 1 / 2$ bushel, $\$ 2.00 ; 1$ bushel, $\$ 3.00 ; 1$ barrel, $\$ 7.00$. 


\section{THE SNOWFLAKE. (Pringle.)}

\section{1,41 lbs. (23 6-10 bushels,) grown from 1 pound Seed.}

This new variety, first sent out by us ill the Spring of 1873 , has been thoroughly tested, both - in this country and in Europe the past two seasons, and we have yet to learn of the first instance where it bas failed to give entire satisfaction. The superior quality claimed by the originator, when first offered, has been confirmed in every case as far as heard from.

It is one of the earliest varieties, ripening about the same time as the Early Rose. The tubers are of a good medium and uniform size; shape elongated oval, compressed, exceedingly symmetrical and remarkably uniform; eyes few, entirely flat on the base and body of the tuber, and but slightly and sharply depressed near the seed end; skin white with a russety tinge, and somewhat roughish and tessellated. Its flesh is of exceedingly fine grain, snow-white when boiled, and of a lightness and porosity almost approaching a snowflake. In quality, we do not besitate to say nothing can surpass this new variety; its mealiness, its pure, delicate flavor, and the evenmess with which it cooks through, have never been eclipsed by any Potato. As a baking Potato, it is equally valuable, and as such is distinguished for its pure starchy texture, and delicate nutty flavor. The tubers have attained the full development of their quality as soon as they are fit to dig, and do not lose it during Winter; samples kept till the first of June, did not show the least deterioration. The vines are of medium hight, stout and vigorous; leaves medium, and of dark green color. The tubers are compactly clustered around the base of the stalks,-an important consideration in digging the crop. The variety has been tested on widely varying soils-sand, gravel, loam, as well as heavy clay-and has, in every case, given the same favorable results, and often produced a yield of from 300 to 400 bushels per acre. In every case it has proved healthy and hardy, while other varieties alongside of it failed to give satisfactory results.

We could fill quite a volume with the many letters of commendation that have been received from various growers throughout the country in favor of this fine variety, but for want of room we publish those only which have been received from the successful competitors for the prizes offered by us last Spring. These will be found in the report of the Committee in the last pages of this Catalogue.

We take pleasure in submitting the following extract of that report to our friends, which cannot but satisfy the most incredulous of its superiority.

"The Snowflake has received more and higher praise than has probably ever been bestowed upon any Potato. There is no dissenting voice among the whole list of reports, nearly every one of which contains ' $I t$ is the best Potato $I$ ever saw.' Its quality and uniformity of size are especially commended. In many cases, 25 to 40 perfect Potatoes were found in every hill planted, and 'tubers of two and three pounds each cooked readily and completely through.' Mr. Perkins could select 1000 tubers weighing 1000 pounds from a gross product of 1304 pounds, and finds them preferable to any Potato out of over a hundred varieties he grew. Mr. Salter 'never saw so fine a Potato; beautiful in color and shape, firm in texture, flesh white; luscious cooked in any way; it stands unrivalled.' There is certainly within our knowledge no variety which combines all the essential points of a Potato in as high a degree as the Snowflake. Quality, shape, size, color, yield, are all that can be desired, and it is difficult to perceive in what direction further improvement can be obtained."

By mail postpaid, per pound, 60 cents; two pounds, $\$ 1.00$. By express or freight, charges paid by the purchaser, 1 peck, $\$ 1.00 ; 1 / 2$ bushel, $\$ 1.50 ; 1$ bushel, $\$ 2.25 ; 1$ barrel, $\$ 5.00$.

(From the Report of Messrs. Carter's Royal Metropolitan Root Show, in Bell's Weekly Messenger, Nov. 20 1876.)

A dish of Snowflake Potatoes, sent by Mr. Penny, head gardener to his Royal Highness the Prince of Wales, cannot be adequately described in words; but we may advise any professional or amateur grower to secure a supply of this stock for trial next year, that they may put it to a practical test under their own eye.

(From the London Gardeners' Chronicle of Jan. 16, 1875.)

"It is not many years ago, since our American cousIns introduced us to the first of their wonderful 'T'aters,' and just see what a revolution they have caused! On the exbibition tables, frequently no other than American varieties are to be found-they are unmistakably great croppers and of fine, taking appearance. We caunot say in points of quality they are always so superior, yet, we can say, from personal experience, that some of the best potatoes we tasted during the past season were of the American sorts. Of this year's introduction, we would tirst especially note Snowflake. The tubers of this sort are of a long ovate form, the eyes very full, skin rough, pale straw, the most handsomely formed of all, and of excellent quality. 


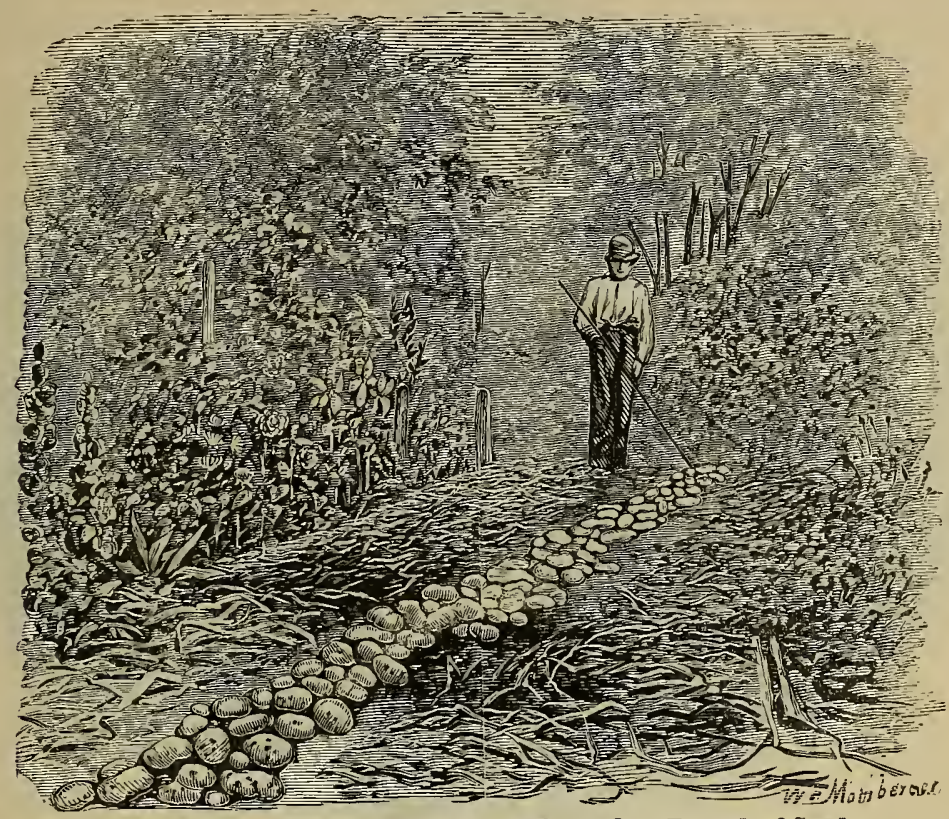

Mr. Burnett's Crop of Snowflakes from One Pound of Seed.

Skaneateles, N. Y., September 27, 1875.

Messrs. B. K. BLISs \& Sons :-Accompanying this please find Stereoscopic view of the Snowflake Potato as grown in my garden the past Summer. It exhibits the product of one pound of seed purchased of you last Spring. The earth was carefully removed, leaving each potato attached to the root exactly as it grew. They were grown in good garden soil, without extra manure, and had the same cultivation as the other potatoes. No one could have been more surprised than $I$ at the wonderful production. I had them on exhibition all one day, and a large number of farmers and amateur gardeners called to see thenl. For size and quantity all admitted they had never seen its equal. At the nearest end of the row, as shown in the picture, the yield was affected by a shade tree, but at the other end they were very large and in one solid mass-in fact, there was no room for a jack-knife between them. It makes quite a pretty picture, with rose bushes, geraniums and tuberoses on the left and my boy "Frank" and the grapevines for a background. I have created no little excitement by exhibiting the Snowflakes at our Town Fair. Yours respectfully, JOSEPH H. BURNETT.

A Trial of the Snowflake in June.

In orcler to show the wonderful keeping properties of the Suowflake Potato, we annex a letter from the well-known horticulturist, Chas. Downing, Esq., to whom a sample grown in 1874, was sent in June for trial.

NewbURGH, June 28, '75.

Messrs. B. K. BLiss \& SoNs-Dear Sirs: The box of potatoes was received in due time. The quality is equal and I think superior to any potato I ever ate so late in the season, and being of goor size and so smooth and regular in form, it will be an acquisition if the production is sufficiently good.

Please accept my best thanks for your kindness, and for the opportunity to test them. Very respectfully, CHAS. DOWNING.

From Nash \& Crook, proprietors of the well-known and popular restaurant in the Times building, opposite the new post-office on Park Row :

NEw YoRK, July 1, 1875.

Messrs. B. K. BLISs \& SoNs:-We have been using the Snowflake potatoes, supplied by you in our restaurant for the past mouth, and find them superior in every respect to the Bermuda or any other early variety in the market. They cook dry and mealy, and are of excellent quality; and on account of the eyes being so nearly even with the surface, there is but little or no waste in peeling. They give general satisfaction to our customers. We have no hesitation in pronouncing them the best potato we ever used in our business at this time of the year. 


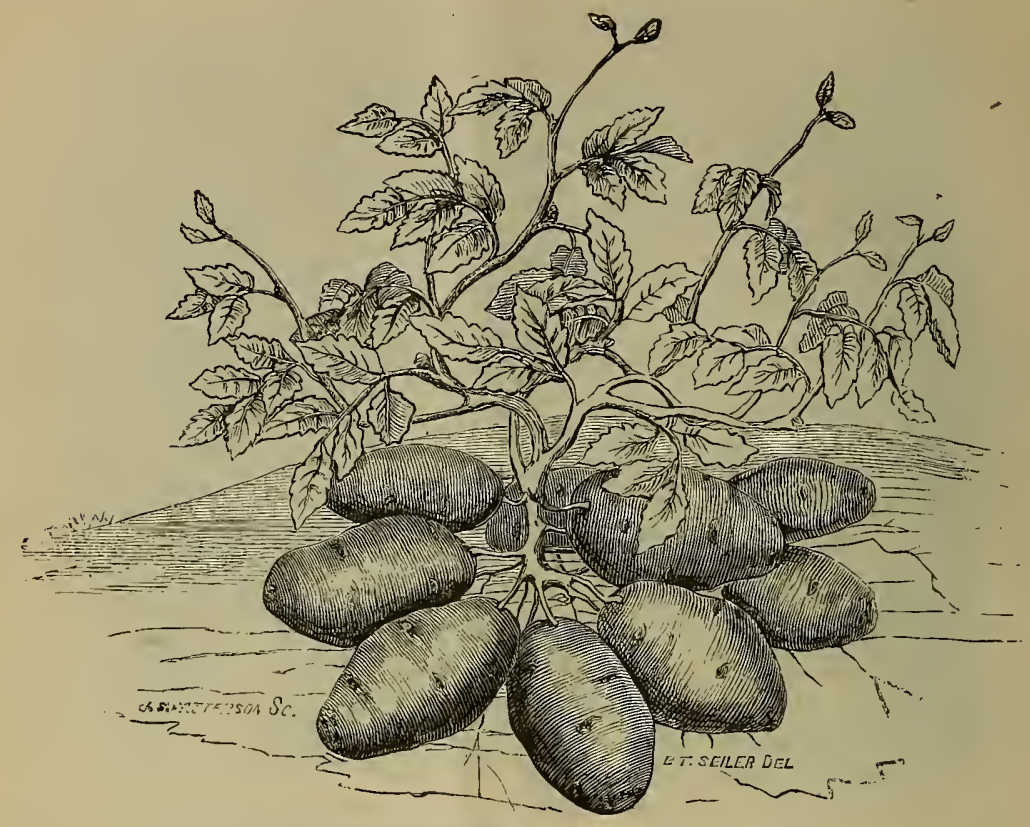

SNOWFLAKE.-Showing Habit of growth in Hill.

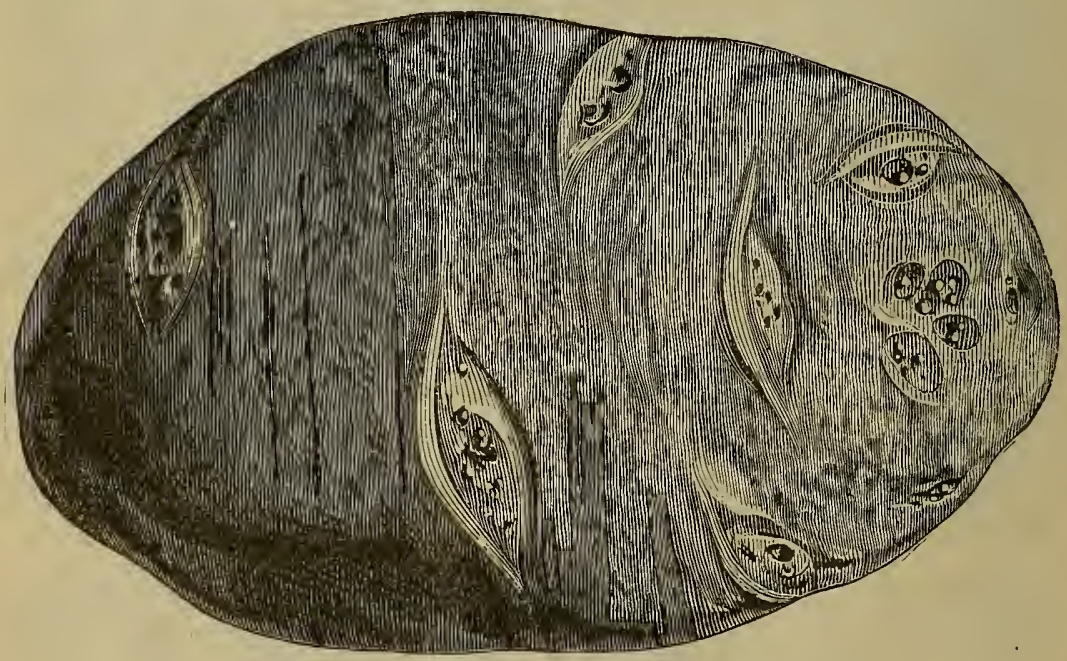

SNOWFLAKE. (Pringle.) Page 20. 


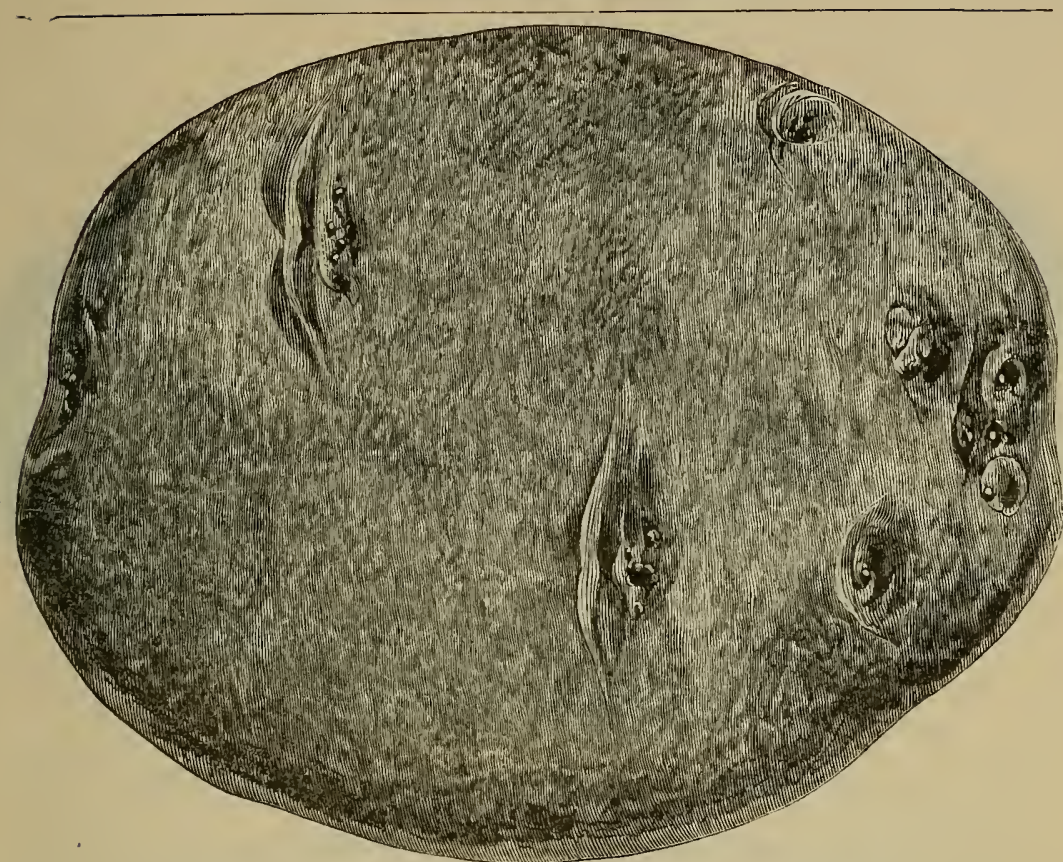

\section{BROWNELL'S BEAUTY. (Brownell.)}

This is another of the varieties first sent ont by ins in the Spring of 1873 , the beauty and superior keeping qualities of which, together with its fine quality as a table variety and productiveness, places it in the front rank of those rccommended for general cultivation. We know of no varieties whose good qualities can be retained for the entire year, as this has done. Potatoes of the crops of 1873 and 1874 have been exhibited side by side at several State and County exhibitions, those of 1573 having been kept in an ordinary cellar without any especial care, being equally fair and sound as those of this year's growth. Samples were sent in 1873 to the gardens of the Royal Horticultural Society of London, where they received a first-class certificate, and have also received many premiums at varions Agricultural Fairs in this country. Size, medium to large, growing very fair and smooth. Eyes few and small, nearly even with the surface; shape oval, somewhat flattened; skin reddish, or a deep fiesh color; flesh white, fine-grained and very delicate. For the table, they cook either by baking or boiling equal to the very best, and with ordinary boiling they cook throngh to the center evenly, dry and mealy, and are never hard, bollow, watery, or discolored at the center; flavor unexceptionable. Vine of medium growth; foliage deep green, and very hcalthy in all respects. The tubers grow compactly in the hill and are easily dug, ripening in about three months from time of planting, though suitable for cooking about two weeks later than the Early Rose, with the same culture. They are very productive. with but few small tubers. Its beautiful appearance, fine quality, extraordinary productiveness and remarkable keeping qualities render it a most valuable variety for the market.

To show the wonderful productiveness of this favorite variety-are among the following from the successful competitors for the first prize offered by us in 1874.

[From H. C. Pearson, Pitcairn, St. Lawrence Co., N. Y.]

I hereby certify that I ordered of you, March 25, 1874, 1 lb. of Brownell's Beauty Potatoes; planted trem May 16, and dug them September 28, and from the $1 \mathrm{lb}$, planted, I raised ten hundred eighteen pounds, (1018 lbs.) The soil was light loam, with some gravel, with a sand and gravel subsoil, not underdrained but having good natural drainage. The land is new, having produced only one crop before. Applied broadcast a two-horse load of barnyard manure three years old, plowing it under 7 inches deep; then went over the ground 3 times with a pulverizing harrow. Placed in each hill before planting, 2 quarts of a compost, composed of 10 bushels decayed manure, 2 bushels of ashes, 4 quarts salt, and $2 \mathrm{lbs}$. sulphur. Cut the tubers to single eyes, dividing some of the stronger into 3 pieces, making in all 112 pieces, and planted them in rows $3 \frac{1}{2}$ feet apart and 3 feet apart in the rows. planting one set in each hill and covering them about 3 inches deep. They grew to an enormous size, 491 selected tubers weighing $500 \mathrm{lbs}$., and 37 fair sized tubers weighing $15 \mathrm{lbs}$. . were dug from one hill. They are the most beautiful potato I ever saw. Have tested their quality by cooking them in various ways and find them dry and mealy, fine-grained, and of a flavor not surpassed by any potato I have ever tried. They matured about September 18.

ísigned,) H. C. PEARSON.

PRICE :-One pound, 60 cents; two pounds, $\$ 1.00$, by mail to one address, postpaid.' Br express or freight, charges to be paid by the purchaser, 1 peck, $\$ 1.00 ; 1 / 2$ bushel, $\$ 1.25 ; 1$ bushel, $\$ 2.25 ; 1$ barrel, $\$ 5.00$. 


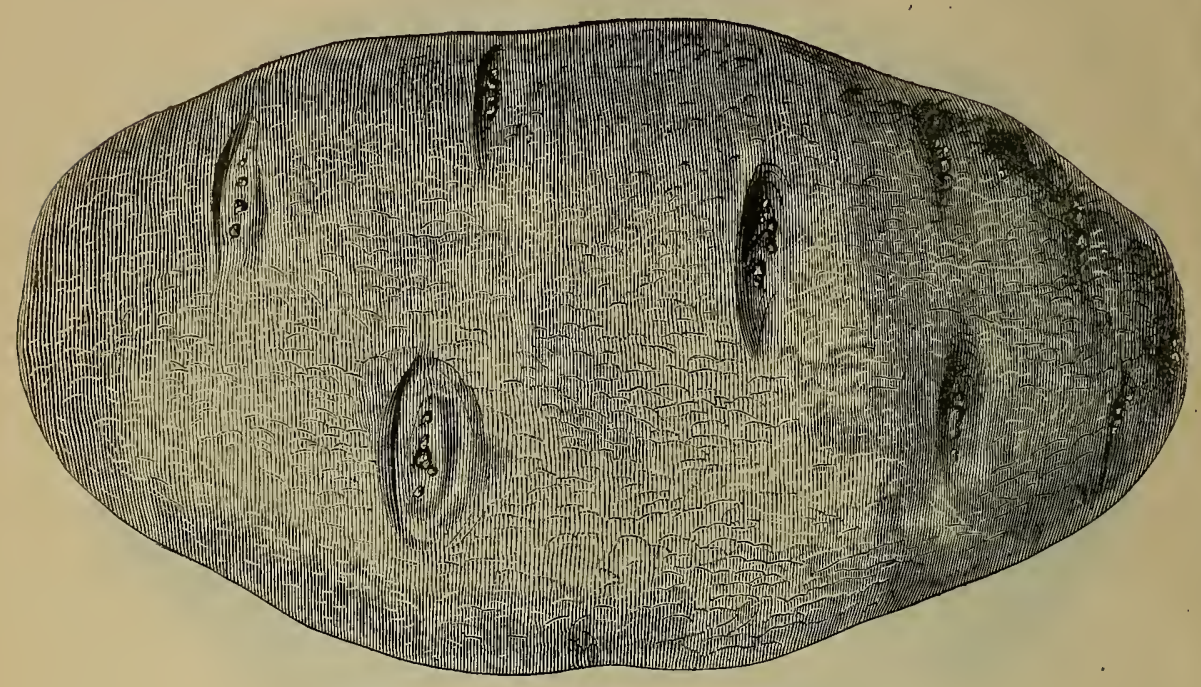

\section{EXTRA EARLY VERMONT.}

The superior merits of this variety, first sent out by us in the Spring of 1872, may now be considered as fully established. It has been largely cultivated over every section of the country, the past two seasons, and fully sustains the high character given it by the committee for awarding the premiun offered by us in 1873, in the following statement, after examining the reports of the various competitors:

"The Early Vermont, as proved by the numerous reports before us, more than sustained its previous reputation. Nearly all the competitors declare it from one to two weels earlier than the Early Rose, and many even more. Its uniform and large size is recognized by every one. Mr. McLeod says: "There are more than 100 in the amount I raised that would weigl from one to two pounds each;' and Mr. Salter raised one tuber that weighed THREE POUNDS TWELVE ouNCEs. Its superior cooking and eating qualities are unanimously commended, as well as its compact growth in the hill and its freedom from disease, and with the thonsands of cultivators who have grown it alongside the Early Rose, there seems to be no doubt left that in quality, hardiness, earliness and yield, it far surpasses that celebrated variety."

A first-class certificate was awarded this variety by the Royal Horticultural Society of London, 1873.

Caution.- In consequence of the great similarity between the Extra Early Vermont and the Early Rose, many of the latter will doubtless be offered by unprincipled persons as the Early Vermont. To avoid imposition, we caution purchasers to beware of itinerant peddlers, and purchase their stock of reliable parties only. We employ no peddlers or agents. Address all orders directly to our house.

PRICE :-By mail, postpaid, one pound, 60 cents; two pounds, $\$ 1.00$. By express or freight, charges paid by purchaser, 1 peck, $\$ 0.75 ; 1 / 2$ bushel, $\$ 1.25 ; 1$ bushel, $\$ 2.00 ; 1$ barrel, $\$ 4.00$.

\section{Tomato "Little Gem" (the earliest variety known).}

This new variety was raised by Mr. Pringle, the originator of the Conqueror Tomato, heretofore considered the earliest in cultivation, and is a combined hybrid or cross of that popula variety with two other unnamed early varieties of fine quality. The vines are of inedium length, compact growth, and excessively loaded with bright red fruit of medium size, round and of uniform shape. varying from four to six inches in circumference, of superior quality flavor, either raw or cooked. Its bright glossy red color, uniform size, shape, and otherwise beautifu] appearance, make a dish of LITTLE GEMS almost as tempting as a plate of Strawberries. It may be relied upon to yield several pickings, a week or ten days earlier than any other variety. $15 \mathrm{cts}$. per packet; half oz. packets, 75 cts. 


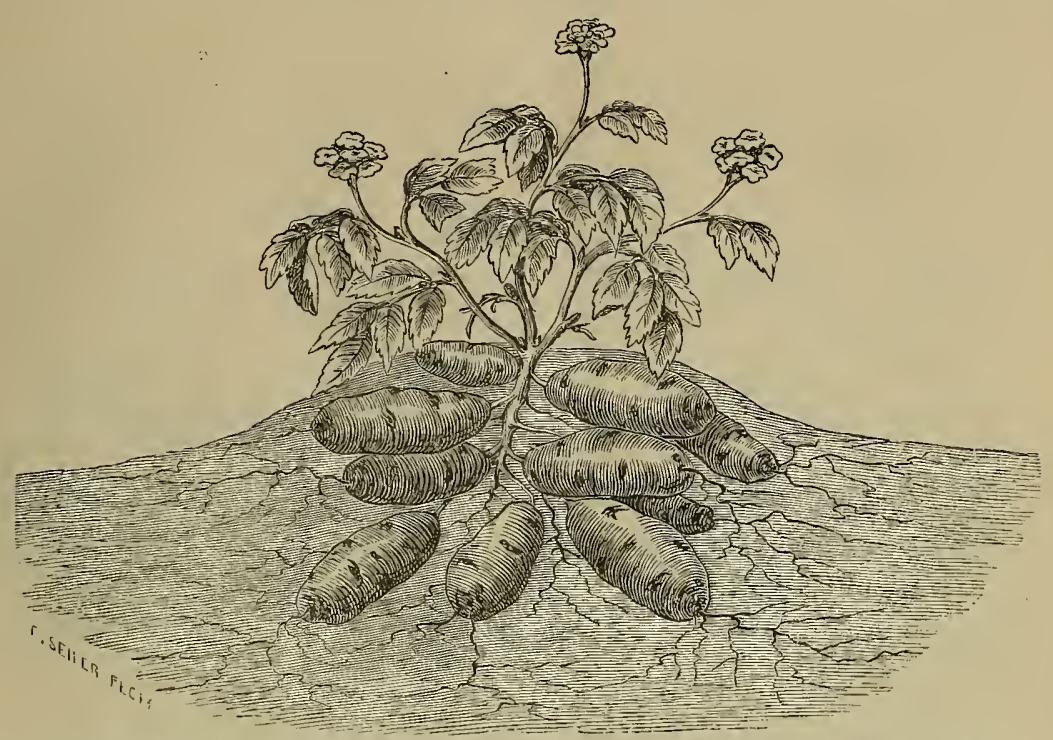

POTATOES-EXTRA EARLY VERMONT.-Showing Habit of growth in the Hill.

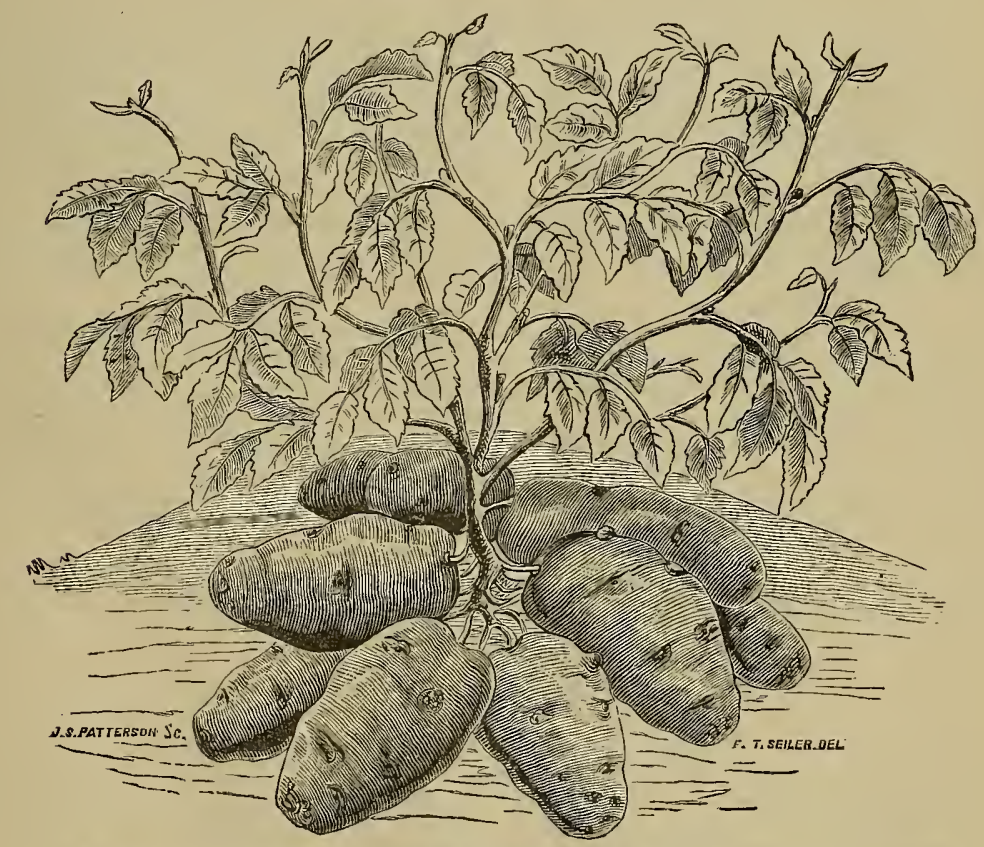

BROWNELL'S BEAUTY.-Showing Habit of growth in the Hill. Page 23. 


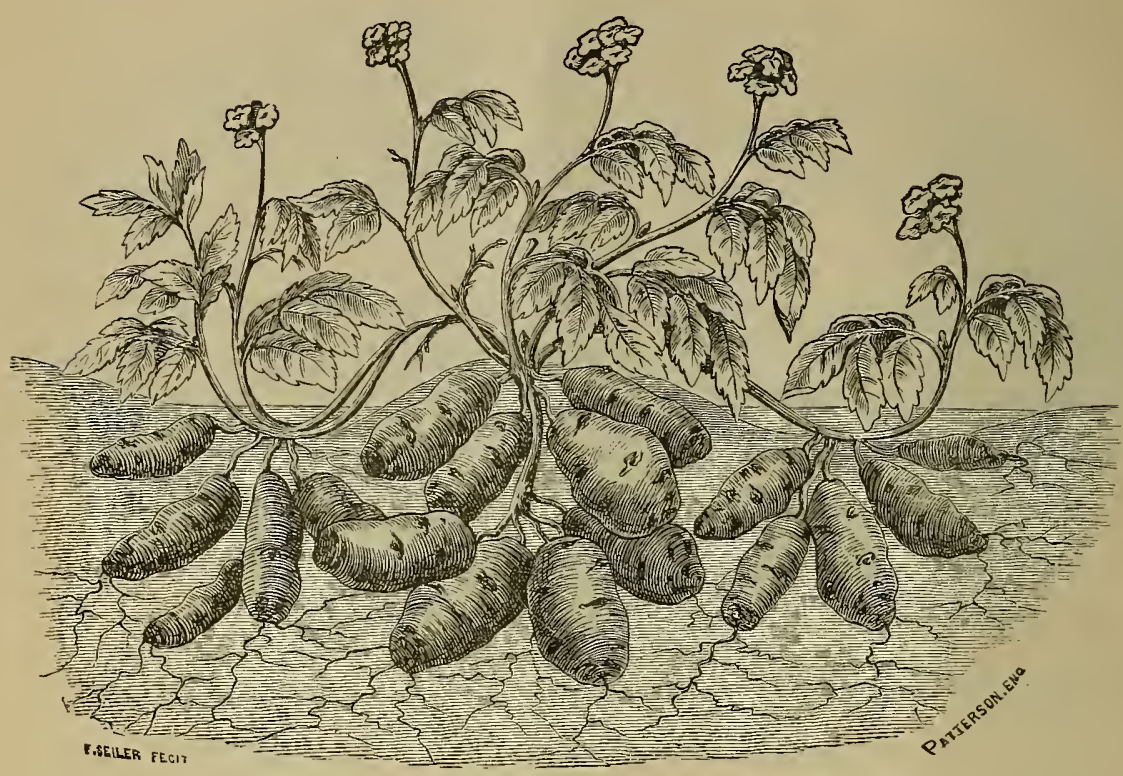

Compton's Surprise Potatoes.

Showing the growth from a single eye in the grounds of F. Seiler, Verona, New Jersey, who raised $384 \mathrm{lbs}$. from one $\mathrm{Ib}$. of the tubers, with ordinary culture.

Remarkable for its size, quality and productiveness. Its shape is oval-oblong, eyes sunken, brow prominent, skin smooth, color reddish-purple, flesh white; grows to a large size, and is invariably sound to the center. It retains its quality perfectly throughout the year, appearing on the table like a ball of flour. Remaining plump and free from spronts when kept until June and never having that wilted appearance common to early sorts. Thousands have testified that they never ate a better Potato. Its uniform mealiness of grain, combined with the purest flavor and its snowy whiteness of flesh, which is not in the least affected by its blue skin, cannot fail to make it highly valnable.

The following extract from the report of the Committee awarding the premiums offered in 1873, confirms all that was claimed for them by the originator when first introduced.

"Compton's Surprise has received the unanimous verdict for the most prolific Potato cultivated at present. Yields of from twelve to twenty ponnds to the hill are reported by the hundreds, and in one instance $281 / 2$ pounds were dug from one hill. As a rule, the most prolific varieties are not of the best eating quality, but to this, Compton's Surprise is an exception. Thonsands bave testified that they never ate a better Potato. Its uniform mealiness of grain, combined with the purest flavor, and its snowy whiteness of flesh, which is not in the least affected by its blue skin, cannot fail to make it highly valuable.

One pound, 60 cents; 3 pounds, $\$ 1.25$ by mail, prepaid; by express or freight, charges paid by the purchaser, 1 peck, $\$ 0.75 ; 1 / 2$ bushel, $\$ 1.25 ; 1$ bushel, $\$ 2.00 ; 1$ barrel, $\$ 4.00$.

\section{Early Paragon.}

A new early variety introdnced last season, and said to be a few days earlier than the Early Rose. The vines are of dwarf habit, shape oblong, eyes very shallow, skin smooth and general appearance very attractive; productive and of good quality.

By mall, prepaid, one pound, 60 cents; 3 pounds, $\$ 1.25$; by express or freight, charges paid by the purchaser, 1 peck, $\$ 1.00 ; 1$ bushel, $\$ 2.25 ; 1$ barrel, $\$ 5.00$. 


\section{General Collection.}

Two pounds of either of the following varieties will be mailed, post-paid, to any address in the United States, upon receipt of $\$ 1.00$, or one pound for 60 cents.

Not less than one pound, or more than one variety in one package, will be mailed.

Early Rose.-This was the tirst of Mr. Bresee's Seedlings, offered by us in January, 1868, and has now become the standard variety for earliness, quality and productiveness. Per peck, 75 cents; bush., $\$ 2.00 ;$ bbl., $\$ 1.00$.

Bresee's Prolific.-Vines of medium hight, quite bushy, somewhat spreading. Tubers large, regular in shape, and very smooth, slightly oblong, somewhat flattened. Skin dull white, inclined to be russeted, eyes but little depressed and slighly pinkish, flesh white, cooks quickly, is very mealy and of excellent quality, yield very large, matures about three weeks later than the Early Rose; a valuable variety for field culture. Per peck, $\$ 1.00 ; b u s h ., \$ 2.25 ; b b l$., $\$ 5.00$.

Brownell's Eureka.-This seedling resulted from a seed-ball grown on an Excelsior potato vine, blossoms fertilized with pollen from the White Peachblow. Vines of strong and vigorous growth; tubers of good medium and uniform size; shape elongated oval, somewhat flattened; eyes few, skin white and fair, season second early. It is one of the most productive in cultivation, besides being an excellent keeper; its flesh is exceedingly fine grained, white, and when boiled or baked, mealy and of excellent flavor, cooking through uniformly without fault at center. A silver medal was awarded this variety by the Massachusetts Horticultural Society in 1874.

Climax.-Early; uniformly large; long, cylindrical; skin white; eyes sharp, shallow; flesh white and solid. This has been the most prolific early variety during the past season, and has proved hardy and healthy. Per peck, $\$ 1.00 ;$ bush., $\$ 2.50 ; b b l ., \$ 6.00$.

Late Rose.-This variety, first offered by us in the Fall of 1871, has been largely cultivated in various parts of the country, and has given universal satisfaction. It ripens two or three weeks later than the Early Rose, and has proved to be much more productive, hardier, healthier, and a better keeper, retaining its good quality till new potatoes come in. Per peck, 75 cents; bush., $\$ 2.00 ; b b l ., \$ 4.00$.

Peerless (Bresee's No. 6.)-Skin dull white, occasionally russeted; eyes shallow; oblong, flesh white, mealy, grows to a large size, often weighing from one and a half to two pounds, and enormously productive, frequently producing from 100 to 150 barrels to the acre. Its great beauty, superior quality, and enormous productiveness, place it among the best varieties for general culture. Per peck, 75 cents ; bush., $\$ 2.00 ;$ bbl.. $\$ 4.00$.

Lapstone Kidne..-Of English origin. Medium early; very long, kidney-shaped; skin very smooth and white; eyes small and entirely flat; flesh white, finely grained, sound and solid, and is not excelled in its qualities for baking or salad. Per pecl, 75 cents; bush., \$2.00; bbl., $\$ 5.00$.

Jackson White.-A northern variety. Medium late; large; irregular, round to longish; skin white and smooth; eyes deep; flesh white, finely grained, and of good table quality; is a good keeper, and very productive in some localities. Per peck, 75 cents; bush., $\$ 2.00 ;$ bbl., $\$ 4.00$.

White Peachblow.-A seedling of the old Peachblow. Very late; medium to large; round; skin white, with bright pink eyes; flesh white, cooks very dry and mealy. This variety has for years been the principal market potato in New York, and has proved a remunerative crop to the producers. Per peck, 75 cents ; bush., $\$ 2.00 ; b b l ., \$ 4.00$.

Peachblow (Jersey).-A well-known variety, very productive, superior for the table, and one of the best for the market and shipping purposes. Per peck, 75 cents; bush., $\$ 2.00 ; b b l$, $\$ 4.00$.

Any other varieties not in our list will be furnished at lowest market prices.

\section{A NEW EARLY TOMATO-ACME.}

This new and beautiful variety far exceeds anything ever before introduced among the many varieties of this valuable esculent. It has been carefully tested the past season, in many localities, and all agree that it is not only one of the earliest, but the handsomest variety ever introduced. It seems to possess all the good qualities that can be desired in a Tomato, and will eventually supersede many others now in the field. The plants are of a strong and vigorous growth, very productive; fruit of medium size, large enough for any use, form perfect, round, slightly depressed at the ends, very smooth; color a glossy dark red with a sort of purplish tinge; ripens all over and through at the same time; bears continnously until frost; delicious in flavor, has no green core and but few seeds; unequaled for canning, preserving, or as salad; a splendicl market variety, and well adapted for culture in the Southern States, for shipping to the North in the early part of the season. Price, 15 cts. per packet of about 100 seeds; $1 / 20 z$. packets, 75 cts. each. 


\section{THE GREAT CENTENNIAL EXHIBIT}

\section{Named Varieties of Potatoes.}

The Largest Collection of Potatoes in the World, for which was Awarded

THE GRAND CENTENNIAL PRIZE MEDAL AND DIPLOMA:

Acme.

Adirondack.

Advance.

Agawam.

Akron.

Alaska Blue.

Albion.

Alexandra.

Alpha.

Amazon.

American Breadfruit.

Anderson.

Andes.

Angola.

Armonk.

Armstrong.

Ashleaf Fluke.

Ashleaf Kidney.

Ashtop Fluke.

Baơger.

Baldwin.

Baltimore.

Banks.

Barron's Perfection.

Beauty.

Bellaire.

Ben. Merritt.

Berkshire.

Black Diamond.

Black Kidney.

Black Mercer.

Black Prince.

Blanchard.

Blanche.

Blue Kidney.

Blue Pinkeye.

Blue Western.

Blush.

Bolton.

Bountiful Kidney.

Bradford.

Bradford Seedling.

Breakfast.

Bresee's Prolific.

British Queen.

Brownell's Beauty.

Brownell's Nonesuch.

Brownell's Success.

Brownell's Superior.

Buckeye.

Bucyrus.
Bulkeley's Prince of Wales. Bulkeley's Seedling.

Busam's Early.

Busam's Late Prime.

Byram.

Calico.

California.

California (purple).

California Mercer.

Callao.

Campbell's Late Rose.

Carmel.

Carpenter.

Carter.

Carter's Early Forcing.

Cascoe.

Cayuga.

Central City.

Champion of England.

Chase.

Checker.

Chenango.

Chenery.

Cherry Blow.

Chester.

Chili No. II.

Circassian Kidney.

Climax.

Cluster.

Coldstream.

Colebrook.

Collum's Seedling.

Columbus.

Colorado.

Colorado I.

Colorado II.

Compton.

Compton's Surprise.

Con.

Concord.

Conn. Blue.

Conover.

Coppermine.

Cornell's Kid.

Cornish.

Cowhorn.

Cullock.

Cuzco.

Dagger.

Dana's Seedling.

Davenport Seedling.
Davis' Seedling.

Delmahoy.

Dickinson's Saybrook.

Dover.

Dover Seedling.

Dr. Bretonneau.

Duke of Cumberland.

Dutch Pinkeye.

Dykeman.

Dyright.

Early Blue.

" Cottage.

" Dexter.

" Dimmick.

" Don.

" Durham.

" Golden.

" Goodrich.

“ Handsworth.

" Henry.

"Indiana.

" June.

" Kidney.

" Lilac.

" Manly.

"Minnesota.

"Mohawk.

" Ohio.

" Oneida.

" Paragon.

" Peachblow.

"Pearson.

" Pinkeye.

" Prince.

" Purple.

"Queen.

" Racehorse.

"Rose.

" Russet.

" Samaritan.

"Scotch Cottage.

" Shaw.

"Snowball.

" Sovereign.

“ Stevens.

" Victor.

" Violet.

" Wendell.

"White.

" York.

Eastport. 


\begin{tabular}{|c|c|c|}
\hline East Branch. & Heins. & Massasoit. \\
\hline Eclipse. & Hemlock. & Mercer. \\
\hline Economist. & Hickory. & Mereer Seedling. \\
\hline Egg. & Hinman. & Merino. \\
\hline Elder. & Holly Hock & Mexicall, \\
\hline Empire. & Holmes. & Michigan Red. \\
\hline Empire State. & Hoosier. & Miller. \\
\hline English Kidney. & Hugh. & Miller's Seeulling. \\
\hline Eureka. & Huntington Seedling. & Min'sescta Seerling. \\
\hline Excelsior. & H. Ward. & Missour White. \\
\hline Extra Early Rose. & Ice Cream. & Model. \\
\hline " " Rose Seedling. & Improved Ashleaf Kidney. & Monas Pride. \\
\hline “ “ Seedling. & Improved Gem. & Monitor. \\
\hline " “ Vermont. & Improved Shaw. & Monon. \\
\hline " " White. & Iona Red. & Motley. \\
\hline " Large Beedling. & Irish American. & Mountain Blue. \\
\hline “ Peerless. & " Blue. & Mount June Pinkeye. \\
\hline Fancy Red. & " Cup. & Multiplier. \\
\hline Farmer's Delight (red). & " Cup White & Multiply. \\
\hline Farmer's Delight (white). & " Orange. & Myatt's Prolific Ashleaf. \\
\hline Eavorite. & J. Quinby. & Nansemond. \\
\hline Fenn's Early Market. & Jackson Seedling. & Nannet. \\
\hline Eenn's Early White. & Jackson White. & Napoleon. \\
\hline Fenn's Perfection. & Jenny Lind. & New Hampshire Seedling. \\
\hline Ferris' Seedling. & Jersey White. & New Hartford. \\
\hline Fersey White. & John Bright. & New Kidney. \\
\hline Field Crop. & Jones' Seediling. & New Nutmeg. \\
\hline Findlay. & Jug. & New Peachblow. \\
\hline Fisher. & Kalamazoo. & Noblow. \\
\hline Fluke. & Kansas. & Nonesuch. \\
\hline Forest Rose. & Kearsarge. & North Castle. \\
\hline Forfarshire Red. & Kennyon. & Nova Scotia. \\
\hline Fortune. & Ketchum's Seedling. & Noyes. \\
\hline Foster's Late Rose. & Keystone State. & Niggerhead. \\
\hline Fox Seedling. & Kid. & Niggertoe. \\
\hline Frankfort. & King of Jacksons. & Nutmeg. \\
\hline Freeman. & King of Potatoes. & Ohio. \\
\hline Fremont. & King of Sweden. & Ohio Beauty. \\
\hline French. & King of the Earlies. & "Chenango. \\
\hline Galva. & King's Seedling. & " Mercer. \\
\hline Gardner. & Kinney. & " Red. \\
\hline Garnet Chili. & Kruger. & " Russet. \\
\hline Gem. & Lackawanna. & “ Victor. \\
\hline Gen. Grant. & Lady Finger. & Old Fleshcolored. \\
\hline Genesee Co. King. & Laing's Seedling. & " Kidney. \\
\hline German Russet. & Land's Prolific. & "Red. \\
\hline Giant. & Lapstone Kidney. & " White. \\
\hline Gilman. & Late Pinkeye. & Oneida. \\
\hline Globe. & Late Rose. & Orange Peel. \\
\hline Golden Gem. & Leathercoat. & Orono. \\
\hline Golden's Seedling. & Ledding's Seedling. & Oscar. \\
\hline Goodrich Seedling. & Lincolı Red. & Pale-Blush Pinkeye. \\
\hline Granite State. & London White. & Palmer. \\
\hline Gray Nonesuch. & Long Island. & Palmyra. \\
\hline Gray Russet. & Long Pond. & Para. \\
\hline Great Britain. & Mahopac Seedling. & Paterson's Albert. \\
\hline Great Western. & Maiden's Blush. & " Blue. \\
\hline Greenfield. & Maine Mercer. & " Early White. \\
\hline Guernsey. & Manatan. & " Golden Don. \\
\hline Hall. & Marchioness of Lorne. & " Queen. \\
\hline Hamburg. & Marjolin Letard. & “ Regent. \\
\hline Harison. & Massachusetts White. & Patoka. \\
\hline
\end{tabular}


Peachblossom.

Peerless.

Peun. Searchwarrant.

Philadelphia.

Philbrick's Early White.

Pierpont.

Pigeon Eye.

Pink Blow.

Pinkeye.

Pinkeye Rustycoat.

Pinkeye Strawberry

Pink Peachblow.

Plymouth Rock.

Porter's Excelsior.

Prairie Flower.

Prairie Seedling.

President.

Prince Albert.

Prince Arthur.

Prince of Wales.

Purple Kidney.

is Mercer.

Putnam.

Quarantaine Violette.

Quadroon.

Queen of the Earlies.

Queen of the Roses.

Queen of the West.

Quinby's Seedling.

Rand's New Peachblow.

" Red.

"White.

Raspberry-Leaved.

Rathbone

Rattails.

Rector of Woodstock.

Red Carter.

"Climax.

¿ Emperor.

“ Fluke.

" Gem.

* Jacket.

-6 Kidney.

is Neshannock.

" Orange.

" Peachblow.

“ Streak.

is Ulink.

" Utica.

Ridgefield Seedling.

Rochester Seedling.

Rodes.

Rogmore Rose.

One Tuber of each variety of the entire collection, correctly labeled, carefully packed, expressage or postage prepaid, for $\$ 100$.

Collections of 250 varieties, one tuber of each, for $\$ 50.00$; 100 varieties for $\$ 25.00 ; 50$ varieties, $\$ 15.00 ; 25$ varieties, $\$ 8.00$.

\section{Collection of Seedling Potatoes.}

We have on hand 200 varieties unnamed Seedlings raised witlin the past two years from Pringle's Hybridized Potato Seed, which have been selected from upwards of a thousand varieties for further trial. Among them are many that are exceedingly promising and well worthy of the attention of Farmers. They will be offered in collections as follows, and mailed postpaid:

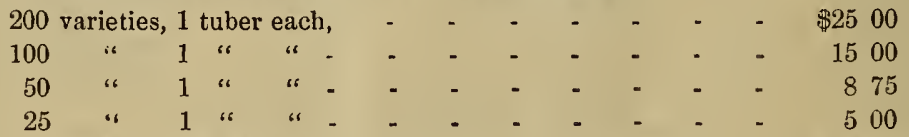

N. B. Orders for Potatoes, received during Winter, will be forwarded in Spring as soon as the weather will pernit, which is usually about the first of April. They can be forwarded earlier, if desired, at the risk of the purchaser.

Rose Bud.

Rose of the West.

Rough and Ready.

Roxbury.

Russet Kidney.

Scotch Blue.

Sebec.

Sedilla.

eedling Cuzco.

" Mercer.

" Peachblow.

Sharon

"i"s Fancy.

Sheridan

Silverskin.

Six Weeks.

Smith's New Seedling.

Snapdragon.

wilake.

Sonth Bend.

Starch.

Stevens.

nehouse.

ppecan

Titicaca.

Topeka.

Yorkshire Hero.

Young.

Young America.
Finger.

Tuberose.

Union.

Vica Pinkeye.

seedling.

Wampoo.

:: II.

Weeks' Seedling,

West Windsor.

Whipple's Seedling.

Vhite.

"Apple.

Cowhorn.

Lily.

Mountain Early.

Peachblow.

Pinkey

Russet.

Sprouts.

"illard.

. R. Prince.

.6 Seedling

erful Red.

Woodard.

Worcester.

York Seeding. 


\section{POTATOES.}

\section{ENGLISA AND FRENCH VARIETTES.}

The following varieties, the very best cultivated in Europe, were in nearly all of winning stands at the International Potato Exhibition at the Alexandra Palace, London, for the past two years, and are highly recommended both for their extra fine quality and productiveness. Onc pound of the following-named varieties will be mailed postpaid for 75 cents. They are also offered in collections of one tuber each, as follows:

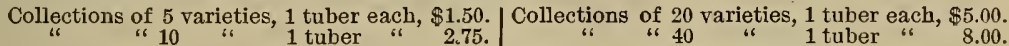

Ashtop Fluke.

Barrows' Perfection.

Blanchard.

Bountiful.

Coldstream.

Dawes' Matchless,

Early Dimmick.

Early Union.

Excelsior Kidney.

Fenn's White Kidney.

Fenn's Early White.

Fenn's Early Market.

Fenn's Perfection.

Hayes' Superb Kidney.

Headley's Nonpareil.

\section{Jersey Blue.}

King of Potatoes.

Marceau.

Marchioness of Lorne.

Iarjolin Cetard.

McKinlay's Lady Webster.

Mlodel.

Myatt's Prolific Ashleaf.

Prince Arthur.

Prince Teck.

Prince of WVales Kidney.

Patterson's Victoria.

Patterson's "The Qucen."

Porter's Excelsior.

President.
Quarantaine Violette.

Rector of Woodstock.

Red Emperor.

Red Fluke.

Kivers' Royal Ashleaf.

Rogmon Rose.

Sedila.

Scotch Regent.

Stanton's Premier.

St. Helena.

Sutton's Red Skin Flourball.

Sutton's Exhibition Kídney.

Sutton's New Hundredfold Fluke.

Wonderful Red Kidney.

Yorkshire Hero.

\section{Pringle's Hybridized Potato Seed.}

The extraordinary success which has attended Mr. Pringle in his attempts to improve this valuable esculent-which has resulted in the production of the Snowflake and Alpha, and last, though not least, the Ruby-has encouraged him to still greater effurts is his favorite pursuit of hybridization, and we have now the pleasure of offering a very choice strain of seed saved by him, which is the product of numerous hybridizations between the above named and many of the best new and old varieties in cultivation, both English and American, and includes every strain, which Mr. Pringle will himself sow the coming Spring. Full directions for sowing accompany each packet. Numerous testimonials have been received during the past season in favor of the superior quality of this seed, as well as of its extraordinary productiveness, 5 to 22 pounds of good sized potatoes having been grown by several parties from a single seed.

\section{Directions for Cultivation.}

Sow in pans or shallow boxes, of a mixture of leaf mold and loam, and place under glass or a gentle hot-bed; as the plants appear, they should be partially shaded from the full sumlight; if they begin to crowd, transplant, giving them ample room; when danger from frost is over, set them in the open ground, giving them the full space usually allowed to potatoes. With this treatment they will, with good attention attain to full size and maturity the first year.

The following letters are selected from a number received from our customers, who have given this seed a trial, showing its wonderful productiveness. Samples of the tubers were also sent us, which were marvels of beauty, and will be sure to create a sensation when they become known.

Charlotte, Vt.

From Pringle's Hybridized Potato Seed, purchased of you last Spring, I raised from one seed, 45 potatoes, weight seven and one-quarter pounds; from another, 95 potatoes, twenty-two and one-half pounds; from another, 115 potatoes, twenty-seven and one-half pounds.

O. H. ALEXANDER.

Pitcairn, N. Y., September 28, 1876.

B. K. BLISs \& Sons:-The packet of potato seeds I received from you the first of April last, were planted the 9th day of April, in boxes, transplanted the 13th day of May in rich soil; used some bone dust in each hill; the plants were under glass most of the time until Jume; hoed them often, and they grew fast; watered several times in July and August with liquid manure. The packet contained 29 seeds; 24 grew, and one was destroyed by worms; the largest product from a single bill was 9 5-16 pounds of handsome, smooth, red potatoes.

$$
\text { Yours truly, }
$$

H. C. PEARSON.

Price 25 cents per packet; 5 packets $\$ 1.00$. 


\section{Report of Committee}

\section{For avarding PREMIUMS offered by B. K. BLISS \& SONS to growers of the largest quantity of POTATOES, from One Pound of Seed.}

After becoming fully satisfied of the superiority of the new varieties of Potatoes, introduced by us during the past five years, we have offered, from year to year, preminms to those who should grow the largest quantity from one pound of seed, of the different varieties with ordinary farm culture, and have paid out within that time upwards of Three Thousand Dollars to the successful competitors. The premiums offered for each variety were as follows:

\section{$\$ 250.00$ in Premiums.}

For the largest quantity of Potatoes grown from one pound of seed, - - - - $\quad-\$ 10000$ For the second largest, - - - - - For the third largest, - - - - - - - - - - - - - -4000 For the fourth largest, - - - - - - - - - - - - $-\quad-\quad-3000$

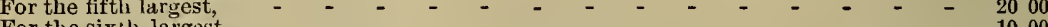

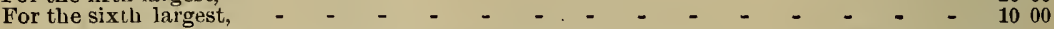

Competitors for the prizes were required to give the date on which they gave their order for the potatoes, date of planting, date of digging, with a written statement of their mode of culture, characteristics of the soil-whether elay, alluvial, sandy or loam-nature of the subsoil, whether mnderdrained or not; also the kiud and quantity of fertilizers used, how and when applied, the number of hills, and distance apart each way, with the weight of the crop when dug, and the number of square feet occupied by the crop, which must be witnessed and sworn to before a justice of the peace, notary, or any other one competent to administer the oath.

The awards were made by a committee composed of the following well-known gentlemen in the agricultural community: Prof. George ThURber, editor American Agriculturist, Dr. F. M. Hexamer, and P. T. Quinn, Horticulturists. They were published in the leading Agricultural Papers, and a copy mailed to each competitor. The prizes were awarded the first of January, of each year.

N. B.-To prevent misunderstanding, we wished it distinetly understood that no prizes would be awarded unless the above requirements were complied with in every particular. Competitors for premiums were placed under no restrictions, as to their mode of culture, excepting that they must not be grown from slips or forced by artificial heat, our object being to ascertain their respective merits with such culture as is usually given to crops in a well-managed vegetahle garden or farm.

\section{REPORT.}

The number of competitors, who, tempted by these liberal prizes, tried their skill and industry in producing a premiun crop, was naturally very large. Thousands of reports-representing every Potato-producing State and Territory of the United States, and even many Foreign Countries-nearly all from practical farmers, and many from men who have made Potato-growing their life's work, and may well be called the Champion Potato growers of the world. The practical information embodied in these Reports must naturally be of great value to every tiller of the soil, and at the request of the committee I bave endeavored to condense the leading features of the modes and conditions under which these immense crops were grown.

YIELD FROM ONE POUND OF

\begin{tabular}{|c|c|c|c|c|c|c|c|c|}
\hline 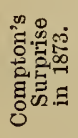 & 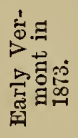 & 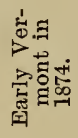 & 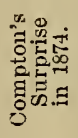 & 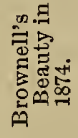 & 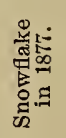 & 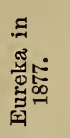 & 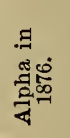 & 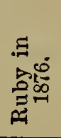 \\
\hline $\begin{array}{l}511 \\
450 \\
390 \\
386\end{array}$ & $\begin{array}{l}607 \\
437 \\
393 \\
380\end{array}$ & $\begin{array}{l}708 \\
698 \\
690 \\
674 \\
629 \\
615\end{array}$ & $\begin{array}{l}900 \\
874 \\
832 \\
811 \\
684 \\
588\end{array}$ & $\begin{array}{r}1,018 \\
811 \\
782 \\
749 \\
720 \\
696\end{array}$ & $\begin{array}{l}1,417 \\
1,304 \\
1,125 \\
1,090 \\
1,089 \\
1,069\end{array}$ & $\begin{array}{l}1,666 \\
1,403 \\
1,149 \\
1.145 \\
1,087 \\
1,066\end{array}$ & $\begin{array}{l}1,707 \\
1,665 \\
1,535 \\
1,511 \\
1,426 \\
1,280\end{array}$ & $\begin{array}{l}1,982 \\
1,694 \\
1,576 \\
1,571 \\
1,534 \\
1,353\end{array}$ \\
\hline
\end{tabular}


The gradual increase in the yield, from year to year, is at once apparent, and when we consider that several of the largest yields in 1876, were grown by the same persons to whom the highest awards were given at the first trial, and when we consider that this increase in the yield is not due to the greater productiveness oi the newer varieties, but solely to the increasing skill of the competitors, and the better management given their crops, we are forced to appreciato the great amount of good which these competstıve trials have produced. I am aware that the largest yield from one pound is not always in proportion to the largest yield per acre; nor do these immense yields, produced by the lavish appication of manures, regardless of expense, give a criterion of the profits of the crops, after deducting the premiums. Many growers who have produced less than one thousand pounds from one, may have obtained larger profits per acre, than the successful competitors yet no one who has grown a thousand, or even five hundred pounds from one, can have done so without learning something which will be of value to him in growing Potatoes as a field crop, nor can any one read an intelligent report of his methods of cultivation, without benefit.

Soil.-Many of the premium crops were grown on new lands, and on soil of almost unequaled quality. The largest yield was produced on "a mixture of sand and clay, very rich in vegetable matter to the depth of eighteen feet, and underlying this is a gravelly subsoil. For three years the ground was useo as a stock-yard, the straw being left on the ground to rot and be burned." The secoud largest product, was grown "on a very rich, sandy loam, rich in decayed vegetable matter to the depth of between two and three feet, and lying upon a compact formation known as hard-pan, which has never been underdrained." Another competitor describes his soil as "black loam, four feet deep, on the bank of a creek, and it has been used as a cattleyard for ten years." Another, "as vegetable mould and sandy loam, three feet deep, never cultivated before." Most crops however, were raised on deep, alluvial lands, underlaid with gravel ; others on light loam with clay or gravelly subsoil, and in a few cases on heavy clay highly manured. In but very few instances was the land artificially underdrained, which seems to be a noteworthy fact, as most writers consider drained soil indispensable for the production of good crops.

Manures.-The large quantities of Fertilizers used by most competitors is something astonishing, and may well serve to disprove the general belief that heavy manuring is injurious to potatoes. Mr. Pearson added to an already very rich soil, about 60 two-horse loads of manure, nearly 200 bushels of wood-ashes, and 24 bushels of lime, per acre, together with bone-dust and other fertilizers in smaller quantities. Mr. Rose, after covcring his land three inches thick with rotte11 barn-yard manure, and three bushels of wood-ashes per square rod, applied in addition, a large shovelful of rotted hen manure, and two handfuls of ashes to each hill, besides several surface dressings with other fertilizers. But all this must appear but a small attempt at enriching the land, to our Scotch friend, Mr. Robertson, who would not entrust his seed to a black sandy loam, four feet deep, underdrained and trenched, to probably the entire depth, before spading under a coat of five inches of well rotten cow-dung, and applying afterwards to the hills three cart-loads of wood-ashes, two of sheep droppings, and several other fertilizers.

About the value of wood ashes and especially in mixture with hen manure and plaster, there seems to be no doubt left; they weie used by a large majority and may be considered the Special Potato Fertilizer. Even when plied in very large quantities they have produced no injurious effect. In a few cases, as much as one pint of ashes has been applied to each hill as top-dressing, and in one instance the sets were actually planted in and covered with ashes. Plaster, lime and salt have likewise been extensively used and with great advantage. Strong nitrogenous manures have generally been considered as detrimental to the potato, but here we find that many successfu] growers have used large quantities of Blood, Fish and Peruvian Guano; hen manure as well as barn-yard manure, at the rate of fifty loads per acre, to the greatest advantage and without producing diseased potatoes.

Planting. - The time of planting in nearly all cases was between the 10th and 26th of May, and in the majority of these before the 15th. Thatsingle eyes and eyelets will, with good care, produce large crops, has been sufficiently proved. All the large yields were grown from very small sets. In some cases, single eyes were divided into ten pieces, and in one instance two hundred and ninety (290) sets were made from one pound, nearly all of which grew well. The sets, with few exceptions, were planted singly, yet we find a product of nine hundred and seventy (970) pounds raised from fifty-two (52) hills, two sets to each, nearly nineteen (19) pounds per hill, and six hundred and seventy-seven (677) bushels per acre. Whether this large yield is due only to the very favorable soil they grew in-a rich black loam, formerly used as a hog yard-and the immense quantities of ashes applied in the hills and as top-dressing-one peck to the hill-or to the two-set system, does not appear. It is to be regretted that a part of the plat was not planted with one set to the hill, and the products weighed separately. These practical tests, of the feasibility of raising large crops from small sets, become of much importance in seasons of scarcity of seed 
potatoes. For it is shown here that, even without carrying the division of the eyes to extremes, nine-tenths of the seed may be saved.

A comparison of the distances between the hills with the average yield per acre gives a most interesting and valuable table, as follows:

The sets planted at a distance of

\begin{tabular}{|c|c|c|c|c|c|}
\hline$\times 4$ & $66^{\circ}$ & 46 & 66 & & \\
\hline $3 \times 3$ & "6 & " & " & 6 & \\
\hline & "6 & 6 & 66 & 4 & \\
\hline
\end{tabular}

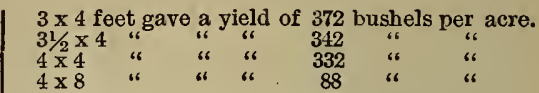

The large number of data of which the above figures form an average, give these statistics a special value. It will be seen that although the greatest yields from one pound grew from hills four feet apart, the largest crops per acre were raised at distances of three feet each way, and that as the distances between the hills are increased or decreased, the yield diminishes in regular proportion. In the first ease, there remains wasted ground which is not reached by the roots of the plants, and in the latter, the roots are so crowded that they cannot obtain all the nourishment they are capable of consuming.

Cultivation. - It will be hardly necessary to state that in many cases the cultivation and care these growing potatoes received were unremitting and indefatigable. In no case were weeds to be seen in the patch; some of the plantations received semi-weekly hoeings, and all were kept scrupulously clean, and the soil loose and mellow. Yet many large crops were grown with but ordinary care. Mr. J.I. Salter swears "that the cultivation, manuring, etc., was the same he has given his general crop of potatoes for the last five years, and in no respect had there been extra care and labor bestowed." Mr. H. C. Pearson certifies " that these potatoes were grown with the most ordinary farm culture, being hoed only twice and receiving no extra treatment in any respect."

The mode of planting and eultivating with a larger number of the best eultivators consists in crossing their fields with furrows six and more inches deep. The sets are dropped at the crossings and immediately covered with about two inches of soil or compost. The vines as they grow are hilled up gradually and frequently to a final height of twelve to eighteen inches. Then large, broad hills are made, using all the soil between the rows.

Irrigation.-The fact that the largest yields were produced in the Eastern States, in regions which suffered from one of the severest droughts known, where the general crops failed almost entirely, induced us to investigate more closely the nuanner in which these premium potatoes were grown. As the result we find that all these competitors attribute their success to the judicious application of water during the dry season. One of the competitors had arranged an ingenious system of irrigation, by inserting six inches from each hill, two inch drain tiles, six inches deep, and filling these with water, twice a week, during the dry weather. In reply to a letter he writes: "I attribute my success the past season to the fertilizers applied, but more especially to the mode of applying water. I find that, even without manure, this plan gives great results. Give me drouth and this means of applying water, and I can grow a much larger crop than with the most favorable weather and no watering. This I have proved by two years' experience." Many may not be so situated that they can apply as complete a system of irrigation, but thousands of farmers have running through their lands, brooks and streams which might, without much cost, be made to furnish nutriment to their parching crops. One acre of potatoes would in many cases pay for more than the entire expense of a permanent system of irrigation. The information about this important subject, derived from the accompanying reports, cannot but prove of the greatest value to all cultivators of the soil.

Although these short extracts, from material sufficient for a large volume, can do but little justice to the importance of the subject, yet they may serve as an outline of the important and valuable information which could in no other way be obtained.

Trusting that the increasing interest in potato culture, stimulated largely by these competitive trials, may be still more productive of information and progress in this important branch of Agriculture, I am jours respectfully,

\section{F. M. HEXAMER, Secretary.}

\section{Extracts from the Report of Mr. Nardy, delegate from the French Government to the Centennial Exhibition at Philadelphia in 1876.}

"The collection exhibited by the house of Messrs. B. K. Bliss \& Sons of New York, is the most remarkable of its kind in the Exposition. The varieties of Potatoes in their exhibit, and the evident care and attention bestowed upon their collection, manifest constant study on the part of the exhibitors. In our opinion theirs was the most complete display of this valuable escu- 
lent in the exbibition. To this remark we desire to add a few observations. We sincerely hope that the infiuence of this horticultural exhibition at Philadelphia will long be beneficially felt among farmers and growers of plants and vegetables. That were in reality all the fruits and vegetables which we to-day eujoy, when Asia, Africa and America sent them to us in their wild state? unfit for eatiug! Now, after having been cultivated and improved by the gardeners, they have become succulent and nourishiug, and pleasant to the taste. By patience and careful oultivation, horticulture has been enabled to transform the type of many species of vegetation into a great number of varieties. Let me take as an example of this, the collection of Potatoes exhibited by these gentlemen which consists of 500 varieties, and we can thus appreciate the patience and researches which must have been necessary to obtain so many useful varietres. The service rendered to the farmers of the United States by the house of B. K. Bliss \& Sons is so evident, th it we do not hesitate to call attention to them, for agriculture in general derives an immense benefit from these great improvements in useful vegetables, which are mainly due to their initiative. The cultivation of the Potato takes an important rank in the agricultural productions of this country. As a source of revenue, it comes immediately after grain and before tobacco. It is now many years since the senior partner, having a special aptitude for horticulture, devoted himself to that study. In $18+5$ he founded his first establishment, and year by year, by steady application, and especially by his energy in collecting the rarest seeds and best varieties of useful vegetables from all countries, the reputation of the house constantly increased. He was the first to introduce the Early Rose Potato, which he did in 1867, and his establishment then acquired the important position which it now enjoys. Animated by the spirit of the amateur he has not only sought out varieties in this product, but has endeavored in every way to render a benefit to agriculture by inducing the farmer to improve the cultivation of this esculent.

But if we were to dwell longer on this question, we should be carried too far from our object, which is to call the attention of our French Government to the importance of this house who were so highly distinguished by the jury at Philadelphia, and close this report by expressing our desire that they will send some of their rare specimens to our Paris Exhibition of 1878."

\section{Reports of Three of the Successful Competitors FOR THE PREMIUMS OFFERED BY US IN 1876.}

\section{How to Grow Twenty Bushels and Upwards of Potatoes from One Pound of the Seed.}

The following reports have been properly witnessed and sworn to before a Justice of the Peace-in their respective residences-they have also been carefully examined by the committee and found to conform to the rules prescribed in our offer for the Premiums.

\section{(From H. C. Pearson.)}

Pitcatre, N. Y. October $4,1876$.

Messes. B. K. BLrss \& Sons :-I ordered of you April 1st, 1876, one pound each of Ruby and Alpha Potatoes, and planted them May 10th, 1876, and dug them September 28th. The Ruby produced 1,982 pounds an:l the Alpha produced 1,707 3-4 pounds. The soil was light loam with some gravel with a sand and gravel subsoil not underdrained. The soil was very rich, and its fertility wasincreased in the Fall of 1875 , by spreading broadcast hifty-two horse loads of well rotted manure, three years old, and 150 bushels of ashes per acre, and plowed it under about eight inches deep; plowed and harrowed until perfectly pulverized eight inches deep last May. Placed in each bill before planting, two quarts of compost, composed of thirty bushels of decayed manure, five bushels of ashes, three bushels slacked lime, eight quarts salt, and four pounds of sulphur; the tubers were cut, some of the eyes divided into as many as seven and eight parts, planted one set in each hill, and covered them about three inches deep with soil mixed with some bone dust, making in all 195 hills of the Ruby, 210 of the Alpha; they were planted three and one-half feet apart each way, the number of square feet occupied by Ruby, was 2,364 feet, the number occupied by A]pha, was 2,546 feet. I hoed them three times, making very high, broad hills, watered them several times during July and August, with liquid manure, dug from one hill of Rubys, forty-three potatoes, weight 17 1- 2 pounds; used no slips or artificial heat. H. C. PEARSON.

\section{(From J. I. Salter.)}

ST. Clodd, MrNN., October 24, 1876.

Messrs. B. K. BuIss \& Sons-Sirs:-On the 7th of April, 1876, I ordered of you, one pound each of the "Ruby" and "Alpha" Potatoes. Planted the Ruby on the 31st day of May. Prepared the ground as follows: I spread as evenly as I could on the sward, about equel parts of hen and barn-yard manure, at the rate of five heaping garden wheelbarrowfuls to the square rod, 
before plowing, then plowed, turning a furrow ten inches deep and ten inches wide. I then planted my sets, after dividing every cluster of eyes into from three to twelve pieces, in rows four feet apart and as near as convenient, three and one-half feet apart in the rows, dropping but one piece in a place. I covered from two to three or four inches with loose earth. From the pound I made two hundred and ninety (290) sets, the space planted was sixty by seventy feet, ( $t, 200$ square feet); hoed but once, when the plants were about ten inches high, making a broad and continuous ridge, flat on the top, and a little depressed in the center; covered the vines all but a very little of the top. Before hoeing, I applied to each plant a large shovelful of fermenting hen manure; it was so hot that it would turn the leaves of plants black, and give them the appearance of being scalded, in less than a minute; I would manure three or four plants, and then cover as quickly as possible. The plants, in a day or two, began to grow and retained a dark green, almost black color until they were killed by the frost. I did nothing more in the way of cultivation.

On the 19th of August, I dug one hill of the "Ruby," and had ten and one-half (101/2) ponnds; on the 9th of October, I dug of the Ruby eight hundred and twelve (812) pounds; on the 10th of October, I finished digging the Ruby, digging eight hundred and serenty-one and one-half $\left(871 \frac{1}{2}\right)$ pounds, making a total of sixteen hundred and ninety-four $(1,694)$ pounds. The "Alpha" was plauted the same distance apart each way, had the same cultivation, manuring, etc., as the Ruby, except about fifty hills, that I covered the sets about four inches deep with coarse, unfermented horse manure, and applied no other manure afterward. I covered this manure with earth, the same as I covered the hen manure. I did not get as many large potatoes from these so treated, but about the same in weight per hill; made two hundred and fifty sets. The ground occupied by the Alpha was the same as the Ruby, sixty feet by seventy (4,270 square feet). I also planted two rows of this Potato in hills four feet apart each way. The land in both cases, a black sandy loam, rich in decomposed vegetable matter, usually about two feet deep, under which is hard pan. On the 28th of August, I dug two hills of the Alpha, and had 15 3-4 pounds; on the 12th of October, I dug 1,010 pounds of the Alpha, and on. the 13th of October, 640 pounds, making altogether 1,665 $3 \cdot 4$ pounds.

These amounts I dug, were grown alone from the one pound each of the above named varieties, purchased from you as I stated above, and without any sprouting or any other means being nsed than as stated. The land was not drained in any way.

J. I. SALTER.

(From Peter Robertson.)

\section{The Gardeins-Hartriggf House, JedbURgh,}

RoxBOROUGH, Scotland, October 4, 1876.

Messrs. B. K. BuIss \& Sows :-Gentlemen. I beg to forward to you my report. I ordered of you, March 21, 1876, one pound each of Alpha and Ruby Potatoes. I planted them on April 24, 1876; they were dug October 2 and 3, 1876. The Ruby produced 1,534 pounds, and the Alpha produced 1,246 pounds. The soil is a mixture of black, sandy loam, four feet deep, with a red clay subsoil and underdrained; it has been lawns or short grass for many years; it was trenched on or about December, 1875, and remained in Winter fir until about April 10, 1876, it was enriched by about five inches of well-rotted cow dung and gas lime rubbish; the ground was then dug in the usual way, eare being taken to mix and make it as fine as possible; the rows were six feet apart, and the sets were planted three feet apart, a mixture of about three cart-loads of woodashes, two cart-loads of sheep droppings, one lime, two hundred weight salt, all mixed. The tubers were cut and planted in the presence of Mr. Kerr and others. Some of the eyes divided into seven parts; they were very small. Planted one set three feet apart each way; under each, three spadefuls of the above mixture was pulverized three inches deep with the soil, and each set planted one inch deep; they all grew; at first they looked very weak, but gained strength something extraordinary; they were kept free of weeds, and the soil drawn to them as they grew; they were two inches high on May 29, 18i6; they got nothing but kept free of weeds, and the soil drawn to them as they grew, until the tubers began to swell; they were then watered with a mixture of sheep droppings and hen manure a few times until they were lifted; there were 176 sets of Ruby, 164 Alpha, single eyes and very small; from one set single eye I had trventy-one pounds; many of the tubers were two and three pounds each. I may also say that I had some very fine, early Cauliflowers and Early Cabbage on the same ground; they were planted between the rows of the Potatoes, and cut before the Potato vines got up to cover the space between; the ground they occupied was forty-six feet by seventy feet, and would be about 3,220 square feet for each variety. Many of the vines remained green until they were lifted. The season was generally good for Potato culture; no forcing process was used whatever. 


\title{
The Potato Crop.
}

\section{A Paper Read at the American Institute Farmers' Club.}

\author{
By Conrad Wilson.
}

THE annual yiald of potatoes in the United States, according to the returns of the last census, was nearly one hundred and fifty million bushels. In view of the increasing attention lately given to this crop, it will doubtless show, at the close of the present decade, a large increase in the amount of the yield, as well as in the number and improvement of varieties. In fact, it may safely be assumed that, in spite of the fears of many in regard to the ravages of the beetle, this crop will still show a yield, at the next census, of over two hundred million bushels.

By its valuable qualities, and its large consumption, the potato ranks in nearly all countries as a leading food staple. It is therefore in every view important, and may always be discussed with interest and profit. There are, of course, some other crops that are grown on a larger scale, and some that foot up a larger yearly aggregate. Yet no product of husbandry is more variously useful, or more generally raised by farmers, and none, if we except wheat, more universally consumed by the people.

A few examples illustrating the rate of yield and the cost per bushel for this crop will tend to show what possibilities belong to it, and thus perhaps stimulate the average farmer to aim at higher results.

Some experiments in potato culture were reported in January of last year, of which the following are a part of the results:

H. C. Pearson, of Pitcairn, St. Lawrence Co., N. Y., produced from one pound of seed, 1,982 pounds of potatoes, of the Kuby variety. He also raised the same year, from one pound of seed, 1,707 pounds of the Alpha variety. J. I. Salter, of St. Cloud, Minn., got the same year, from one pound of seed, 1,694 pounds of the Ruby, and 1,665 pounds of the Alpha; while Alfred Rose, of Penn Yan, N. Y., got 1,576 pounds, and P. L. Wood, of Ill., 1,571 pounds, each from a pound of seed of the Ruby variety. The year previous J. L. Perkins, of Little Sioux, Iowa, obtained 1,666 pounds from one pound of the Eureka variety.

These amazing products were some of the results obtained by farmers competing for the premiums offered by B. K. Bliss \& Sons of New York.

The inducements thus held out by this enterprising firm has led to valuable consequences, and the competition has developed the prolitic quality of this vegetable to a degree that surpasses all previous conception.

But while duly erediting the liberality and public spirit of B. K. Bliss \& Sons, and the grand success of the winning parties, we cannot help regretting that the most important question in potato culture was not included among the offers. It is easy to see that

\section{The Cost of Production}

is the underlying question which measures the importance of all the others. Yet this does not at all diminish the value of the test made by Mr. Bliss. The Rubies raised by Mr. Pearson from a pound of seed fell short of a ton by only 18 pounds. This fact has arrested the attention of potato growers as well as consumers in both hemispheres, and confers merited distinction on both Pearson and Bliss; and certainly the tendency of such facts is to help forward the solution of the still greater problem of cost. The man who gets the bottom figures in this problem, though he may not "double the blades of grass," will more than double the product of potatoes.

Since these prizes were awarded I have received statements of cost from several competitors, and hope still to hear from others.

Alfred Rose has reported his cost, in one competition, at less than 15 cents per bushel, and J. L. Perkins about the same. J. I. Salter obtained a yield in one case at about 20 cents per bushel. His latest results I have not learned. Henry V. Rose and M. M. Rose have each reported a cost slightly above the figures obtained by J. L. Perkins and the elder Mr. Rose. For the previous year, Alfred Rose reported his cost at $\$ 55$ per acre, and $91 / 4$ cents per bushel. Mr. Perkins has also reported a later crop, since the competition, in which he makes the cost, without manure, $\$ 5.40$ per acre, and $51 / 2$ cents per bushel. 
Various other farmers, since the Bliss competition, have reported to me their yield and cost for potatoes. Lyman Alexander, of Itinnesota, got 400 bushels per acre of the Peerless variety, at a cost of about 7 cents per bushel.

Azro Smith, of Rock Bluffs, Nebraska, raised a crop of Extra Early Vermont, of which the yield was 824 bushels per acre, and the cost, as he made it, $41 / 2$ cents per bushel. But the cost in this instance, as also in the two previous cases, requires some correction. Every crop should be charged for interest on the land, and when no manure is used, a charge should also be made for exhaustion of soil. This would probably add 2 or 3 cents per bushel to the cost of the three last named crops.

C. C. Holton, of Rochester, N. Y., has reported potatoes at 400 bushels per acre, and at a cost of $121 / 2$ cents per bushel. A crop of 600 bushels per acre has been reported by one of the editors of the Agriculturist, 610 bushels by C. L. Bragdon, and 700 bushels by P. F. Rice of Polo, Ill. In one of the competitions for the Bliss prizes, Mr. Perkins obtained 376 bushels per acre, and Alfred Rose got 600 bushels of Brownells and 746 bushels of Eurekas.

Let us now take another view of the potato crop that may perhaps shed some light on its utility and value as a food staple.

\section{Feeding Value of Potatoes.}

Like Indian corn, this vegetable is everywhere extensiveìy utilized as an article of food, both for the human family and for nearly all domestic animals. Hence it is clear that the nutritive properties of the potato are a question of no little importance to the farmer, and one on which the light of further experience is still greatly needed.

How to convert potatoes, with the best economy, and with the largest profit, into other forms of food, into milk, butter and meat, is a problem not yet fully solved. Various estimates have been made by practical men as to the effective value of the potato in the production of beef, mutton and milk; and though opinions still differ, the proportion of other food staples that potatoes are capable of yielding is nearly indicated in the following statement:

$A$ bushel of potatoes when judiciously fed to animals of a good breed will produce:

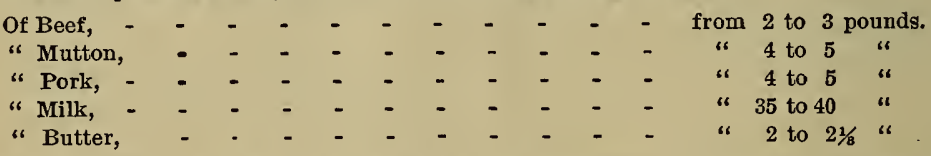

It is of course not supposed that potatoes are fed exclusively in producing these results, but in a suitable combination with other kinds of feed.

Now the practical value of the above table depends materially upon the amount of potatoes produced from an acre. The average yield of the crop for the whole country is probably not over 100 bushels per acre. And yet it will be seen, from the examples above reported, that over 800 bushels have been produced, and even that is not by any means the final limit of yield. Considering the recent progress of potato culture, and conceding the fact that 1,000 bushels per acre have been occasionally achieved by brilliant farmers, it seens hardly credible that the average yield for the United States is only 100 bushels per acre. What shall we say then? Shall we distrust the return of the last census? or shall we rather credit some progress to the eight intervening years, and claim that the average is now very much better. One thing at last seems clear. If the progress of the next two or three years shall correspond to the same period of the past, it may safely be assumed that the average yield of potatoes for the coming decade will not be less than 200 bushels per acre. I venture therefore to assume this figure as the coming average, and if any of our twenty million farmers are disposed to quarrel with me for elaiming this yield, my best revenge will be to prove the possibility and then to tell them how it may be done.

If now we apply to this estimate the figures of the above table, we shall discover

What an Acre of Potatoes Means, when expressed in the form of other food staples. We shall find that it is measured

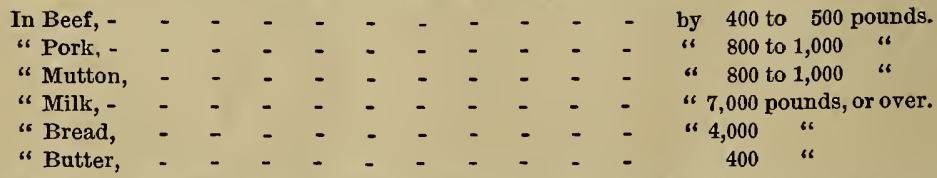

Again, as I have already shown that the total potato product of this country is nearly certain to reach 200 million bushels as the average for the next decade, it will be seen that if the above figures are extended so as to meet this case of the total product, then it will be found that 
is equivaleut

In Beef, -

" Pork, -

" Mutton,

" Milk, -

" Bread, -

" Butter,

The Annual Potato Crop of the United States

Let us now take another view of this subject. If Mr. Pearson had taken his crop of Ruby potatoes that were produced from a pound of seed, and by a right mode of feeding, had converted them into butter, according to the above estimate, the outcome of his experiment would have been about sixly pounds of butter in the Fall, as the legitimate result of one pound of potatoes planted in the Spring. Or if he had converted the potatoes into mutton, the result would have been 120 pounds.

Again, when Azro Smith harvested over 800 bushels of potatoes from one acre, if he had fed that crop to a good breegd of cattle, it would have produced, according to the above estimate, at the rate of two pounds of beef for each bushel of potatoes, making a total of 1,600 pounds of beef, as the product of one acre, or if, instead of beef, he had converted the crop into milk, the result would have been over 20,000 pounds.

These results, of course, depend in part on the above estimate for the feeding value of potatoes. On this point there is room for some difference of opinion. But it would be easy to show that when potatoes are combined with other well-selected elements, and fed in the right proportion to aninials of good breed, and good capacity, the estimate given is not far out of the way. But to place the matter beyond any question, if we reduce the estimate by 50 per cent., it would still be possible for Pearson to plant his pound of potatoes in the Spring, and harvest in the Fall either 30 pounds of butter, or 60 pounds of mutton; and Azro Smith would still be able to show from his acre of potatoes, that an acre of beef is equivalent to 800 pounds, and an acre of milk to 10,000 pounds.

\section{EGYPTIAN, EAST INDIAN OR PEARL MLLET.-(Pencillaria spicata.)}

This new Millet is quite distinct from all other species, and is without doubt, destined to take a place in the front rank of valuable forage plants. Sown in light, sandy soil, the plants at first appear feeble, resembling broom-corn; but when a few inches above ground they begin to tiller, and new shoots appear very rapidly from the original root, until they number a half dozen to a dozen or more. The stems at first are nearly prostrate, but when about two feet long they begin to assume an upright position, reaching a hight of eight to ten feet, not differing in color or substance from our common Indian corn. In fact, it is one of the most "leafy" plants we have ever met in the great family to which it belongs. When the stems have reached nearly their full hight, the seed or flower spikes appear at the summit. As soon as the first or principal flower spike appears, the stems throw out lateral branches from every joint, these in turn producing leaves and flower spikes. When cultivated for fodder, the seed should be dropped in drills, and given plenty of room on account of the peculiar habit of tllering; and, judging from our brief experience with it, we think a quart, or at most two quarts, of seed would be abundant for an acre The fodder is in the best condition for cutting and curing when the stalks are five or six feet high; but, if used for soiling, it might be cut earlier or later, at the convenience of the cultivator; the stumps, sprouting and throwing up a new growth, continue to grow until killed by frosts. Cows, horses and other farm stock are exceedingly fond of this kind of millet, eating it with as much avidity and apparent relish as they do the green leaves of Indian corn; and we are inclined to think that it is fully as nutritious. The seed will not mature in the Northern States. Price, 25 cts. per packet; 5 packets, $\$ 1.00$.

\section{THE CHUFA, OR EARTE ALMOND.-(Cyperus esulentus).}

This plant is extensively grown in the Southern States, and for sheep, hog and poultry feed, it is claimed to be one of the most profitable crops grown. Chufas may be planted in rows two and a half or three feet apart, and two tubers should be dropped twenty inches or two feet apart in the row, and covered two inches deep. In this way, about a half bushel is sufficient for an acre. In the South they are planted during February and March. North they should be planted when the ground is warm; about the same time as corn, or a little earlier. $\$ 8.00$.

Price per packet 15 cts.; per qt., 40 cts.; [by mail 60 cts.;] per peck, $\$ 2.50 ; 1 / 2$ bush., $\$ 4.50 ;$ bush.

For a more detailed description of the above and mode of culture, see our circular of Novelties for the Farm and Garden-mailed free to all. 


\section{New Sweet Potato.}

\section{EARLY PEABODY.}

This variety, first introduced by Mr. C. A. Peabody of Georgia, in the Spring of 1877, has proved a valuable acquisition, and occupies the same position towards other varieties of sweet potatoes that the Early Rose does among our common varieties. At the South they have been potaty for the table six weeks from the time they appeared alove ground. 'The fulluwing report from the editor of the American Agriculturist shows how well they have succeeded at the North:

"We started the potatoes in a hot-bed, and treated the slips, or plants, as we have heretofore treated others. 'The season was unusually wet with us, and the vines grew luxuriantly. Witli the ordinary sweet potatoes, we think it fortunate if we can steal a few from the rows two or three weeks before the viues are stopped by the frost, when the whole must be dug. We had potatoes abundantly large for the table by August 10th, but we did not have them on the table. as they were not fit to eat. So abundant had been the rains, that while the vines gave us a plenty of potatoes, they forgot all abont the sweet, and they were simply useless, as probably any other variety would have been under the same conditions. After this trial we let the crop alone until frost in early Outober, when it was dug. There were three rows across the garden, each 180 feet long, and they yive. without any unusual culture, 9 barrels of Early Peabody. And such potatoes for size! 'Three of them, selected, of course, weighed 12 pounds. We are now having them on the table, and while they are not quite so sweet as those hrought from Virginia and Delaware, they are sweet enoush to suit the writer's taste, and of a most excellent flavor and texture. Our land is very light and suffered so much from drouth in previons seasons, and especially the last, that a steam pimp was put in to enable us to water the garden from the river, but so unlike to the average seasons was that just past, that we have not needed to apply a gallon of water, the rains giving us more than enough. From our experience, under these conditions, we have no doubt that in an ordinarily dry summer, the Early Peabody will not only prove early, but good and productive, and it is especially valuable because, on account of its early maturing, it will allow the eulti$v$ ition of the sweet potato in localities much further North than has heretofore been possible. From nur experience this season, adverse as it was in some respects, we feel that we speak within bounds when we say that the Early Peabody will prove to be at least a month earlier than any other variety-and we have cultivated all that are grown in the Northern States."

\section{Different Methods of Propagating.}

The usual methon is to place the potatoes in a hot-bed, and cover them with a few inches of fine soil; the buds will soon start and form shoots; these, as they grow. make roots of their own, and when they are 8 inches to a foot long, and well rooted, the most forward ones are renoved, and the others not yet large enough are allowed to grow onl. It is customary to split the larger potatoes lengthwise and lay them flatside down in the bed. After the shoots appear, they sliould pot the same care as other hot-bed plants, to prevent them growing weak and drawn up. These have the same care as other hot-bed plants, to prevent "slips" are at the North called "seis" and "plants." Do not set the plants until settled warm weather; then set them well down to the tirst leaf, 15 inches apart in the ridge. There will be below the leaf some joints without leaves. Should a frost nip the top, then a new shoot will start from one of the barren joints. The sides of the ridges and the spaces between them must be kept clear of weeds until the vines cover the of the ridges a the thing root; this is quickly done by means of a rake handle or other stick. Do not break or cut the vines. At the South the seas'on is long enough to lei them take root at the joints, as they will make potatoes then, but at the North we wish to prevent their taking root, and to throw all the strength of the vine, out at the plants not to hoe too deeply, as the earliest potatoes lie immediately beneath the surface. Upon digging, the potatoes they should be carefully handled and put away in boxes or barrels with alteruate layers of leaves or cut straw, in a warm dry place to keep.

\section{The Land and How to Cultivate Them.}

The sweet potato may be cultivated on any soil but a heavy one. We have seen fine crops on white sand that would blow into drifts with every heavy wind. Mr. Peabody says that he has never seen a sand-hill. so poor but what, with judicious manuring, it would bring a gond crop; and that any soil which will produce a fair crop of corn, will produce one of sweet porntoes, proand that any soil which will produce a fair crop of corn, will produce one of sto bus a candy loam. He says that he has known a crop in his county of 800 busheet potatoes to the acre, upon land that would yield 50 bushels of corn, and was fertilized with 400 lbs. of Peruvian Guano to the acre. The manure should be placed on the surface and the ridges turned upon it from $3 \frac{1}{2}$ to 4 feet from center to center. Plant the slips on the top of the ridges as above recommended.

In addition to the above we offer the Nansemond and Southern Queell varieties.

Prices of Sweet Potato Planta delivered in May or June.

Early Peabody. -25 cents per dozen; 75 cents per 100 by mail; by express 60 cents per hundred, $\$ 5.00$ per thousand.

Nansemond. -25 cents per dozen; 75 cents per hunỏred, by mail; 50 cents per huudred, $\$ 4.00$ per thousand, packed, by express.

Sou thern Queen.-25 cents per dozen; 75 cents per bundred by mail; 50 cents per hundred, $\$ 5.00$ per thousand, by express. 


\section{Dioscorea Batatas-Chinese Yam.}
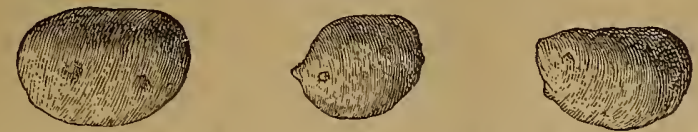

Dioscorea Batatas-Bulblets fron the Axils of the Leates.

One of the most valuable esculents in cultivation, though but little known. Stem twelve to twenty feet in length, of rapid growth, of creeping or climbing habit, forming an excellent covering for a screen; flowers small, white in clusters; leaves, heart-sliaped. The root is of a pale russet color, ob ong, regularly rounded, club-shaped, largest at the lowert end. Plant eight inches apart, in a deep, light soil, tolerably rich, aud thoroughly stirred two feet deep. A mell

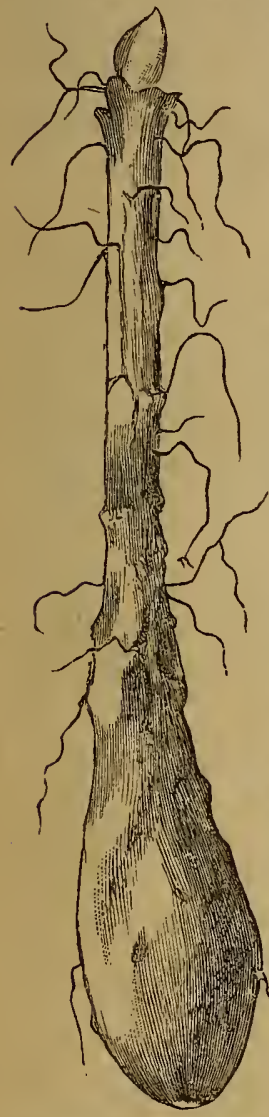
grown root, two years from the bulblets, will measure two feet in length, and $t$ wo and one-half inches in its broadest diameter, and is quite hardy, remaining in the ground over Winter without protection. The flesh is remarkably white, and very mucilaginous in its crude state. They may be boiled or roasted, and when cooked possess a ricln-like taste; are quite farinu ceous, nutritive, and valuable for food. It is aiso a very desirable climbing plant, suitable for covering screens, arbors, and unsightiy places.

Extract from a letter in the Rural New Yorlier from a correspondent who has cultivated this plant for many years.

"The Chinese Iam possesses merits that slould commend it to the agricultural classes of the United States, yet there are many who don't even know that it is grown in this country, althougl it is more than twenty years since its introduction here, from China. The difficulty all new beginners have to contend with in the eulture of this esculent. is a proper understanding of its wants. I have grown them for twelve or fifteen years, and will give the leaders of the RURAL the benefit of my experience:

In the first place, select a soil that is moderately dry, dcep and rich, and prepare it by spading or plowing deeply: then plant the bulblets eight inches apart each way. When the large roots are used for planting they shonld be cut up in pieces about one inch in length. They will produce much stronger roots than those grown from the bulblets. They will need to be cultivated a few times the first year, to keep wecds down and soil loose. After the first year, keep the w seds h ied off or mowed down, as you prefer. The Yams are perfectly hardy, sianding in the ground all Winter and growing agnin whon spring comes, increasing in size for a numbe of years. They increase naturally from the small tubers that grow on the vines just above each leaf. These should be sared in the Fall, and kept during Winter where they will not frecze, as freezing injures their growth, and planted in the Spring as soon as the ground gets warm.

As to the product per acre, in the best of soil, with three years growth and tubers ylanted eight inches apart each way, we could safely calculate on getting six and a quarter tons of Yums per acre. Some may think this a large yield, but I believe it is not as large as I should put it. and think it is not an overestimate. I have only cultivated them on a small scale, but have come to the above conclusion with regard to their proluctiveness. A few years ago, I was digging in an old bed of then where they liad been left to grow for several years, and such a sight! The grounl was literally full of roots, measuring one and a linlf to two Droscorea BATATAS. feet in length, and one and a half to two inclies in diameter at the ChINESE YAM-ONE largest end, and this too where the soil was not more than eight or ten Year OLd Root.

inclies deep.

They grow in a perpendicular position with the larga end downwards. The vines are ornamental, having lieart-shaped leaves edged with scarlet and are very pretty. A few tubers jlinted near a dnor or window and the vines trained over and ahont it, make an ornament worthy the alluiration of all. The flowers are numerous and liave a cinnamon fragrance, but the vines do not hloom until the roots are two years old. In garden culturo $I$ let the vines run on the ground, except those I wish to save tubers from for seerls. These I set stakes or yoles to, as I lhink ly this :nethod the tubcrs are produced iu greater abundince and of lirge size. 
There is scarcely any difference perceptible to the taste between the Chinese Yain, when properly cooked, and the Irish potato, although the Yam is much whiter and somewhat finer grained.

Some object to growing them on account of the great depth to which the roofs penetrate. But to those $I$ find no difficulty. I commence digging at tha end of a row, take out what 1 want, and leave the hole open. The next time I dig I commence where I left off, and thruw the dirt where I dug before; by this way I have the suil stirred so deep that it is in fine condition for planting oit more tubers.

They have no insect enemy, and drought affects them but very little, as they root so deeply. There is no necessity for their being dug at any time of the year, except when wanted for inmediate use. They are suitable for cooking any time in the year. A person can plant enough at one planting to do his family for years, each year bringing bim larger Yams. I consider them safer to derend on than the Irish potato, which has its enemies, and is so sensitive to a little freeze.

I beliere their proper cultivation would be attended with success anywhere in the United States. If the masses of the people better understood their nature and were better acquainted with their many fine quilities, they would be more generally grown. In conclusion $I$ will say that they are the most profitable crop that I cultivate.

Small bulblets, wlich form roots about a foot in length, in one year, in packets of one dozen, 25 cents. Five dozen, $\$ 1.00$. Oue year old roots $\$ 20$ J per dozen; $\$ 12.50$ per 100 .

\section{J. L. True's Improved Potato Planter.}

\section{This Machine will cut the Potato and Plant Six Acres in Ten Hours.}

We invite the attention of the farming community to this machine, which is beyond doubt one of the greatest and most successful labor-saving machines of tho age.

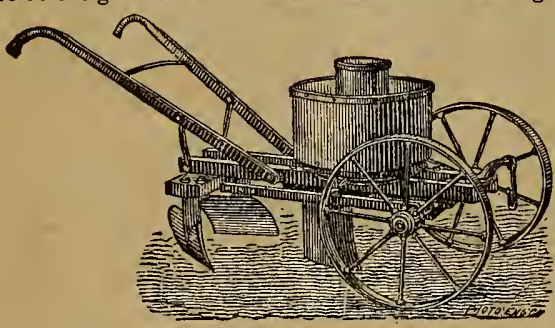

Having been subnitted to thorough practical tests on all kinds of soil, in this country and in Europe, we offer it to farmers for the season of 1878 , with entire confidence in its ability to do the work intended for it, in a thorough and proper manner.

No intelligent farmer can fail to see tbat an implement with which a nan ean, with the aid of a borse, cut the potatoes, and plant six acres in one day, loing the work in many respects better than it is

usually done by lıand, is of inestimable value.

The Machine is very simple in construction, and its arrangement is such as to render it very easy to operate.

The Hopper holds about one bushel of potatoes.

The luife is placed in such a relative position to the seed-boxes that the potatoes are cut into pieces of such a size and slupe as to render it almost impossible for any to drop without eyes on them.

The potatoes drop througli the plow, the back of which being open, the operator can see each piece as it falls, and they are still exposed to his view for some distance as they liy in the furrow. before the coverers reach and cover them, thus affording him the satisfaction of knowing that the work is being well done.

Gange rings are provided for diminishing the size of the seed-boxes, when planting different sizes of pititoes separately.

Ally kincl of dry, concentrated fertilizer may be dropped with the potato in such quantities as may be desired.

The Plow and Coverers can be adjusted to cover the potatoes in a most satisfactory manner, at any depth desirel.

Tho drive wheels mark the rows, which can be made as far apart as the farner chooses, while the seed is dropped 9,18 , or 36 inches apart in the rows.

Prices of Machines on cars in New York:

No. 1-Machine with Fertilizer Attachment, complete (drop/s 9,18 or 36 tuches apart), $\$ 4000$ No. 1-Without Fertilizer Attachınent, - - _ - _ - _ _ - 3700 No. 2-Machine has no Fertilizer Attachment, and drops 18 or 36 inches apart, $\quad$ - $\quad 3000$

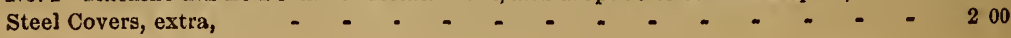




\title{
Antidote for Colorado Potato Beetle.
}

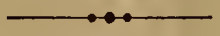

\author{
From a treatise on the "Pest and its Remedy," published by C. T. Reynolds \& Co. \\ New York.
}

The resistless progress of that dreaded pest, the Colorado Potato Beetle, has for several years past been watched with anxiety and alarm by the farmers of the Midule and Eastern States. It was foreseen that it would eventually make its way nortl and east, and the appearance of $1 \mathrm{his}$ farmer's enemy in Pennsylvania, New York, and portions of New Englanı, last Summer, leares but little room to doubt that the bug will be out in full force this coming season, and rapiuly extend its ravages. In fact, we consider its crossing the ocean itself and becoming naturalized in the old world, as merely a question of time. Already several of the European governments hare taken the alarm, and fully alive to the magnitude of the danger with which they are threat ened, have endeavored to forestall it by prolibiting the importation into their dominions of American potatoes from the district devastated by the bug. Whether this measure will prove effectual in warding off the evil from their shores remains to be seen, we believe it will not.

\section{ITS GREAT PROLIFICACY.}

The Coloradn beetle propagates itself with astonishing rapidity; several broods (at least three) following each other in the course of the year. The first batch of larvæ makes its appearance towards the end of May, and sometimes even in April, if the weather be warm. Each feniale lays from 700 to 1200 eggs, in clusters of twelve or thirteen, on the under side of the leaves. In about six days the larvæ are hatched, and immediately begin the work of devastation, whlch continues for about nineteen days. They then descend to the ground, where they are transformed into pupæ, at the surface of the earth. The perfect beetle appears in ten to fourteen days after the pupæ is formed-begins to pair in about a week, and on the fourteenth day commences to deposit her eggs.

\section{THE VORACITY OF THE BEETLE,}

especially in its litrval condition, is truly marvellous. When once a field of potatoes has been attacked, unless very prompt remedial measures are resorted to, all hopes of a harvest will. speedily vanish, as in a very few days nothing will remain but a barren waste of dried-up stalks.

\section{VARIOUS PLANS}

for the destruction of the Colorado potato beetle have from time to time been devised, very few ot them have proverl satisfactory, however, while many of them were wholly impracticable. Picking the larvæ and bugs from off the plants by hand, for instance, has been thoroughly tried but leaving out of the question the great loss of time this plan involves, and the danger of poisoning froin handling the larvæ, it was generally found that after the field had been thus gone over, the insects would be apparently as numerous as ever in twenty-four hours, so that the operation had to be constantly repeated!

\section{PARIS GREEN THE TRUE REMEDY,}

is the general verdict of the Western farmer. This is not only the case with respect to efficacy, but it has also the additional merit of being the cherpest in first cost, and the most convenient and economical in use of all the' lemedies that have been tried. When first proposed as an antidote, some seven or eight years ago, Paris Green met with considerable opposition, but its triumphant success has overcome nearly all prejudice, and whilo some still hesitate to resort to so virulent a poison, experience has demonstrated that with clue care no harm can result from its use, as it will not poison the soil or injure the plant or the Potato.

Prof. Charles V. Rrley, State Entomologist of Missouri. In his furrth aunual report referring to Paris Green, says: "Properly mixed I have used it without the slightest trace of evil on the leaves or tubers; and I know hundreds of otlers who have done likewise; so that with present experience $I$ should not hesitate to recommend its julicious use." In this connection we take occasion to acknowledge our indebtedness to Prof. Riley's able reports for much valuable information. We also refer to the testimony of the same high anthority to Paris Green as "THE remedy for the Colorado potato beetle." 


\section{MODES OF APPLICATION.}

In its application the Western farmers generally use Paris green $d r y$, and as it is a lighly concunt:. tcd poi son it is necessary to mix it with some other substance, such as flour, plaster, or ashes, in proportion varying with the strength of the green, and thus reducing its cost. We give the preference to flour as a velicle, as combining with the dew on the plant, it forms a paste which adheres with greater tenacity than either plaster or ashes. Another method is by mixing with water, say a large tablespoonful of green to a pailful of water. This is in some respects a convenient way, and has the advantage of being free from dust; it can also be used at any time of day. It has some disadvantages, however : 1st, as the green is not soluble-though it quickly gives a green tint to the water when stirred, it soon settles to the bottom, and needs continual agitation to keep it in suspension. $2 \mathrm{~d}$. It settles in spots on the leaves, the natural tendency of water in finding its level being to carry and concentrate in wherever a drop finds rest and evaporates. 3d. Much of it is wasted on the ground in sprinkling.

\section{THE UNPARALLELED DEMAND FOR PARIS GREEN,}

caused by the rapillity with which the Colorado beetle has overrun the country, has greatly stimulated its proluction; and, as usual in such cases, the market is flooded with various brands, representing all grades, from the strictly pure down to the highly adulterated article of merely nominal strength and value. There are several qualities mamfactured, in order to meet the views and conveniences of all who are compelled to resort to its use.

\section{PROPORTHONS FOT MIXING.}

To those who have suitable appliances for mixing, we recommend the "strictly pure," but where these are wanting, and it is an object to avoid much mixing. on account of the danger arising from the dust (and this is the greatest danger attending its use) the cheaper grades are more desirable. Thesu, of course, contain more or less adulteration, but the price is made to correspond, and the buyer has but comparatively little mixing to do. The following are the proportions recommended by experienced Western farmers, and also by scientific men who have arrived at the same conclusions by careful experiment:

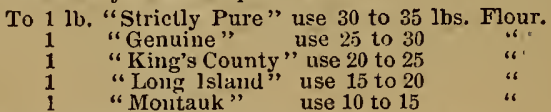

Relatively speaking, the "Genuine" is the cheapest to use, but the "Montauk" has the advantage of being less liable to puison from dusting.

We have made arrangements with the manufacturers of the abore to furnish our patrons at the lowest market rates. In consequence of frequent fluctuations, we do not publish prices, but will give prices upon application.

We have on liand a small quantity ready for use for those who wish to use it in their gardens in one pound pachages, at 15 cents each, mixed ready for use.

There is great danger in mixing this green for potato bug and cottm worm poison, owing to the fine dust which arises in the process, which is inlaled, and also rapidly absorbed by the pores of the skin, especially if the person using it should be in a state of perspiration. To guard against this, the hands and face, (particularly the mostrils) should be protected as muclı as pos-

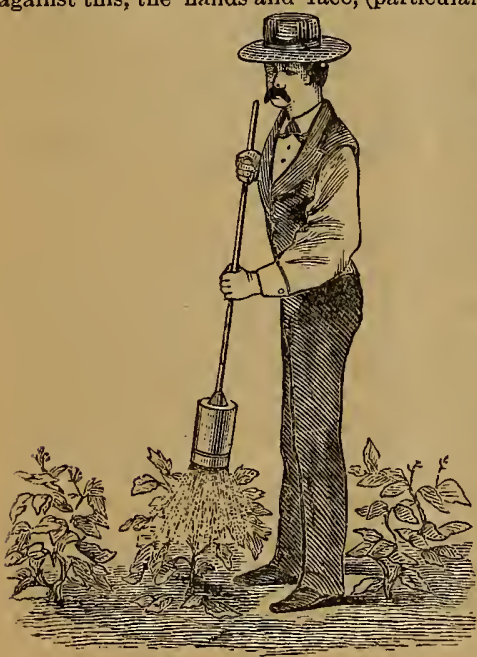
sible, and slould be carefully washed after working in it, or in any of the preparations of which it is an ingredient. As it penetrates and poisons woor-gets iuto the seans and crevices of articles maile of metal -and even into eartlıenw:ıre that is at all porous. All househnld utensils, or anything in. barn or stable (which catlle or horses could have access (o) in which the article may have been mixer, or from which it has been used, should be carefully set aside, and never again used for any other purpose.

\section{APPARATUS FOR APPLYING.}

Several ingenious machines have been invented for applying the poison,--threc of which are here illustrated. The cheapest and most simple is made in the form of a common dredging-box, holding about two pounds each, and is attitched to the end of a pole, as scon in the accompanying engraving. It is used by gently shaking over the plants, taking care to walk to windward, so as to avoid any dust that may arise. It should be applied in the morning, when the dow is on the vines. When mixed with water, it is usually applied by ineans of an orlinary watering-pot, or sprinkled on the vines with a broom, taking care to keep it well stirred. Price, 35 cents each. 


\section{Randolph's Fertilizer Distributor.}

\section{A Dropper for all Hill Crops, such as Corn, Potatoes, Tobacco, Cotton, Etc. THE LATEST AND BEST THING OUT. SOMETHING THAT NO FARMER CAN AFFORD TO BE WITHOUT.}

For dropping Phospluates, Bone Dust, Fish and Peruvian Guano, Poudrette, Ashes, Plaster, and all kinds of Concentrated Fertilizers.

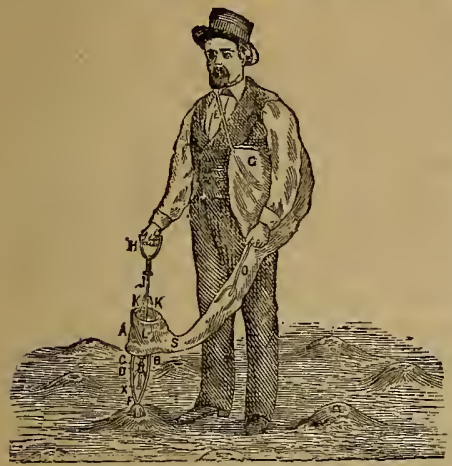

The manner of using the dropper will be readily understood from an inspection of the eut.

The sack G, having been filled with the fertilizer, is attached to the person by passing the adjustable strap. $\mathrm{E}$, over the slioulder as sliown. The handle $O$ if the connecting shoot $S$ is then held by the left hand, and the handle $\mathbf{H}$ of the plunger $J$, hy the right, unless the person is lelt-handed, in which case the arrangement is just the reverse, the dropper being adapted for use in either way.

When thus arranged, the operator walks over the field, and as he wilks, places the ball step $F$ of the dropper, surcessively, upon the spots which he has selecteil for planting. and as the plunger $J$, being unsupported, is necessirily depressed at ear.h rest of the inplement, a charge of fertilizer will be reposited in a circle about ench hill. its quintity being determined by the previnus adjustmeut of 1 he vilves $(;, 0$.

It will thus he seen that the implement is used after the manner of a "'rne. it being nperated by simply swinging it from lill to hill. no exercise of care or judgment being required other than to select the spots upon

which to rest its step F. For windy weather a letachable skirt (not sliown in the cut, is provided which ensures the :iccirate placing of the fertilizer in any required circle even under such unfavorable circumstances.

\section{SPECIAL ADVANTAGES.}

It is not necessary to thuch the fertilizer with the hands, a matter of some importance, when canstic substinces are used.

Tha fertilizer will not itick or clog. even thongh it be clamp anil has a tendency to pack, the vibrating hopper being so effective in its operation, that nothing suitable for use, can withstand its nction.

The quantity sown mav he letermined to a nicety, bv properly adjusting the valves upon the plunger, so thit every lifl in the firld may be supplied with a uniform amount.

The entirt quantity between the valves is always dischirged; the construction of the lower valve with its conical surface, and tlie foction of the plunger, which is suddenly arrested at a limit of its movement hy a stop, servin $r$ to ensure this result.

The amomnt delivered is accurately deposited in a eirele abont the planting spot or hill, no more being deliverel upon one sile than annther, and the center of the hill coveres by the ball step being. of course. withont any deposit, these heing the precise conslitions desired in using moncentraterl fertilizers. 'These effective results, also, can be obtained in windy weatber, by using the protecting skitt.

For nany other remmmendations, and a more complete description-send for circular. Price, $\$ 5.00$ each. A libcral discount to agents.

\section{Allen's Potato Bug Destroyer.}

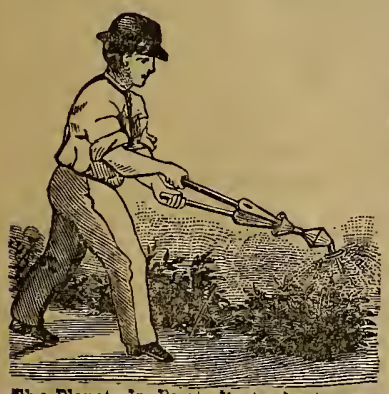

The Planet, is, Potato Beet,e Lestroyer.

Allen's Potato Bug Destroyer, sent out late last Summer, has beell greatly imuroved, and will be found efticient, hankly and inexpersive, and an inportant acquisition where the potato beetlo is either establi-bed or expected. It is especially contrived for the jurpuse of quilkly and economically throwing a mixture of Paris Green and Flour, or other destructive compound in a penetrating cloud, among Potato and other plants, and upon huslies, vines and trees, to clestroy Bugs, Fleas, Worns. Slugs, Caterpillars, etc.

It consists of a pecunarly constructed donble coned reservoir, readily filled, ant by means of bellows, capable of throwing either a jet or cloud of tine poweler, thoroughly dusting a row of potatnes or other plants $a_{i}^{\prime}$ the speed of $a$ walk. It is also especially effective for Pear and Rose Sluzs, Cotton Worms, Plant Lice anul other insects.

Paris Green, before use, should bo earefully mixed with five or six times its weiglit of dry flour or plaster: the quintity applied being easily regulated by the quantity of tlour adiled.

Though the Powder is a dangerous poison, this machine discliarges at so yreat a distrnce from the bands and face, is with reasonable care to make its-use entirply safp. It is desirable to apply in the early morning, the dew then forming a paste, and that time being less windy. Price, $\$ 3.00$. 


\section{HEXAMER'S PRONG HOE. \\ The Best Hand Potato Digger in Use.}

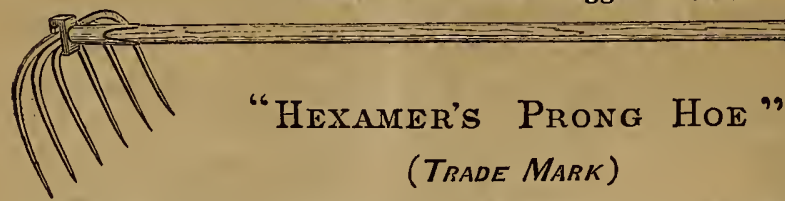

The highest premium in the Horticultural Department of the Great American Institute Fair of 1867, was awarded to it. The American Agriculturist, in speaking of this implement, gives it the following favorable notice:

Hexamer's Proxg Hoe.-Dr. Hexamer, the well-known Horticulturist, has such a way of making his investigations and coming at his facts, that we accept his results with almost the same contidence we would have in our own. He makes use of expensive labor, and the monthly pay-roll is so large as to lead him to employ his men to the very best advantage. The problen was what tool to place in the hands of the laborers for hoeing out between rows of strawberries or other smill fruits, root crops, nursery stock, etc. The common hoe is a slow, hard, old-fogy tool, and, of course, its use is out of the question. The potato hook, or pronged hoe with round prongs, good, but not sufficiently rapid for the outlay of strength, yet vastly superior to the hoe for the sam purposes, except after weerls lave grown large, which ought rarely or never to occur. After haviug male numbrous experiments with tools made expressly for him, lie clecicled upon this intplement. The six teeth or prongs are eight inches in length, the outer ones being ten inches apart, which is the width of the actual cut. The prongs are square, of the best steel, an.l inserted in pairs into a malleable iron head, in which they are firmly wedged. They are delicate, but very strong and elastic.

It stirs the soil thoroughly, nore than a foot wide, and from two to four inches deep, killing all sinuil weeds, lifting ont stones of sinall size, removing weeds and all obstructions as effectually as a rake. On jight soil it is as easily worked as a hoe, and on heavy soils, if dry enongli to work at all, very much easier. It is s: fe to siy that a man. with one of these, can do several times as much wnrk us witi a hoe. We think it will prove more useful as a potato digger ou accout of its breadth, than the implement made for the purpose.

PRICE, $-\$ 1.50$ each; $\$ 15.00$ per dozen.

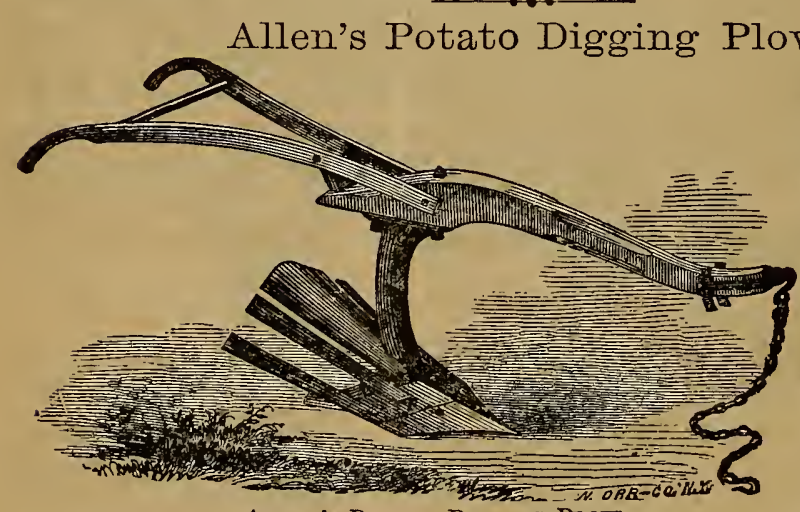

This implemene. weighs one hundred pounds, and is of very light dratt. A pair of small horses or oxen, with a boy to drive will easily dig potatoes as fast as twenty men can pick up. It turns them out so cleanly that scarcely one bushel in fifty, whether small or large, is left uncovered.

The standard is Allex's Potato Digging Plow. high, so as to allow of its working freely, withont clogging from weeds and potato vines, but in harvesting for an early market, when the vines are long and still green, the work will be much facilitated by cutting these and removing them from the rows.

Price of Potato Plow, with cast-iron Mould and Share, $\$ 15.00$. The same, with steel Mould and Share, $\$ 25.00$.

\section{The Planet Horse Hoe and Cultivator.}

This is a new and most perfect tool for horse cultivation. It.is especially adapted to market garden alud farm-lioed crops, and to working Tobacco, Bronm-('orn, Cotton, licice and lioots. It

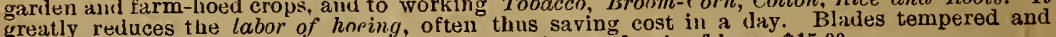
polished steel. Price, st2.00. With extra cross-piece and pair of hoes, $\$ 15.00$.

Planet No. 3.-A Fertilizer sower. Price, \$16.75.

Complete directions for use accompany each machine. Send for a full descriptive circular, with cuts of each implement and testimonials. 


\section{IMPORTANT TO WHEAT GROWERS. PRINGLE'S NEW HYBRID SPRING WHEATS.}

We take much pleasure in announcing two new and distinet varieties of Spring Whent, produced 111870 and $187 \mathrm{t}$ by Mr. Pringle of Vermont, whose skill and judguent as a hybidizer of Ceresls and Potatues have already won for him a world wide reputation. After a careful trial of six years. we now offer these varieties to the public, having entire contidence in their superiority over all other's, feeling assured that they will prove to be valuable acquisitions to the wheat glowers of the country.

\section{CHA MPLA IN}

Was produced in 1870 by Mr. Pringle, in lis enleavors to unite the remarkable hardiness of the IBlack sea with the fine and superior quality of the Golden Drop. Several varieties were the result of this hybridization, from which this one was chosen, as realizing the end in view, showing grealy inereased vigor and productiveness over hoth its parents. A carelul selection from this tor the past seven yedrs, has now fully cstablished its cliaracter, and we liave : whent beitrded like the Black Sea, with the white chaff of the Golden Drop, free tron rust amil smut, yielding a lighter colored grain than the former, which makes a flour of superior quality. Its strong and vigorous straw, giowing 6 to 12 inclies higher than its parent varieties. stands r rect, frequenly learing. even in very ordinary culture, beads rom 5 to in inches in length, containing from 60 to 75 kernels ench.

We confidently recummend this new whent as among the earliest, fromising to give the growers of this most ininintant crop better results thin are produced by the old and "run out "varieties nuw sown. Price, $\$ 1.00$ per $l b ; 3 l b s, \$ 2.50$, by mail post-paid; peck, $\$ 9.00$.

\section{DEFI I NCE.}

Another variety of Spring Wheat of the lighest promise, the result of a series of experiments hv Mr. Pringle in 1871. to incorporate superior qualities upon the hardy stock of onr conmon Cl:1h Wheat, hy hybridizing it with one of the finest, whitest, and most extensively grown sorts of the Piteitic Coast

'This variety displays great productiveness, vigor and hardiness. It is a beardless, white chaff wheat, with hends frequently tive to six inches Jong, very elosely set with large white kemels, frequently numbering 75 to 80 to the single liend its wlite, stiff, erect straw, exempt fiom the attack of rust, its earliness combined with great vigor and superior qualities, should claim for it universal trial. Price, $\$ 1.00$ per $l b . ; 3 l b ., \$ 2.50$, by muil post-paid.

\section{$\$ 250.00$ in Premiums.*}

In order to induce Wheat Growers to give these new sorts a thorough and universal trial. we offer \$250.00 in premi ums for the lugest quantities grown fiom one pound of seet purcliased from us. Parties will please stiate in their order that they desije to conıete for these premiums. For the larg-st quantily of Cliamplain Wheat grown fiou one pousd of seed, - $-\$ 5000$

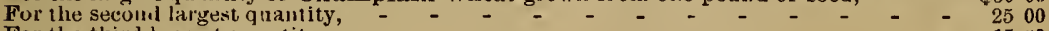

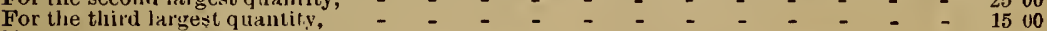
For the fourth largest quantity, - - _ - - - - - - - - -1000 For the liargest quantity of Defiance Wheat grown from one pound of seed, - _ $\quad$ - 5000

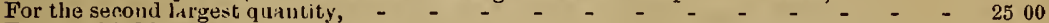

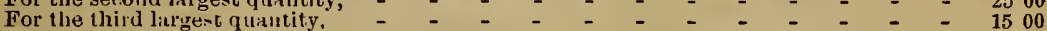

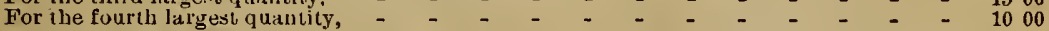

IVe also offer addilional premiums of $\$ 50.00$ fur the best 20 heads of either of the above variities as follows. $\$ 2: 00$ for each variety.

For the best 20 heads of Climplain, - - _ - - _ - - _ - - $\$ 1000$

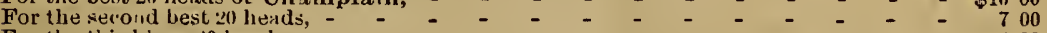

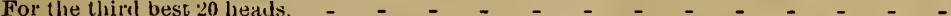
For the fourth best 20 heads, - - - - - - - - - - - - $-\quad-\quad 300$

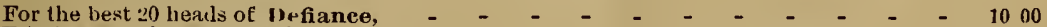
For the second best 20 heads, - $-\quad-\quad-\quad-\quad-\quad-\quad-\quad-\quad-\quad-\quad-\quad-700$

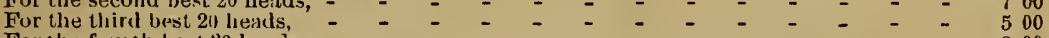
For the fourth best 20 he 2 ds, $-\quad-\quad-\quad-\quad-\quad-\quad-\quad-\quad-\quad-\quad-\quad-\quad-300$

Competitors for the prizes will be required to give the date on which they gave their or der for the wheat. ditte of sowing. tims of harvesting, with a written statement of their mode of enlture, characteristics of the sil, - whether cluy, alluvial, or sindy loam,-nature of tle subsoil, whether under-drain of or not; also, the kind an't quantity of fertilizers used, Jow and when applied, wilh the weight of the erop when harvested and curenl, which must be wilnessed and Sworll to hefore a Justice of the Peace. Nutary. or anv one competent to administer the uath, and sent to our adilress hefore the $H$ irst of Novemher, 1878. The awards will be made by a competent committer of Agriculturists. and will be printed and a copy mailed to each competitur. The prizes will be pail in beember, 1878.

The ellgravings are exact representations of some of the heads grown with ordinary farm culture.

Coinpetitors for the premiums for the best heads of wheat mist deliver them at our office, 34

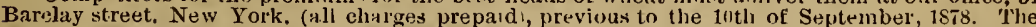
straw nust be "lit not less thin eight inches in length exclusive of the heads, ancl carefully packed to prevent injury in the transportulion. I hev ean be sent by mill or express preprid, at the option of the grower. If sem by mail, they should be boxed in a light wooden or a stiff paste-

*Cirenlits explaining the mode of awarding the Premiums for the largest quality grown from one pound mailed to applicauts. 
board box, the cover of which must be secured by strung twine. and not nailed or fastened in any way to prevenc the examination of the parcels at the New York post-othiee. No writing of any kind must be enclosed in the packages, as in that ase letier postage would be cliarged on the whole package, and would not be taken from the oftice. The name of the sender must be writien on the outsiffe of the packaye, with our address. Notity us by letter when the wheat is sent. All those who wish their samples returned, in the event of their not reetiving a pi eminm. must enclose in their fotter at the time of sending the herils a sum sufficient to pay jeturn charges; otherwise the wheat will uot be returned. The premium samples will be retained by us.

\section{A NEW WINTER WHEAT.}

Arnold's Victor Wheat.-This wheat is the final result of a large number of intererossings. and selections of the best varieties grown in America. After rarefully cxperimenting for a mimber of years. it is clatmed that a variety las been obtained with a hardiness in resisting the effects of a Canadian winter, entirely superior to the Diebl when grown side by side. and subjected tollhe very samat:onditions. One bag, contatining 15 il $1 \mathrm{bs}, \$ 9.00$. One bushel, including bag, $\$ 4.50$. One peck, including bag, $\$ 1.50$. 3 los., by mail, $\$ 1.00$.

\section{COMPTON'S EARLY FIELD CORN.}

This corn, which has made such a sensation in agricultural circles. is the result of years of patient effort by one of our mo it intelligent experimenters. Seeing the great deterioration of the common sorts, and comprelienting the magnitule of the losses frequently sustained in consequence of the partial or total destruction of he crop by early Autumu frosts, he instituted a series of experiments with the view of obtaining a liew variety in which extreme enrliness and great productiveness should be combined. A large plot wis planted wih seed from the small huskless ears sometimes fomm on the tops or blossom branches. Th: kinds so oblained proved to be different from each other, and each distinet from any known rariely. One slalk on which were four fine ears. ripened hy the millll $\Rightarrow$ ot August. The crol' of 1 lis stalk is the souree of the variely of feren. It is is seedling of the D.ttm, ini resembles its parent. si mewhat in appearance. Sialks grow eight to ten feet in hight, ears trom ten to seventeen inche's in length, well filled to the end. Fernel medium, brighi yellow ant of the flinty order.

This virriety $w$ is sent to all parts of tho commly ilue past season. and we have yet to hear one unsatisfactury report. Alt who hitve tried it strongly recommend it. It is an acquisition which farmers cin rot lail to appreciate.

Price, one pint, by mail prepain, 50 cents; one quart, by mail preprid, 80 cents; by express. charges to be paid b!l purch.xver, peck, $\$ 2.50 ;$ bush., $\$ 8.00$. Select ear's, by mail, 25 cents each; by express, $\$ 1.50$ per doz.; $\$ 8.00$ per 100 .

\section{WHITE RUSSIAN SPRING WHEAT.}

The White Russian What was first grown in this enuntry in Wisconsin. It was increased from a small quantity received from Russi.t, anl has been known as the White kussian, although it is not exac ly white, but is of muc, lighter color than most varieties of Spring Wheat.

It is a balli white ch:aff wheidt, and h is proved itself to be one of the best Sining wheats erer grown in Wisconsin. Such lon:s, straight, strong, lealtlyy yellow straw, bearing large long white ehaif he:uls. well filled with plump kernels. weighing of thimes from 60 to $6:$ lbs, to the measnred busliel, and the whent producing 5 to 10 busliels more per acre than other once well thouglit of virieties that are now fast rmmin ont, ati all wheat does after heing sown a. long series of years uniler the influence of the sam; soil and clinate. As sonn as it can be got in sufficient qu+ntity. it is destingl to crowil out 10 a greak, extent onlier varieties, and will become the staple s'pring Whent of the Uuited States, until other new raieties iake jis place.

The White Rns-i,n Whear. stancls well alter being riple, and is not lialle to lodge when green. or rust; it is decidedly a healthy anl sure crop wheat. that lias in niany cases lirnduced a full average crop, where other varietiss along side of it have failed. $3 l b s ., b y$ mail, $\$ 1.00 ; 1$ peck, $\$ 1.00$. 1-2 bush., $\$ 1.75 ; 1$ busl., $\$ 3.00$.

\section{GOLDEN MHLLET.}

Golden Millet is of extraordinary valıe, and coming into great favor as an annual hay and forder crop. It is mistakenly called German Millet. which is a very !ndefinite nane for seed imported from Europe under this n ime proves to be the Panicum miliaceum or common Mlillet of our catalognes and persons ordsting Germ'un Millet of orlinary sef demen. will prol ria Germanica, or Hungari un grass. Henee Golden Millet is the nuly definite name. for vo other plant beirs the some. The experience of those to whom we sold seed last year, wartants our speaking of it in the highest termi.

Prices: IVe can. furnish the seed at the following prices. bn express or freight charges paid by purchaser; per bushel, $\$ 2.00$; per $\frac{1}{4}$ busliel, 60 cents; by mail, postage pre paid by us, 40 cents per quart.

\section{KENNEY'S EAIRY AMIBER SUGAR CANE.}

In this variety we have a plant that is destined to prove of immense value to the northe:n portions of our enuritry. It has heen lested in Miunesota for several years past. A large grower gives the following statement to the State Commissioner:

I planted a piece of this eame this year. ami the zitli of May, on new land, and hefore any frosts it wa: entirely ripe. Its sacrlurine qualities are of the first order, fine and ricl, and its earliness lighlyly recommend it to the whole country. It los amilher desiralile quality, it slands uy well. loes not etsily blow down, usually glows eleven and twelve feet ligh with us. Wlien planted hetween the first and tentli of Mav. the seed ilmost invariahly ripens. 1hus giving one the alvantage of a donthle crop in one year. from one plonting. somie 20 or 25 bushels of seed, and 150 or more ga'lons of tine syrmo ner nere. that $i$. if it is skillfully handled. All kinds of farm stock are fond of the seed; when gromnl and mixed with bran it mikes a good lieavy feed for horses; hens are very fomil of the seed, and I lielieve it niakes them produce eggs more abundantly than almnst any other kind of grain. We have seen sugar produeed from this variety equal to the best coffee sugars in the market.

By mail, 75 cents per $l \vec{b}$. When sent by express at the expense of purchaser, 60 cents per $l b$. 


\section{No. 1 PERUVIAN GUANO, PURE BONE,}

\section{Mapes' Complete and Special Manures,}

(Inclucing the celebratod Formulas of Prof. Georso Ville.)

THE MAPES' FORMULA AND PERUVIAN GUANO CO.

CASH MUST ACCOMPANY ALL ORDERS FOR FERTILIZERS.

The following quotations include cartage, excepting when total quantity ordered is less than haif a ton, then add fity cents for cnrtage.

\section{PERUVIAN GUANO, at Gov't Stores, Brooklyn, N. Y.}

\section{No. I PERUVIAN GUANO-"Standaro," or "GCanape."}

Ammonia, 10 per cent.; Phosphoric Acid, 12 to 15 ; Potash 2 to 3.

No. 1 PERUVIAN GUANO-"Lobos."

Average weight of Bags 1 so lbs.

Amraonia, 6 to 7 per cent.; Phosphoric Acid, 15 to 20; Potash, 3 to 5 .

Average weight of Bags 210 lbs.

\section{No. PERUVIAN GUANO-Guaranteed.}

Cargo B...Ammonia, 11.50; Phosphoric Acid, 17.10 ; Potash, 2.30......Bags 200 Ibs. Cargo F...Ammonia, 6.30; Thosphoric Acid, 18.70; Potash, 3.20......Bags 2 Co lbs.

No. 1 PERUVRAN GUANO-Rectified.

Cargo......Ammonia, 9.70; Phosphoric Acid, 14.25; Potash, 2........Bags $200 \mathrm{lbs}$. Cargo......Ammonia, 3.40; Phosphoric Acid, 16.90; Potash, 3.40......Bags 260 lbs.

No. 2 FERUUTAN GUANO.

Ammonia, 3 per cent.; Thosphoric Acid, 15; Potash, $2 \ldots \ldots \ldots \ldots \ldots \ldots \ldots$ Bags 200 Ibs.

No eharge for Delivery at Govermment Stores, at Brooklyn, to vessel.

Official descriptive Pamphlets on Peruvian Guano furnished to dealers, with their name on cover. Liberal concessions made to manufacturers and dealers, from even the official price list of the Agents of the Percvian Government

\section{CHEMICALS, FURNISHING AMMONIA, ETC.}

NITRATE OF BODA.

STANDARD 05 per cent., equal to 10 per cent. Ammonia.......Bags......lbs.

SULPHATE OF AMTIONIA.

STANDARD 25 per cent. Ammonia..........................

GROUND DREED EBLOD-(Pure).

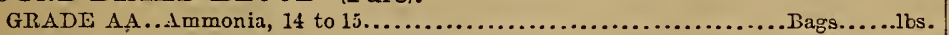

GIROUND DFIED FLESP-(Odorless).

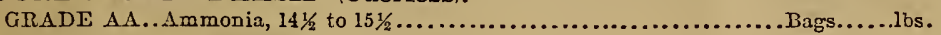

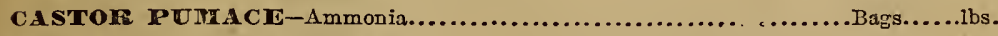

SULPHATE OF MAGNESTA.

GRADE....... per cent. Sulphate Magnesia.............................

PLASTER, Nova Seotia-Very finely ground.................. (Bags 200 lbs. .t $\quad\left\{\begin{array}{l}\text { Bbls. } 250 \text { lbs. } \\ \text { Bblete }\end{array}\right.$

All Chemicals, grades of Bone, Formulas of Prof. Ville, Complete and Special Crop Manures, Super-Phosphates, and Potash Salts, sold by us subject to test by Prof. Geo. H. Cook, New Jersey State Chemist; Prof. W. O. Atwater, Connecticut Fxperiment Station; Dr. Wm. M. Habirshaw, Chemist INew York State Agricultural Society.
Per Ton, Pingl:gooo lbs. Prekige,

$\$ 56.50 \quad 3 c$.

$47.50 \quad 21 / 2 \mathrm{c}$ Pev $1 \mathrm{bm}$

$70.00 \quad \$ 7.35$

$56.00 \quad 5.90$

$69.00 \quad 7.25$

$51.00 \quad 5.35$

$38.00 \quad 4.00$

Single Package, $\$ 75.00 \quad 4 \frac{1}{4} \mathrm{c}$.

$90.00 \quad 51 / 2 \mathrm{c}$.

$50.003 c$.

$50.003 c$

$22.50=1 / 2 c$.

8.00 


\section{PRICE LIST OF MANURES.}

\section{PROF. VILLE'S FORMULAS.}

COMPLETE IMA U ER-(Ville Formula)-Ready Mixed.

A substitute for barn-yard manure, adapted for general use, especially on light or sandy soils, or those deficient in potash.

Ammonia, 7.69 per cent.; Phosphoric Acid, 5 ; Potash, 7.59.............Bags 200 lbs.

FOF ONIONS and Vegetables-Use the above Complete Manure.

TURNIP IIANURE-(Ville Formula)-Ready Mixed.

Ammonia, 2.53 per cent.; Phosphuric Acid, 7.50; Potash, $7.59 . \ldots \ldots$..... Bags 200 lbs.

POTATO IMANURE-(Ville Formula)-Ready Mixed. Ammonia, 4.50 jer cent.; Phosphuric Acld, 5.97; l'otash, 13.64..........Bags 200 lbs.

These formulas are now furnished by us at the above quoted prices, in a ready-mixed and fincly grousd, dry condition.

Any of these formulas, when ordered in lots of two tons and upwards, may be obtained in the form of the materials of which they are composed, all shipped in their separate and original packages, at a reduction of five dollars per ton from the above prices.

The prices charged for these formulas in the unmixed form, will be found to be based upon the actual per centages of the following ingredients at the annexed low rates.

Ammonia, from Peruvian Guano, Ground Dried Blood or Flesh. 171/2c. per Ib.

Phosphoric Acid, all in form of Peruvian Guano......... 9c.

Potash, as Phosphate, Sulphate and Muriate................ $7 \frac{1}{2} \mathrm{c}$.

\section{MAPES' COMPLETE AND SPECIAL MANURES.}

In the preparation of these Manures, particular attention is paid to supplying all the required ingredients to meet the demand of each crop; not only in the proper proportion, but also in those forms and conditions which practical and vuried experience has shown to develop the healthiest growth and best quality of product, as well as the largest yield.

This will be readily appreciated in the case of such crops as Tobacco, also Spring Wheat as compared with Fall Wheat, \&c.

The materials from which these Manures are prepared are Peruvian Guano, INitrate of Soda, Sulphate of Ammonia, Dried Blood or Flesh, Fine Bone, Sulphuric Acid, and Potash Salts. They contain no plaster. They are all supplied in a ready-mixed state, finely ground, and easy of distribution.

M A PES, COIMPLETE MANURE.

Ammonia, 6 to 7 ; l'hosphoric Acid, 10 to 12 ; Potash, 3 to $4 \ldots \ldots \ldots \ldots$........ Bags $200 \mathrm{lbs}$.

Adapted for general crops on heavy soils or average clay-loams, or those requiring an increased per centage of Phosphoric Acid as compared with Potash, such as fair Corn or Potato lands.

This Manure for clay lands, as well as the Ville Complete Manure for light or sandy soils, is recommended as our WHEAT MANURE, and for seeding down to permanent mowing or pasture lands, also for Oats, Barley, Rye, and Irops, as well as for general use, as a substitute for barn-yard or stable manure.

HA PES, CORN IMAN URE.

Ammouid, 4.50 to 5 ; 1'ho phoric Acid, 10 to 12 ; Potash, 6 to $7 \ldots . . \ldots \ldots$....... Bags $200 \mathrm{lbs}$.

IIAPIS, FODDEF CORN IMA NUIRE.

Ammonia, 4; Phusphoric Ackd, 6; Putash, 12 to $13 . . . \ldots \ldots \ldots \ldots \ldots$................. $200 \mathrm{lbs}$.

MAPES, IBEET AND MANGOLD IIA VUIEC.

Ammonla, 6.50 to $7.5 \mathrm{~J}$; l'tosphoric Acid, \pm to 5 ; Potash, 7 to 8 '......... Bags $200 \mathrm{lbs}$.

The above Formulas and Manures should be reduced in strength by mixing with plaster or dry earth. This will secure better distribution and guard against injury to the young roots, especially if used in the hills or close to the seed. 
IIAFES' TOBACCO MANURE.

Ammoniu, 5.00; Phosphoric Acid, 5.00; Potasb, 11.90...................... 200 lbs.

The Potash in this manure is all in the form of a Sulphate.

MAPES FRUIT AND VINE MIANURE.

Ammonia, 1.50 to 2.00 ; Phosphoric Acid, 7.50 to 11.00 ; Potash, 6 to $7 .$. Bags $200 \mathrm{lbs}$.

MAPES' SPRING WHEAT MANURE.

Ammonia, 6 to 7 ; Phosphoric Acld, 7 to 8 ; Potash, 5 to $6 \ldots \ldots \ldots \ldots$......... $200 \mathrm{lbs}$. May be drilled in with the seed.

MAPES, CAULIFLOWER AND CAFEAGE MANURE.

Ammonia, 5.50 to 6.60; Phosphoric Acid, 4 to 5 ; Potash, 10 to $12 . \ldots . \ldots$. .... Bags $2001 \mathrm{bs}$.

MARES' GRASS ANE GRAIN SPRING TOP-DRESSING.

....Bags $200 \mathrm{lbs}$.

This Manure, owing to the solubility of its Phosphoric Acid, will be found very useful as a spring top-dressing to winter grain which has suffered injury from winter exposure; also, as a dressing to any crop around the hills or rows to promote rapid growth.

MAPES' SUGAH CANE OR SORGHUM MANURE. Ammonia, 2.00 to 3.00; Phosphoric Acid, 10.00 to 12.00; Potash, 6.00 to 8.00.Bags 200 lbs.

We prepare this Manure to meet the special requirements of the sugar lands of South America, West Indies, and the Southern States. The effect of this Manure is particularly to increase the proportion of SACCHARINE MATTER.

MAPES, LAWN TOP-DRESSHNG. For Lawns, Croquel Grounds, Grass Plots, dc................................. 200 lbs.

FOR COT'TON-Use Mapes' Nitrogenized Super-Phosphate.

\section{MAPES' SUPER-PHOSPHATES, ETC.}

\section{IIAPES' NITROGENIZED SUPER-PFOSPHATE-(with Potash).} Fine and Dry.

Ammonia, 23: to $3 \frac{1}{2}$ per cent ; Phosphoric Acid (soluble and available), $\left\{\begin{array}{l}\text { Bags } 200 \mathrm{lbs} . \\ \text {. }\end{array}\right.$

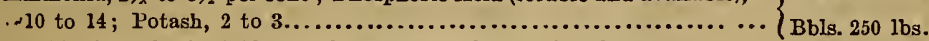
The Phosphoric Acid, ALl from Bone and Peruvian Guano.

MAPES' NTTROGENIZED SUPER-PHOSPR ATE (Old Brand) (Bags 200 lbs. Ammonia, 3 to $3 \frac{1}{2}$ per cent.; Phos. Acid (soluble und available), 10 to $14 . .\{$ Bbls. $250 \mathrm{lbs}$. The Phosphoric Acid, AlL from Bone and Peruvian Guano.

AMIIONIATED DISSOL VED BONE-(Moosehead Brand).......... (Bags 200 lbs. Ammonia, 21/2 to 3 per cent.; Phos. Acid (soluble and available), 10...... $\{$ Bbls. 250 lbs. The Phosphoric Acid, All from Bone.

DISSOLVED BON E-BLACK-(Mapes Brand)

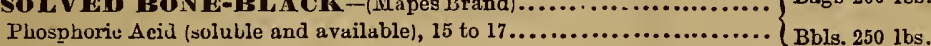

A CID PFOSPHATE.

Phosphoric Acid (soluble and available), 11 to $14 . \ldots \ldots \ldots . . . . . . . . . .$. Bbls. 250 lbs. The Phosphoric Acid from South Carolina Phosphate.

PRERARED DRY FISH GUANO-Mapes Brand)................ (Bags 180 lbs.

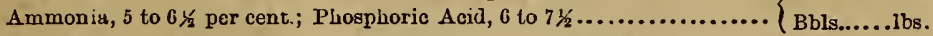

The dry, fine condition of this preparation of Fish Guano, renders it convenient for Transportation, especially when packed in barrels.

It is in considerable demand for shipment to the Truck Growers in Charleston, Florida, and Bermuda.

MAPES POTASH BONE PHOSPHATE.

Ammonia, 2 to 3 per cent.; Phosphoric Acid, 11 to 13 ; Potash, 6 to $7 . .$. .....Bags 200 lbs. Prepared from Bone and Potash Salls.

This Manure is intended to meet the demand for a cheap and effective fertilizer for restoring worn-out lands, such as old orchards, side-hill stony pastures; to take the place, in fact, of finely ground Pure Bone and Wood Ashes. May be used broadcast as a top-dressing, spring or fall.
PerTon, Per $20001 \mathrm{bs}, 2001 \mathrm{lug}$ $\$ 49.34 \$ 55.20$

35.00

50.00

49.00

51.00 5.35

45.00

4.75

60.00

630

45.00 4.75

43.00

40.00

35.00

30.00

40.00

35.00 3.70 


\section{PRICE LIST OF MANURES.}

\section{GROUND BONE-STRICTLY PURE.}

PURE BONE IMEAC-(Mapes Brand).

Ammonia, 4 to 5 per cent.; Phosphoric Acid, 20 to $20 \ldots \ldots \ldots \ldots \ldots$............ $200 \mathrm{lbs}$.

PURE GROUND BONE-(Mapes Brand)-Extra Fine)

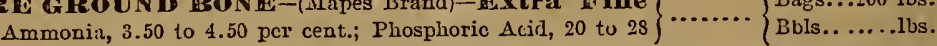

Per Ton. Per Bag,

2000 Ibs. 200 lbs.

$\$ 42.00 \quad \$ 4.40$

$40.00 \quad 4.20$

This grade of bone will be found to be nearly as fine as ordinary Bone Irteal.

PURE GROUND BBONE-(Mapes Brand)-Fine............... Bags...200 lbs. Ammouia, 3.50 to 4.50 per cent.; Phosphoric Acid, 20 to 28$\} \cdots \cdots \cdot$ Bbls..........bs.

$38.00 \quad 4.00$

This grade of Bone designated Fine, consists of the three other grades, viz: Meal, Fxtra Fine, and Medium, in about equal proportions, and is therefore well adapted to meet the wants of those who desire permanent effects as well as immediate action.

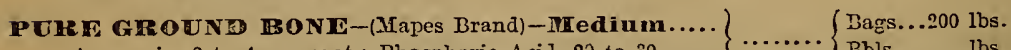
Ammoniil, 2 to 4 per cent.; Thosphoric Acil, 20 to $30 . . .$.$\} ............$

$36.00 \quad 3.80$

$42.00 \quad 4.40$ Ammonia, 2.50 to 3 per cent.; Phosphoric Acid, soluble and available, 12 to 16.

This brand is prepared from only bone and new Sulphuric Acid, and will be found to be more economical to the farmer than any homemade preparation.

PURE BONE IrEAL, for Feeding

C0.00

6.30

PURE BONE, for Chickens.

50.00

5.25

A.11 of the above grades consist of absolutely pure Bone, reduced by improved machinery to fine condition, without admixture or treatment with any dryer, salt or nitre-cake, plaster, natural phosphate, "Kettle Bottoms" or adulterant.

The Ammonia is therefore all intimately blended (in the form of the gelatine and organic matter of the Bone) with the phosphates of the Bone, and thus secures rapid decomposition and best action on plant growth.

Any desired grade of Bone prepared to order. Deliveries in bulk made at our Works on Morris Canal, Newark, N. J.

\section{POTASH SALTS, Etc.-Our own Importation.}

MUREATE OE POTASH-(High Grade).

STANDARD 30 per cent., equal to 50 p. c. actual Potzsh. Bags about 200 lbs.

II UREATR OF POTA SH-(High Grade) " Douglasshall."

(This Grade contains about 10 per cent. Sulphatc Mragnesia).

STANDARD 30 per cent., equal to 50 p. c. actual Potash.

SULPEATE OF POTASH-iHigh Grade).

Bags even weight $225 \mathrm{lbs}$

Test 70 to 8.7 por cent., equill to $38 \frac{1}{2}$ to $46 \frac{1}{4}$ per cent. aclual Potash....... (Bags......lbs.

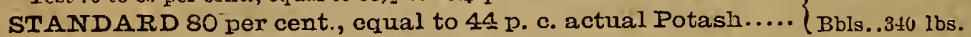

SUL PHATE OF TOTASH-(German).

Test 40 to 60 per cent., equil to 22 to 33 per cent. actual Potash.......Bags............

STANDARD 50 per cent., equal to $27 \%$ p. c. actual Potash.

GERMAN POTASH SALTS-Kainit-"Leopoldshall," "Stassfurt."

Test 20 to 32 per cent. Sulphate of Potash equal to 11 to 13 per cent.

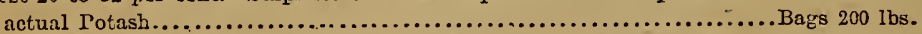

STANDARD 24 per cent., equal to 13 p. c. actual Potash.

\section{NITEATE OF POTASH.}

Test 90 to $9 j$ per cent., cqual to 42 to 46 per cent. actual Potash. Contains

also some $121 / 2$ per cent. of Nitrogen, (Ammonia, 15)........... Bags about $200 \mathrm{Ibs}$. STANDARD 95 per cent., equal to 46 per cent, actual Potash.

Ammonia, 15 per cent.

SPICIAI, PAFGE will be given on all of the above grades of Potash Salts, delivered in bulk or packages direct from vessel in which imported, (Involving no expense to us of storage, etc.) Dealers can obtain their supplies in this way at very low figures.

$.45 .00 \quad 21 / 2 \mathrm{c}$

Single

Pachage,

Per 1 b.

$\$ 45.00 \quad 21 / 2 \mathrm{c}$.

$65.00 \quad 4 c$.

$35.00 \quad 2 c$.

15. to $18 \quad 11 / 4 \mathrm{c}$

$170.00 \quad 93 / 2 \mathrm{c}$ 


\section{Can Concentrated Manures be Used with Profit?}

The following table gives the estimatcd cost [per-busliel, etc.] to grow farm produce in cxcess of the natural yield of the suil. The estimates include all the Phosphoric Acid and Potash cointained in the plant, together with the full proportion of Nitrogen, as recommended by Prof. Geonge Ville.

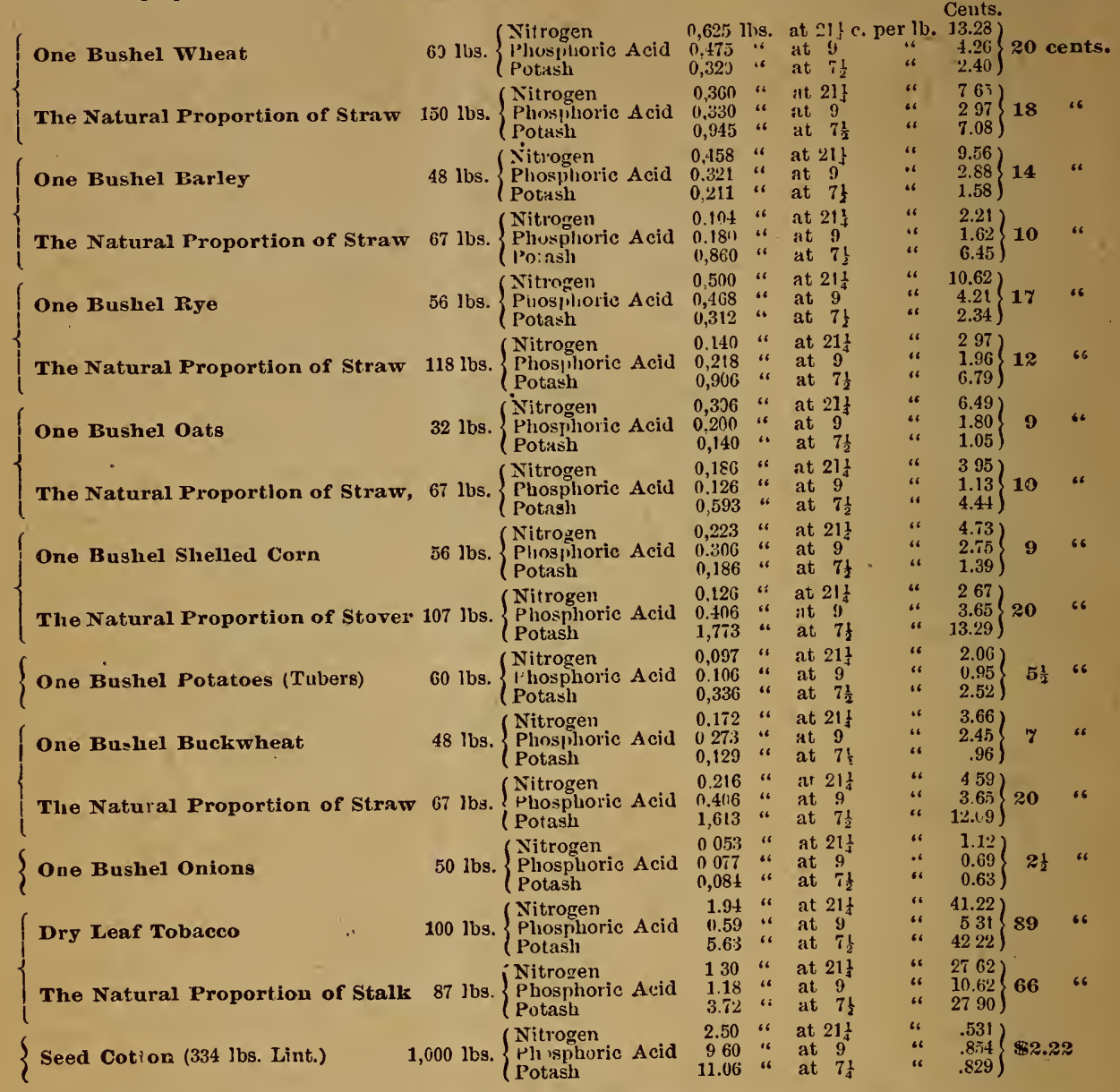

The cost of raising the staple products with Mapes' Complete and Special Manures has proved in practice to be much less than shown by the figures of the above table. This has been uniformiy the case even upon poor ligbt soils.

Owlng to the difficnlty of bringing the ferthizer, especially during the first season of its application. in contact with the rnots of the plants, there will always remain a laree proportion untisert and ready for fiture crops. As before stateil, the markeil effects of the fertilizer on subsequent crops, particularly on grass after grain crops, give evidence of the increased stock of available plant fond left in the soil after rrofnping.

Agailu, the natural fertility of the soil is increased by the acti in of the fertilizer in liberating and rendering availihle, for plant use. the ingredients which it already contains, but which withuut the presence of the manure, would reminin inert and useless.

For tilese reisons the cost of raising farm-pro lucts with Manes' Manures, including fertilizer. seed. lahor, interust on land, etc.. on poor as well as gnod land, is found to be less than the estimated cost if the fertilizing ingreitimuts alone required as per above fable.

With $300 \mathrm{lbs}$. "Complete Maunue" per acre on 60 acres pnor land this season in Connecticnt. the cost of raising corn wer hitsliel was less than twent $y$-five cents. This inclulerl all expenses of fertilizer, cultivation, interest. ine vielil of corn with 310 los, to ton lbs. per acre of this s ime manilre. his been from 80 to 96 bushels thelled corn per ac'e. Ir one instance. wliere the vield was at the rate nf over 90 bishels shelled coru per acre, the writer stated that the "land was so pnor that withwit the fertilizer it would have nroluced nothing."

On potatnes, the notato manure. 300 to $400 \mathrm{lbs}$. per acre, has profucerl from 350 to 375 busliels per acle under ordiuary culture. The cases reported were principally "Lite" and "Early Rnze" In one instance, diuring the ordinary culture. The cases reported were principay do manure. produced nuly 150 bushels of indifferent quility,

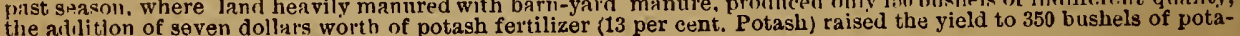
toes of large size and very fine quality. 
$\frac{27}{100}$ of a Cent per Day, 8 1-2 Cents a Month, or $\$ 1.00$ a Year, PAYS FOR A TRUE FARMER'S PAPER,
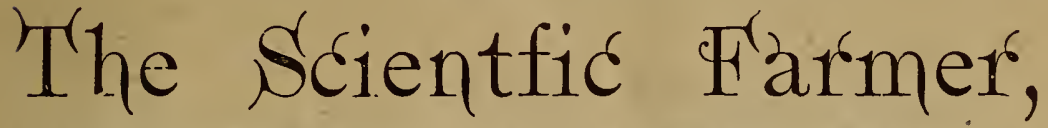

A Handsomely Illustrated Monthly Journal in the interests of Profitable Agriculture.

For all farmers gardeners, stock raisers, grain growers and dairymen. For all who wish to l.arn about fertiiizers and manures, about the principles under]ying successful practice in the field and stable. it is full of the most valuable and practical information. Its articles on PLANT FEEDIXG liave intensely interested thousands of farmers; for it is an acknowledged authority on all subjects relating to manures and fertilizers; and its articles are so useful, so practical, and so reliable, that no farmer ean ifford to be without it.

In HORTICULTRE and BOTAYY it publishes the latest and best. Its DAIRY and STOCK department is in the hauds of pructical and successful dairymen and breeders. It employs lle best talent on the subjeets of TILLAGE AND GENERAL FIELD OPERATIONS, DISFAsEs of Fa min Srock, Insect Pests. Poultry, Rukal akt and Apchitecture, Window Gardening, ete. All its departinents are of every-day interest, and are conducted in a manner tar above that of the colunion uewspaper.

'The Scientific Farmer aims to be the most thoroughly instructive farmer's magazine ever published. It strives to be entirely accurate iu statement; to make science practical; knowledge useful; anil the farm projitable.

Ever dignified and seeling the highest, it is still bright and cheery, and always on the look out for the brighter and pleasanier phases of farm life. Brinful of meat, and without a trashy line in it; and all for about one-quarter of a cent a day.

'There are few better uses to which an ina.elligent farmer can put a dollar than to send for this "Farmer's Magazine." A specimen number will be sent for ten cents, or 3 postage stamps. Aduress,

Scientific Farmer Co., Boston, Mass.

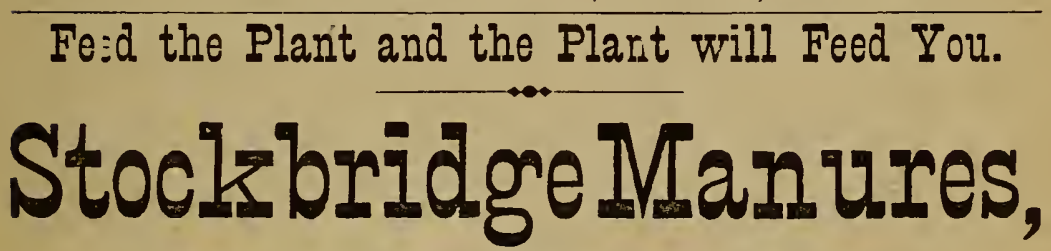

Originated by Prof. Levi Stockbridge, Professor of Agriculture in the

\section{A S S ACH USETTS A GRICULTURAL COLLEGE.}

These manures are made according to the analysis of plants for different crops by formulas worked ont by Prof. Stockbridge, and supply the plant food in an available form, which is not ol,tained from the soil or air in sufficient quantity. These manures also recognize line fact that plants, like aninals, differ. and require different fond or in different pronortions to insure the best results at the least enst. 'lliey have been extenslvely used for FIVE YEARS and were used in $18 \%$ ' on over 10,000 acres with very satisfactory results, many larmers ralsing from 75 to 100 BUSHELS of COR. per acre, and with like results on other crops. As they silpply the principal elements of plant food which erops remove. THEY DO NOT EXHAUST THE LAND, but actualiy leave it richer: for being composed largely of eliemlials. they have a strong cheinical action on the soil, and liberate other n]ant foid. In sliort, the Stockbridge Manures, based as they are on tho analysis of the crop, does away with guess work in fertilization, for they supply just what the erop wants.

They contain 110 weed seeds, and often cost less than the hauling of stable manure and are much more quickly applies. Send for Pamphlet for 1878, Malled Free, containing PIRICES, the experience of furmers all over the country who have used these manures, and other valuable information.

W. H. BOWKER \& C0., Sole Agents and Manufacturers.

Also proprietors of Bowker's Hill and Drill Phosphates, and dealers in High Grade Agricultural Chemicals.

BOSTON AND NEW YORK.

Orders will also be received by

B. K. BLISS \& SONS, 34 Barclay Street, New York. 


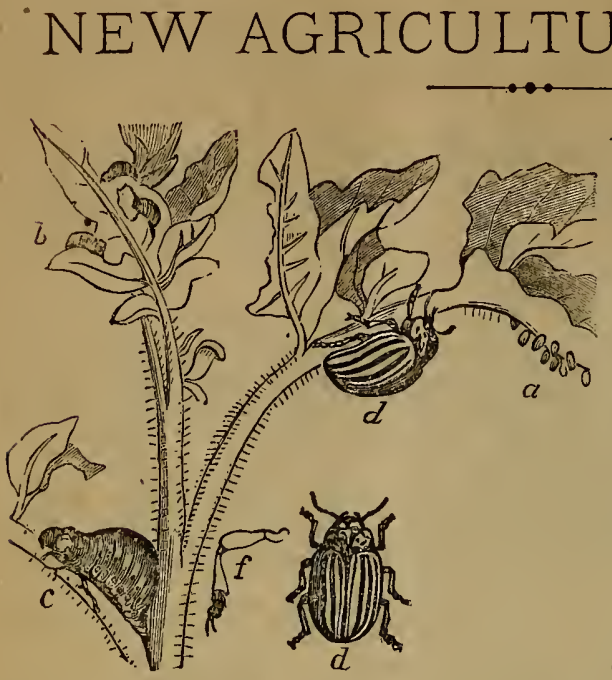

AN EGG FARM. THE MANAGEMENT OF POULTRY IN LARGE NUMBERS.

Being a Series of Articles written for the American Agriculturist, with Otler Articles. Illustrated.

CONTENTS-Introduction.-Plan of Farm.-Manner of Feeding.-Location of Farm.-Kind of Boil.-Crops on the Farm.-Supplying Water and Food.-Collecting and Storing Dry Eartli, Houses for Linyers. - Feeding House for Winter. - Houses for Sitters. - Arrangements for Breeding Stock.-Fowls for Layers. - Fowls for sitters.-Managenent of Breeding Stuck. - Coops for Chickens.-Feeding Chickens.-Setting the Eggs.-Management of Sitting Fowls.-Testing the Eggs. - Winter Management.-House for Eurlv Hatched Pullets.-Shelter's for Fowls and Chickens.-Kind of Food.-Building for Storing and Conking Food.-Management of Young Clickens. - Feerling and Sheltering Cbickens.-Adlitional Builılings.-Generul Conclusions. - Farın l'oultry House.-Poultry Farming.-Poultry Kecping as a Business.

Price, postpaid, paper covers, 50 cents; cloth 75 cents.

\section{THE POULTRY YARD AND MARKET;}

Or, A Practical Treatise on Gallinoculture.

BY PROF. A. CORBETT,

Inventor of the New Process for Hatcling Eggs and Raising Poultry, by means of Horse Manure alone, for whi:l] Gold anil Bronze Midals, and several Diplomas. liave leen awarded by State and County Fairs, and the American Institute. I.ealiug newspapers endorser the valuable discovery of this simple process, which is fully clescribed in this book, giving the valuable information acquired by 20 years' experlence in Poultry Breeding.

CONTENTS.-Origin of Artificial Incubation.-Its Prolificness.-Particulars of what lias been done in Artificial Incubation np to the present time.-Tlie discovery of how Eggs could he Hatcherl in Minure.-The Researches of Prof. Corbett aud his Disenvery.-Prof. Corbett's snecess-Amount of Protit to be Made Annually by Anybody with Tivelve Hens.-Hinw Poultry Breeders can Raise Chickens in Manure, with Slight Fxpense, All the Year Ronnd.-'J'lie Raising Poulury with Large Protits. - The Kind of Manure to be Used.-'llie Best Breed of Protiable Fowls.-Advice to the Laties. - Important Hints How to Keep Poultry and Make Money.-Diseases and their Cure.-How to Fatten ani Prenare for Market.-Opini.ns of the Press and IRewards given for this Process. Price, postpaid, 50 cents.

\section{THE SHEPHERD'S MANUAL.}

A practical treatise on The Sheep. Designed especially for American Shepherds. By Henry Stewart. 1llustrated. Price, postpaid, $\$ 1.50$.

PLAY AND PROFIT IN MY GARDEN.

By E. P. Roe. Author of “Barriers Burned Away," etc. Price, pistpaid, \$1.50. 


\section{Valuable Books for sale by B. K. Bliss \& Sons.}

Sent by mail, post-paid, at following prices.

Allen's (R. L. \& L. F , New American Farm Book.

Bllen's (L. F.) Ameriean Cattle, $-\quad-250$ Jersey, Allerney, and Guernsey Cow,
Allen's (k. L.) American Farm Book, $\quad-150$. 150
Jolinson's How Crops Feed, -

Jennings on the Horse and his Diseases, $-\$ 175$

- $\$ 250$ Jemings on Slieep. Swine and Poultry, -

$\begin{array}{rr}1 & 75 \\ 1 & 50 \\ - & 2\end{array}$

Allen's (L. F.) Rural Architecture, - - 150 Johnson's How Crops Grow, - $\quad-200$

Allen's (R. L) Diseases of Domestic Ani-

unals, -

Americau Bird Fancier

American liose Culturist, - - -

Anerican Wveerls and Usefuil Plants, - $-17 \overline{5}$ King's Beekeeper's Text Book. - Paper, 40

Johusou's Peat aud its Uses,

125

30 Johuston's Elements of Agricultural Chem-

Atwood's Country and Suburban Houses, 150

Barry's Fruit Garden,

Bement's Rabbit Funcier, - - - -

Bommer's Method of Making Manures,

Breck's New Book of Flowers, - - $\quad 17$

Brill's Farm-gardening and Seed-growing,

Broom-Corn and Brooms, paper, 50e., cloth,

Brown's Taxitermist's Manual,

Bruekner's American Manures,

Buel's Cider-maker's Manual, -

Burr's Vegetables of America, -

Butler's Family Aquarium,

Butler on the Dog, - - -

Canary Birds. Paper, 50 cts. ; cloth,

Chorlton's Grape-grower's Guide,

Cubbetc's American Gardener, -

Coburn's Swine Husbandry,

Cole's A merican Fruit Book, -

Cule's American Veteriuarian, -

Cooked Food for Domestic Animals,

C'ook's Manual of the A piary,

Corbett's Poultry Yard and .iarket, paper, 50 ets.; cloth,

Datld's Modern Horse Doctor, 12mo.

Dxdd's Ameritan Catrle Doetor, 12 mo., -

Dadd's American Reformed Horse Book, -

Dana's Ml uck Manual

De Voe's Market Assístant.

Downing's Landseape Gardening,

Dwyer's Horse Book,

Eastwood on Cranberry, - $\quad$ -

Entielil's Indian Corn, - -

Every Horse Ownei's Cyclopedia, -

Pilper, 50 ets.; cloth,

Field's Pear Culture, - - - -

Flint (Charles L.) on Grasses, - -

Frenclh's Farm Drainage, - - -

Fuller's Forest Tree Cullurist, - -
Filler's Grape Culturist. -

Fuller's Illustrated Strawberry Culturist,

Fuller's Small Fruit Culturist, - -

Fulton's Peich Culture, - : -
Gerelin's Poultry Breeding,

Grant's Beet Root Sugar, - - - - 125

Gregory on Cabbages,

Gregory on Carrots Mangola Wurtzels, etc.

Gregory on Onion liaising,

Gregory on Squashes,

Guenon on Milkh Cows, - - -

Harris's Insects Injurious to Vegetation.

Plain, s4; colored cngravings, - -

Harris on the Pig. - - - - 150

Hazard's Butter and Butter Making,
Hedges on Sorglio, or the Northern Sugar Plant,

Helmsley's Hardy 'Trees, Slurubs and Plants

Henderson's Gardening for Pleasure, -

Henderson's Gardening for Profit, - - 150

Hender'son's Practical Floriculture, - -

Hooper's Dog and Gun. Paper 30c.; cloth,

Hoopes's Book of Evergreens, - - -
Hop Culture. By nine experienced cultiHoward's Grasses and Forage Plants at the

South, Make Candy, : - : - :

Hunter and Trapper, $-\overline{-}-\overline{-}-\overline{-}$

Jemings' Horse Training Made Easy,

250

Leuclar's llow to Build Hut-Houses,

Lyman' Cotton Culture,

10 NeClure's Ameriean Gentieman's Étable

75 Guide, $-\overline{-}-\overline{-}-\overline{-} \bar{H}_{\text {merse }}^{-}$

100 . McC.

150 Cattle and Sheep - - - - -200

150 Miles on the Horse's Foot, - - - - 75

N5 Nolw on the Grape Vine, - - $\quad-\quad-\quad-100$
Ny Vimevarl at Lakeview.

200 Niclul's Cliemistry of the Farm and Sea, - 125

75 Norris' A merican Fish Culture, - - 175

5 Nortou's Seientific Agriculture, - -

5 Onions-How to Raise them I'rofitably, - 20

5 Our Farm of Fonr A eres. Paper, 30c., cloth,

Pardee on Strawberiy Cuiture, - - - 75

5 Parsons on the Rose, - - - - - 150

20 Pedder's Land Measurer, - - - $\quad 60$

Potato Culture. (Prize Essay.) - - $\quad-125$

75 Quirby's Mysteries of Bee-keeping, - - 150

150 Quincy (Hon. Josiali) on Soiling Catile, - 125

150 Quimn's Money in tlie Garden, - - - 150

250 Quinn's Pear Culture for Profit, - - 100

125 Randall's Fine Wool Slieep Husbandrs, - 100

- 2 5i) Randall's Blieep Husbandry, - _ - 150

50 Rarey and Knnowlson's Horse Tamer, - - 50

200 Rithardson on the Dog. Paper, 30c.; cloth, 60

75 Riley's Potato Pests. Paper, 50 cts.; cloth,

$\begin{array}{llll}1 & 90 & \text { Rivers's Miniature Fruit Garden, } \\ 3 & 75 & \text { Roe's Manual on the Culture of Small }\end{array}$ Fruits, - - - - - - 50

100 Roe's Play and Protit in my Garden, $-\overline{-}$ - 150

- 125 Saunders's Domestic Poultry. Paper 40 cts.;

30 clotlı, - - - - - 75

150 Skillful Honsewife, - - - 75

150 Stewart's A merican Farmer's Horse Book, 300

150 Stewart's Irrigation for the Farm, Garden,

n and Orchard,

Stervart's Sorghum and its Products, $\quad-\quad-150$

Stewart's Stable Book, - - - - 150

Stoduard's An Egg Farm. 50 cts, cloth, -

Field. Amcrican edition, 12mo., - -200

30 Tegetmeier's Poultry Book. - - - 900

30 The Rifle: Its Theory and Practice, _ $\quad 50$

30 'Thomas's American Fruit Culturist. New edition, - - - - - - - 375

Thomas's Farm Implements and Machinery, - - - - - - 150 Thompson's Food of Animals, - - $\quad-\quad-100$

Tobacco Culture. By fourteen experienced cultivator's,
Turner's Cotton Planter's Mianual, - $\quad-\quad-150$ Tinrner's Cotton Planter's Manual, - $\quad-150$
Ville's Chemical Manures. Warder's American Pomology, - $\quad-300$ Wrarler's Hedges and Evergieens, - - 150

50 Waring's Drainlng for Protit and Health, 150

Waring's Earth Closets and Earth Sewage, 50

300 hlite's Cranberry Culture, - - - - $\quad$ - 125 White's Gardening for the'South, - - 200

30 Wright's Brahma Fowl, - - - - -250 Wright's Practical Poultry-keeper, - - - 200

0 Youatt and Spooner on tlie Horse, - - 150

50 Yountt and Martin on Cattle, - - $\quad-150$

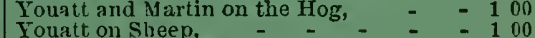

175 Youatt on Sheep, - - - - $-\quad-100$ 


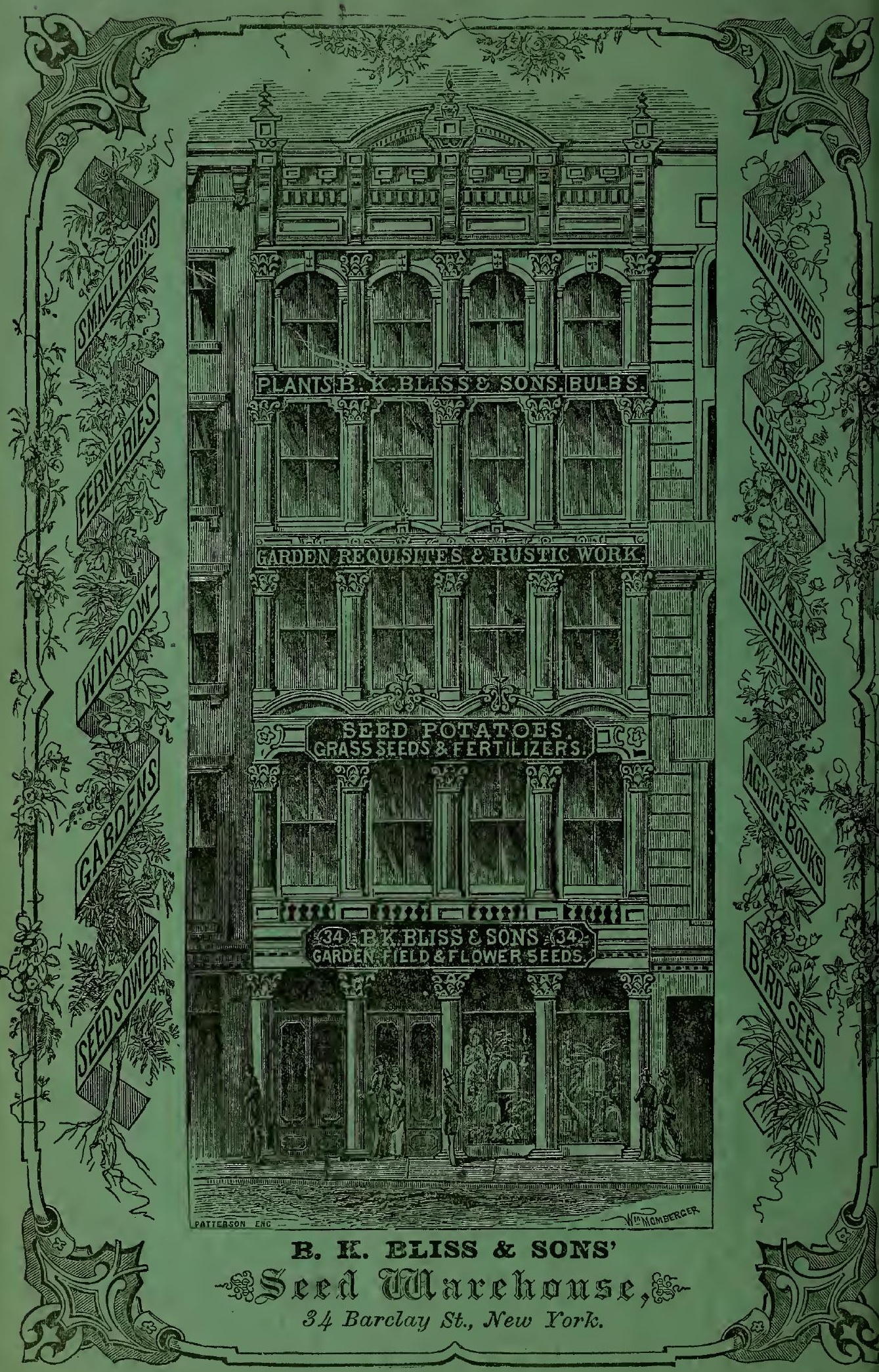




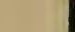




